\title{
An Assessment of the Air Quality Modeling Efforts in Southwest Wyoming
}

\author{
Draft Interim Report
}

Prepared for:

William $\mathrm{H}$. Hochheiser

Director, Office of Product-Line

Department of Energy

Washington, DC

Prepared by:

Melissa Lunden, James Fine, Brett Singer, and Nancy Brown Environmental Energy Technologies Division

Lawrence Berkeley National Laboratory

Berkeley, CA 94720-1740

Steven Reynolds

Envair

12 Palm Avenue

San Rafael, CA 94901

Philip Roth

Envair

836 Fawn Dr.

San Anselmo, CA 94960

Contact person

Dr. Nancy J. Brown

Phone: (510) 486-4241

Fax: (510) 486-7303

e-mail: njbrown@lbl.gov

JUNE 28, 1999 


\section{DISCLAIMER}

This report was prepared as an account of work sponsored by an agency of the United States Government. Neither the United States Government nor any agency thereof, nor any of their employees, make any warranty, express or implied, or assumes any legal liability or responsibility for the accuracy, completeness, or usefulness of any information, apparatus, product, or process disclosed, or represents that its use would not infringe privately owned rights. Reference herein to any specific commercial product, process, or service by trade name, trademark, manufacturer, or otherwise does not necessarily constitute or imply its endorsement, recommendation, or favoring by the United States Government or any agency thereof. The views and opinions of authors expressed herein do not necessarily state or reflect those of the United States Government or any agency thereof. 


\section{DISCLAIMER}

Portions of this document may be illegible in electronic image products. Images are produced from the best available original document. 
I. INTRODUCTION

I. METHOD FOR ASSESSING THE POTENTIAL ENVIRONMENTAL EFFECTS OF POLLUTION..... 3

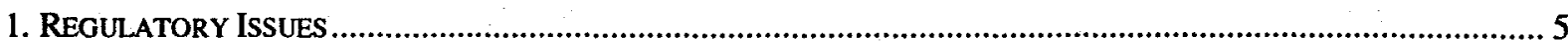

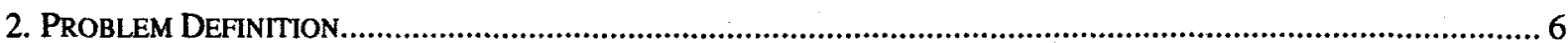

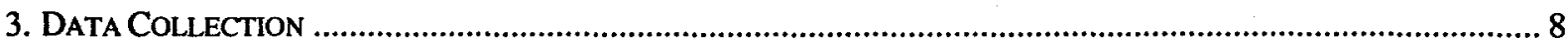

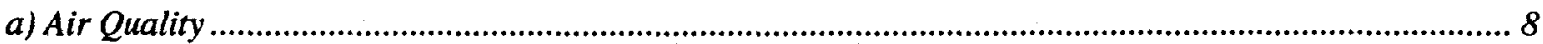

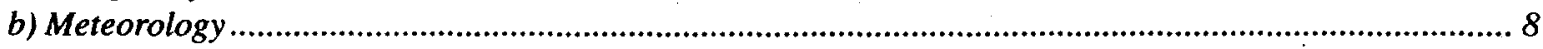

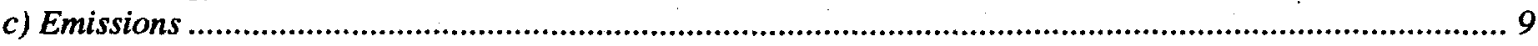

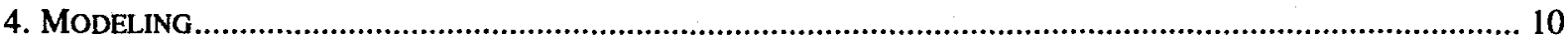

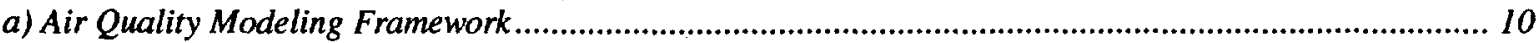

b) Meteorological Modeling .................................................................................................................. II

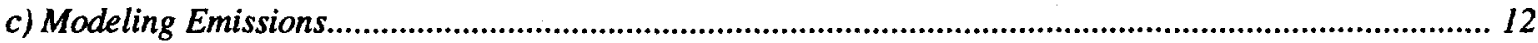

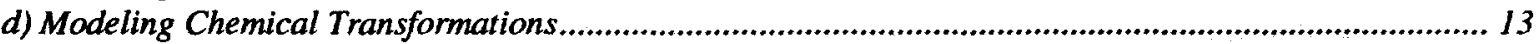

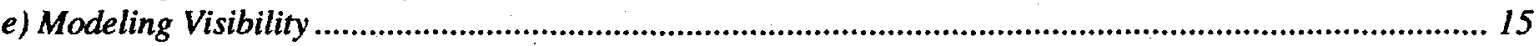

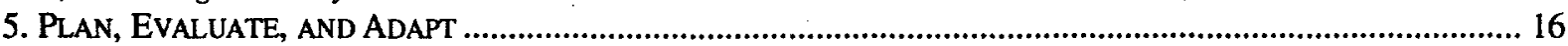

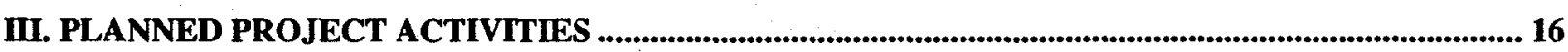

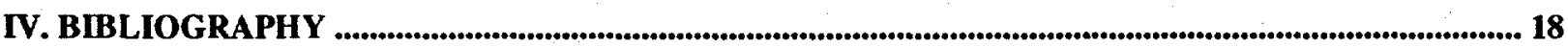

APPENDIX I REGULATIONS AND POLICY QUESTIONS...........................................

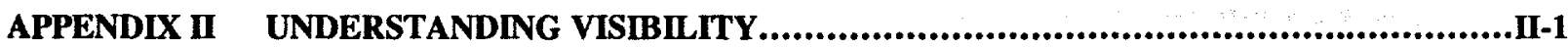

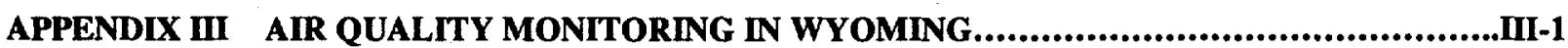

APPENDIX IV AN INITIAL REVIEW OF METEOROLOGICAL PHENOMENA, DATA, AND MODELING FOR SOUTHWEST WYOMING AIR QUALITY ASSESMENTS.........IV-1

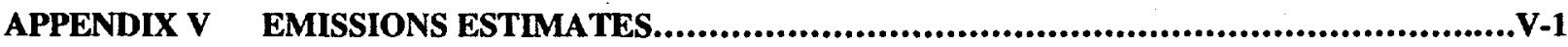

APPENDIX VI MODELING ATMOSPHERIC CHEMISTRY TO ESTIMATE AEROSOLS............VI-1

APPENDIX VII A COMPARISON OF CALPUFF WITH GRID-BASED MODELS.........................VII-1

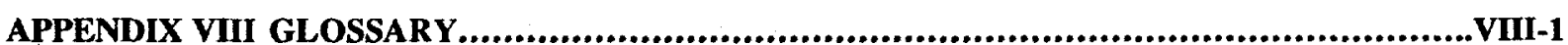




\section{INTRODUCTION}

Fossil fuel exploration and extraction in Wyoming is an important part of the production and processing of mineral resources, which has been the foundation of Wyoming's economy for most of this century. In recent decades, however, Wyoming's vast, open landscapes and parklands spawned tourism. Growing national demand for natural gas has resulted in pressure to increase the amount of oil and gas extracted from the central Rocky Mountain region. Particular focus centers on southwest Wyoming because it contains nearly one-half of the undeveloped gas resources of this region. Projections range from 1,000 to 11,000 new wells by 2010, or up to a three-fold increase from today's 5,600 wells.' Similar fossil fuel development is anticipated to occur elsewhere in Wyoming and in other states. Emissions associated with current and planned fossil fuel extraction may cause air quality, visibility and acid deposition impacts in nearby national parks and wilderness areas. Thus, the national demands of the fossil fuels industry may conflict with clean air mandates and associated benefits such as the tourist trade, creating a contentious debate reliant on the science of air quality impact assessment to clarify and resolve disputes.

The Southwestern Wyoming Technical Air Forum (SWYTAF) convened in April, 1996, to "determine the most appropriate tools and assumptions to be used in determining air quality impacts in Class I Areas due to the long range transport of pollutants from the proposed natural gas field developments in southwest Wyoming"(WDEQ website). ${ }^{2}$ SWYTAF approved EarthTech, Inc.'s proposal to use the CALPUFF model to study the effects of potential new emissions sources on air quality, visibility and acid deposition. In addition to selecting analytic tools (i.e., air quality models), SWYTAF is overseeing model application. SWYTAF's efforts are intended to produce a model for use by the Wyoming Department of Environmental Quality (WDEQ), Federal Land Managers (FLM) and project applicants in evaluating the impacts of air pollutant emissions from proposed projects near the Bridger and Fitzpatrick Wilderness Areas.

The Department of Energy has concerns about the model choice, model performance, and the use of the model in the policy arena. Of particular concern are the lack of scientific understanding required to model visibility and the inadequacy of the supporting data. This has lead to additional concerns about the process by which other oil and gas development impacts will be evaluated and managed throughout the country. The application of CALPUFF by SWYTAF has raised a number of technical questions. Therefore, the Department of Energy has sponsored the Atmospheric Program of the Environmental Energy Technologies Division at Ernest Orlando Lawrence Berkeley National Laboratories (LBNL) to examine the adequacy of the modeling and analysis procedures associated with evaluating the current and future air quality and visibility impacts of oil and gas development in southwestern Wyoming. LBNL is to provide recommendations for how to improve the assessment process. The first phase of LBNL's effort is an assessment of the modeling effort, the supporting data, and a survey of the regulatory issues. This report summarizes the initial findings of this assessment.

\footnotetext{
' One estimate projected 1,100 to 3,100 new gas wells to meet a 170 percent increase in gas demand between 1996 and 2010. (J. Rudolph, 1998) Environmental organizations estimate between 6,000 and 11,000 new wells will be constructed by 2010. (D. Chu et al., 1996)

${ }^{2}$ Federally designated "Class $\mathrm{\Gamma}$ " areas of particular concern to SWYTAF include the Bridger and Fitzpatrick Wilderness Areas.
} 
During the past twenty years air quality modeling has made the transition from a research and development endeavor (in the 1970s) to an activity commonly employed in planning and analysis and required in specifications of the 1990 Clean Air Act Amendments. In the best of circumstances modeling poses numerous challenges to the investigator. [See Roth (1998) for a discussion of issues to consider in planning and conducting a modeling study.] Restrictions of budget, schedule and permissible duration of the work, staff availability, and data availability generally exacerbate the difficulties. Thus, considerable thought must be given to the enterprise at the start to ensure that a "best effort" is launched. At the same time one cannot assume that this effort will be "good enough". It is entirely possible that, despite best intentions and effort, undetected errors (perhaps undetectable, given the availability of data) or modeling decisions that become politicized in the face of regulatory uncertainty will taint the modeling study and result in incorrect findings. This is both the challenge and the fear.

Three key limitations must be confronted in conducting modeling for southwestern Wyoming: (a) a very sparse aerometric data base, (b) a plan for and commitment to only limited model evaluation (in part due to the paucity of data) despite a very real possibility that the "best available" model may not be "good enough", and (c) a very small budget to support the work. In the "best of circumstances", based on past experience, we can expect that considerable uncertainty will accompany the modeling and analyses of both the base cases and control strategies. This uncertainty typically will be due to errors in model inputs and formulation and to the inevitable contribution of intrinsic variability attributable to natural and anthropogenic stochastic processes. These three challenges comprise the core of our concerns about modeling currently being carried out by SWYTAF.

Nevertheless, the technical effort itself poses a variety of concerns. In this report we identify them and suggest the reason for their importance. The report places these concerns in the context of a method for assessing the potential environmental effects of pollution. First, a general overview of the method is presented. The way in which different technical activities contribute to the assessment is detailed. It is hoped that by linking the concerns from each technical activity in the framework of the assessment process, we will clarify the importance of specific comments and help to relate the different activities to the whole.

Properly addressed, the concerns presented in this report would enhance the prospects for improved modeling. However, unless the core challenges outlined are seriously confronted and surmounted, uncertainty is likely to dominate findings, issues will probably not be resolved, and the potential for conflict or differences among interested parties unfortunately will remain. 


\section{METHOD FOR ASSESSING THE POTENTIAL ENVIRONMENTAL EFFECTS OF POLLUTION}

We present our evaluation of the technical study being conducted by SWYTAF within the context of the environmental impact assessment process. Toward that end, a schematic of a model-based air-quality impact assessment process is shown in Figure 1. In the diagram, all of the various technical pursuits occur within the regulatory setting. By identifying specific areas of concern and mandating the methods by which these concerns are addressed, the regulatory framework drives the technical tasks that include planning, monitoring, and modeling. This diagram is not meant to be a guide for what an assessment process should be. Rather, it is presumed to be representative of the process as it currently exists.

The technical assessment steps outlined in Figure 1 involve the following progression:

1. Define Problem: Identify the environmental effects and the pollutants of concern, and identify the physical and chemical processes that influence the pollutants and environmental effects.

2. Collect Data: Estimate and/or measure pollutant emissions, and monitor ambient pollutant concentrations and environmental conditions.

3. Model: Develop or select a modeling system that simulates the relationship between pollutants and effects. Conduct a modeling study. Evaluate the ability of the modeling system to predict current or historic air quality. Develop future emissions estimates and predict future environmental impacts.

4. Plan: Decide if projected emissions will cause unacceptable environmental impacts. If so, design a control strategy.

5. Evaluate and adapt: Through a process of ongoing monitoring and analysis, determine if emission control strategies are adequate to achieve or maintain designated environmental quality goals. These decisions are made through an iterative process that involves revisiting some or all of the previous steps. If goals are not being met, modify emission control strategies through an adaptive process.

In this document, we provide the following;

- technical guidance with respect to the modeling system and assumptions selected by SWYTAF

- a description of the regulatory setting within which SWYTAF is operating

- a definition and discussion of the visibility-related environmental impacts

- a review of the aerometric data available for the region

Our analysis addresses only the salient features of each technical activity. Our key findings regarding the regulatory setting, problem definition, and the monitoring and modeling tasks are summarized below. In this report, we do not comment on the planning, evaluation and adaptation steps of the impact assessment process. The appendices discuss our findings in more detail. The appendix that touches on each activity is noted in the diagram (in italics), and is referenced in the summary findings. For the convenience of the reader, a glossary has been included as Appendix VIII that contains definitions of important terms. 


\section{Model-Based Air Quality Impact Assessment Process}

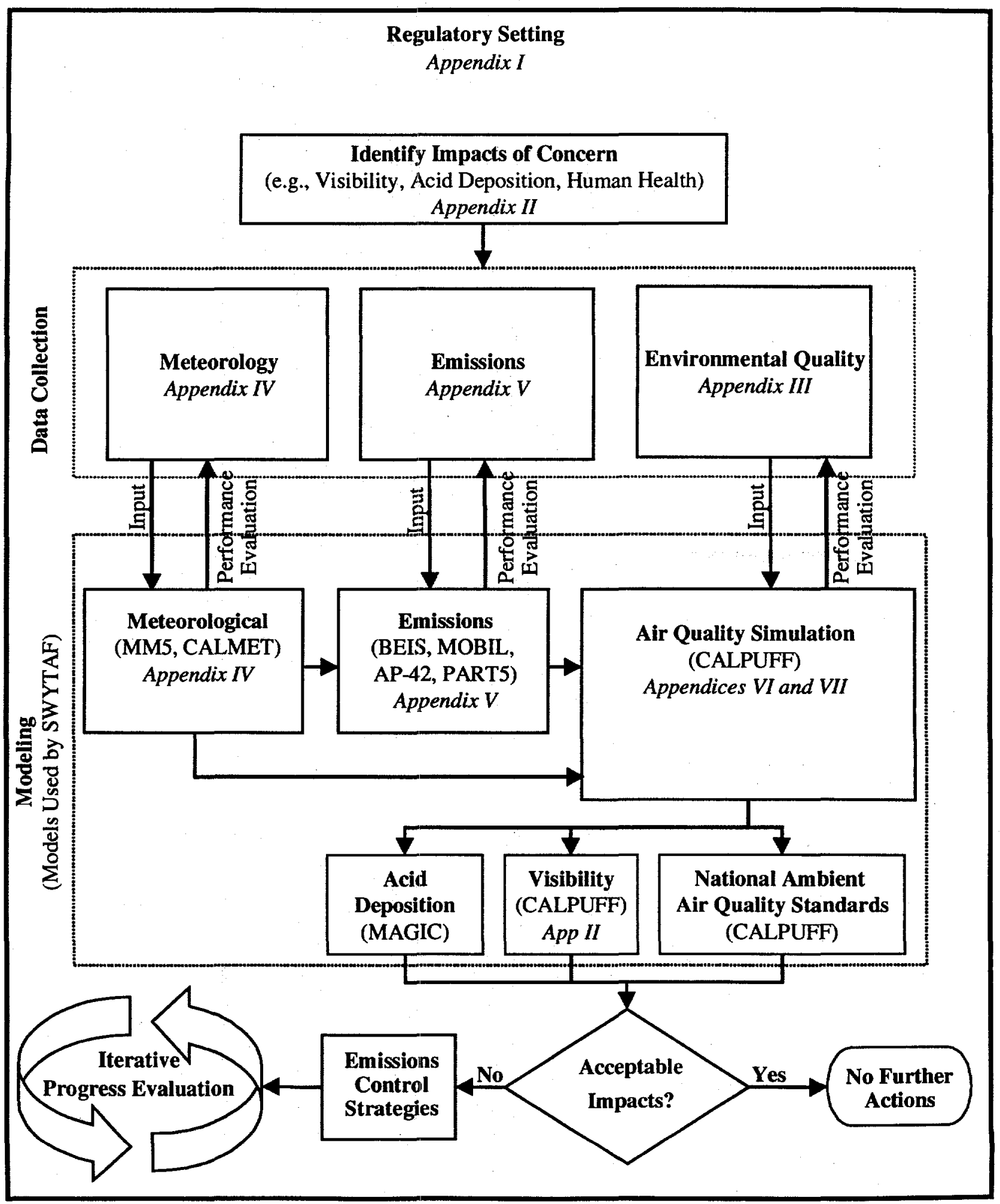




\section{Regulatory Issues}

The regulatory setting within which SWYTAF operates is complex, detailed, at times ambiguous, and ever evolving. Understanding this setting and questions arising from it clarifies the interplay of regulatory and technical questions, the anticipated utility of technical information, and, in turn, the implications of the uncertainties in technical studies. SWYTAF is principally concerned with the question, "What, if anything, must be done to limit air pollutant emissions from oil and gas exploration and extraction?" Answering this question requires increasingly detailed and specific questions that are not simply technical in nature. Instead, numerous policy decisions define the type of technical information developed and the extent to which this information is incorporated into planning decisions.

The SWYTAF study is concerned with impacts on air quality, visibility and acid deposition. Although numerous Federal and state laws relate to these impacts, the New Source Review (NSR) provisions of the Federal Clean Air Act provide the impetus for the SWYTAF inquiry. Within NSR, so called Prevention of Significant Deterioration (PSD) rules prohibit new projects that will cause unacceptable impacts on air quality and air quality-related values in national parks and wildernesses (i.e., Class I areas). Indicators of air quality include CAA-defined "criteria air pollutants"; air quality-related values include visibility and the acid-neutralizing capability of lakes, amongst others. These seemingly straightforward rules generate a myriad of regulatory questions, such as:

- What are air quality-related values and how should they be measured? What constitutes unacceptable impacts on air quality-related values? In contrast to the precisely defined measures of air quality (i.e., National Ambient Air Quality Standards), air quality-related values are not explicitly characterized in the Federal Clean Air Act. For example, the appropriate indicator of visibility (e.g., deciview or light extinction), and acceptable impact thresholds have not been agreed upon by the EPA and FLM. Although an interagency task force, Federal Land Managers' Air Quality Related Values Workgroup, has convened to resolve these uncertainties, their efforts may not proceed apace with SWYTAF.

- What agencies have authority to deny a proposed project based on expectations of unacceptable environmental impacts? The Wyoming Air Quality Standards and Rules (WQAQS\&R) include a provision to deny a permit if Federal Land Managers (FLM) demonstrate that the project will cause "adverse impacts" in Class I areas. However, the WDEQ is given authority to override FLM findings. In practice, decision-making authority is not as clear as the regulations suggest. For example, in March 1977, the Bureau of Land Management established an emissions cap of 977 tons NO $\mathrm{x} /$ year for their Rock Springs District (located in SW Wyoming). The cap was intended to prevent a 0.5 deciview impairment of visibility in the Bridger Wilderness, a Class I area. The WDEQ, natural gas industry and PAW subsequently challenged BLM's authority to set the cap. The Interior Board of Land Appeals found that indeed BLM was exceeding its authority and that only the WDEQ can prohibit new projects. In response, BLM downgraded the cap to a "level of concern" threshold, which subsequently opponents also appealed. 
- What options are available to prohibit or limit project emissions? If "permitted potential" emissions for a proposed project are expected to exceed acceptable levels, the FLM is then responsible for examining more closely the potential impacts on air quality related values. This examination may include monitoring to document impacts and/or additional modeling. However, when initial analyses indicated that the proposed Jonah Field II Natural Gas Development Project may cause unacceptable impacts, the FLM deferred to SWYTAF, citing the more advanced modeling study. Nonetheless, the FLM was left with no real authority to oversee further evaluation of the proposed project, despite their legal mandate to do so.

- What is the best approach for evaluating impacts on air quality, visibility and acid deposition? SWYTAF is proceeding with a modeling study. However, it is not clear that this modeling approach is the best method for evaluating the questions faced by SWYTAF.

- If modeling is chosen as the analysis method, which models should be used? The modeling system selected by SWYTAF uses CALPUFF as the air quality simulation model, but it is not clear that this "best available" model is "good enough."

- What assumptions about emissions should be used to model impacts of existing or proposed projects? Any modeling study, including the one currently endorsed by SWYTAF, will involve a number of assumptions. The rationale for these decisions is not always clear and frequently relies on considerations other than scientific. For example, one contentious issue faced by SWYTAF is the accuracy of current emissions estimates from oil and gas operations. The WDEQ and the Petroleum Association of Wyoming each argue that their emissions inventory is more accurate (SWYTAF, 1998). At this point, the parties have agreed to split the difference.

SWYTAF is necessarily grappling with some of these ongoing debates while settling others. Many of these questions are also being addressed through other interagency efforts. Although SWYTAF will rely on the results of these other efforts, it will be most helpful if a clear and unambiguous set of policy and technical questions and responses is developed by SWYTAF. A more detailed discussion of these regulatory issues can be found in Appendix I.

\section{Problem Definition}

To properly define the questions that need to be addressed, it is necessary to unambiguously define the air quality issues targeted by the regulatory agencies, and then to identify the pollutants and atmospheric processes of concern that contribute to the problem. In southwest Wyoming, the environmental impacts of primary concern are degradation of visibility and the acid neutralizing capability of surface waters due to present and future oil and gas development in the region.

Severe restrictions may be placed on oil and gas field emissions to prevent unacceptable impacts on nearby Class I areas given special protection status under the Federal Clean Air Act. Emissions controls may be necessary to assure that only allowable changes occur in the visual scene of these pristine areas. For instance, the U.S. Forest Service defines an unacceptable impact threshold on visibility to be an increase of 0.5 deciviews or more. (A deciview corresponds to 
approximately a 10 percent decrease in perceived visual scene.) A second concern is the acidification of lakes located in Class I areas. In this interim report, we focus on visibility degradation not lake acidification.

Visibility is a complex phenomenon that encompasses physical processes such as meteorology, gas phase chemistry, and a number of aerosol formation and growth routes and as such, poses numerous challenges. The salient points defining visibility and the challenges associated with characterizing it are outlined below.

- Visibility degradation lessens the contrast between an object and its background. It is caused by the interaction of light with aerosol particles and gasses present in the atmosphere. This interaction, called light extinction, is primarily due to the scattering and absorption of light by aerosol particles in the atmosphere.

- Visibility degradation is caused by a complex mixture of aerosol species. The key variables that determine the light extinction caused by any individual particle are the particle's size and optical properties, which depend upon particle composition. The chemical composition of an aerosol can vary with size, or between particles of the same size. The amount of information necessary to characterize this complexity is rarely, if ever, measured.

- The presence of water in the atmosphere is an additional and significant variable affecting extinction. Sulfates, nitrates, and some organic species are hygroscopic, meaning that the particles will gain water from that present in the atmosphere and grow in size. The greater the relative humidity, the larger is the particle size. This increase in particle size generally increases the light scattering from that particle. Therefore, in addition to the ambient aerosol concentration, it is important to know the meteorological conditions, including any long-term trends, which can also affect trends in visibility.

Thanks to federally financed visibility monitoring programs, such as IMPROVE, some statistics about the current visibility conditions in southwest Wyoming are available.

- Fine aerosol particles (less than $2.5 \mu \mathrm{m}$ ) contribute about half of the light extinction in the area. Of the fine mass, organic and sulfate aerosol are the largest contributors.

- Extinction due to natural conditions in the atmosphere accounts for approximately 40 percent of the light extinction in the area, indicating a relatively clean atmosphere.

- Given the relatively clean conditions, only a small increase in aerosol mass is necessary to produce a noticeable degradation in visibility that will result in an increase of 1 deciview. Therefore, when evaluating the model output, it is important to carefully analyze the uncertainties in the calculations. Such uncertainties could lead to estimated changes in visibility that range from unnoticeable to significant.

Further details concerning the definition and calculation of visibility, in addition to a discussion of the measured visibility conditions, can be found in Appendix II. 


\section{Data Collection}

Data collection involves primarily monitoring environmental conditions, but can also include other types of information gathering such as laboratory studies. Monitoring plays a central role in any air quality assessment program. It is important to obtain accurate observations of the state of the atmosphere and the specific species causing the problem. Moreover, measurements are employed to support data analysis activities, to develop model inputs, and to evaluate model performance. Monitoring needs are more extensive than just measuring pollutant concentrations. To characterize an area adequately, monitoring must include measurements of local meteorology and the emissions injected into the system.

\section{a) Air Quality}

Air quality monitoring systems are usually operated and funded by the state and federal agencies charged with air quality regulation. More detail on air quality monitoring can be found in Appendix III.

- There are limited monitoring data for southwestern Wyoming. Extinction (or scattering) and the aerosol chemistry necessary to apportion the extinction according to aerosol species is measured at only three locations in Wyoming. Of these, the only monitoring station that is located in the current SWYTAF modeling domain is in the Bridger Wilderness. The limited data make it impossible to assess air quality model performance for this region.

- Sources of gaseous and particulate pollutant measurements include IMPROVE, Clean Air Status and Trends Network (CASTNet), National Atmospheric Deposition Program/National Trends Network (NADP), and the EPA State and Local Air Monitoring Stations (SLAMS) Network. These are described in more detail in Appendix III.

\section{b) Meteorology}

A thorough characterization of the meteorology of the area is an essential step in understanding key pollutant transport phenomena. Meteorological conditions influence chemical reactions and aerosol processes, and how pollutants and emissions are transported. Meteorological fields facilitate attributing air quality impacts in one area to emissions occurring upwind. The following points concern meteorological monitoring in southwest Wyoming. Further detail can be found in Appendix IV.

- Sources of meteorological data collected in the 1995 modeling period in Wyoming and the immediately surrounding area include National Weather Service surface and upper air measurement sites, the Department of Interior Remote Automatic Weather Stations, IMPROVE, U.S. Forest Service Visibility Program, National Park Service Gaseous Pollutant Monitoring Program, Wyoming State Department of Transportation sites, National Dry Deposition Network, industrial sites, and the Mount Zirkel Reasonable Attribution Visibility Study [Watson et al., 1996]. With the exception of the Mt. Zirkel study, no special meteorological measurements were conducted in the southwestern Wyoming area to support planned air quality modeling activities. 
- A key issue influencing the adequacy of the simulated meteorological fields is the availability of suitable input data. Of particular concern is the absence of information on the vertical structure of the wind and temperature fields in key areas of the modeling domain. The potential complexity of the meteorological fields can be surmised from a review of the Mt. Zirkel Reasonable Attribution Visibility Study where special efforts were undertaken to characterize such phenomena. The paucity of suitable independent measurements in southwest Wyoming will make it difficult to evaluate the performance of the meteorological modeling system.

\section{c) Emissions}

An assessment of the air quality impacts of any single source requires the development of an accurate emission inventory for all major sources of each pollutant that affect the region including, of course, the specific source of concern. Emissions of interest include both primary emissions of pollutants of concern and associated precursors for secondary pollutants. While accurate emission inventories are difficult to compile, they are central to the entire assessment process. Therefore, it is important to provide the best possible emissions estimates and to characterize their uncertainties. Our findings concerning the emission inventory developed in southwest Wyoming are presented below. More information on the emission inventory can be found in Appendix V.

- An emission inventory is typically developed by combining an emission factor (i.e.,pollutant emitted per amount of activity) with the estimated or measured activity of each source. Emission factors can be measured directly from most sources of concern in an area, e.g. through use of continuous emission monitors; estimated from measurements of similar sources in other locations; estimated based on engineering assumptions about the sources; or modeled. (Two important pollutant sources that are typically modeled are motor vehicles and vegetation.) Whenever possible, the indirect emission factor estimates, including output from standard emission factor models, should be validated with measurements from sources in the area being studied. All emission factor and activity estimates should be clearly described and referenced so that they may be evaluated by independent review. The uncertainty of each emission estimate should also be stated.

- There is a paucity of direct measurements of organic compound emissions for two important sources in southwest Wyoming: (1) the oil and gas industry, and (2) vegetation. The methods used to develop emission factor estimates for oil and gas industry equipment and several of the processes are poorly documented in the current inventory, and in some cases may be based on highly uncertain engineering assumptions. Specific concerns include:

- The uncertainties introduced through the use of EPA's AP-42 emission factor database to estimate emissions from oil and gas industry equipment, including diesel engines, in southwest Wyoming.

- The unsupported engineering assumptions, especially regarding the quantity and composition of the organic compound fraction, used to estimate emissions from blowdown and flaring of gas wells.

- The lack of speciated measurements of $\mathrm{C}_{8}+$ organics (compounds having more than 8 carbon atoms) from oil and gas industry processes.

- The lack of uncertainty estimates for all emission sources. 
- The assumption that activity and emission factors reported and measured in two gas fields (Moxa and Wamsutter) are representative of all gas fields in the area.

- There is a need to develop more accurate estimates of oil and gas industry emissions, as well as the associated uncertainty of these emission estimates. This need may be met by collecting activity data from a broader sample of gas wells and expanding programs to directly measure the total mass and speciation of emissions in the field.

\section{Modeling}

The atmosphere is an extremely complex system where a number of physical and chemical processes take place simultaneously. Measurements indicate the results of these processes. However, it is often difficult to develop specific cause-effect relationships, especially when such relations are non-linear. Mathematical models of the atmosphere provide a means for establishing source-receptor relationships. These models then serve as a tool for further study of their interactions and can provide policymakers with the means to better understand the possible effects of an emission control program.

A suitable model provides an adequate representation of atmospheric processes. Therefore, a model requires descriptions of emission patterns, meteorology, chemical transformations, and removal processes. We have reviewed the current SWYTAF modeling efforts as they relate to these processes. In addition, we have reviewed the selected modeling framework, CALPUFF, and identified some concerns regarding its application in southwestern Wyoming.

\section{a) Air Quality Modeling Framework}

Four issues are of particular concern regarding the use of CALPUFF to provide air quality assessments in southwest Wyoming:

- CALPUFF is based on a time-varying, expanding puff approach that has primarily been employed to treat the dispersion of pollutants emitted from large point sources. While it is also applied to aggregates of point sources (i.e., area sources), it is unclear that this approach is as well suited for such applications as the traditional grid-based model. In southwestern Wyoming, "build-out" scenarios include up to 10,000 individual sources. Grid models are designed to address this type of source situation; further work is needed to demonstrate the suitability of the CALPUFF approach for such applications.

- Grid models were designed and are applied to situations in which the treatment of gas phase chemistry is a primary feature of the dynamic system in which pollutants are formed in the atmosphere. They simulate these dynamics explicitly by a detailed description of fundamental chemical interactions. In contrast, CALPUFF is primarily a multi-source plume model that treats transport downwind and dispersion along the transport path. The representation of gas phase chemistry is highly simplified, relying on linearization and parameterization of the chemical relationships. These simplifications are likely to be deficient when applied to situations in which complex chemistry dominates the processes responsible for formation of secondary air pollutants. Such secondary air pollutants are an important source of visibility 
degradation in southwestern Wyoming. (Refer to our more detailed discussion of gas phase chemistry below and in Appendix VI.)

- Grid models provide a framework for accommodating more fundamental treatment of aerosol dynamics and gas phase chemistry. CALPUFF cannot incorporate such treatments; instead, derived correlations are used. Generally, these are less able to describe the dynamic behavior of aerosol formation.

- Application of CALPUFF in southwestern Wyoming entails the modeling of a large number of plumes, which inevitably will overlap in many cases. The chemistry of overlapping plumes is not treated directly in CALPUFF, or for that matter, in any model. In grid-based modeling systems, the chemical reactions that occur in areas of plume overlap can only be represented insofar as such models can provide adequate spatial resolution of the individual plumes. (In many instances this resolution is limited by the grid cell dimensions, which are usually of the order of several kilometers). While the plume orientation of CALPUFF provides some means for spatially resolving individual plumes, it is not designed to treat the chemical reaction phenomena that may occur in the area where plumes overlap.

Table I in Appendix VII compares grid-based modeling systems and CALPUFF with respect to a number of other attributes. However, those attributes discussed here raise serious questions about the appropriateness of using CALPUFF.

\section{b) Meteorological Modeling}

In reviewing the meteorological data base and modeling approach, we make several observations. Additional detail concerning meteorological modeling can be found in Appendix IV.

- Data analyses conducted as part of the Mt. Zirkel Reasonable Attribution Visibility Study indicate that complex wind flow and mixing conditions are likely to occur in the southwestern Wyoming area. The adequacy of air quality and visibility model performance will be contingent on the availability of suitable measurements and the ability of the meteorological modeling system to adequately represent these transport phenomena.

- The development of meteorological inputs for CALPUFF involves using both the CALMET diagnostic model and the MM5 prognostic model. Although MM5 represents the state-ofthe-science in meteorological modeling, it was deemed impractical to apply on a spatial grid sufficiently fine to resolve important terrain-induced features in the flow fields. Instead, MM5 is being applied to a nested domain with 60 and $20 \mathrm{~km}$ grid resolutions. The MM5 results are then used as inputs to the CALMET model, which is being applied on a grid with $4 \mathrm{~km}$ horizontal resolution.

- The combined use of CALMET and MM5 is a pragmatic means for developing meteorological inputs for air quality and visibility modeling. The approach might be improved by a full nested grid application of MM5 to the $4 \mathrm{~km}$ horizontal grid resolution being employed in CALMET. However, it is unclear that significantly more reliable meteorological 
fields would result from such an approach. Considerably more computing time would be required to develop the meteorological inputs needed for annual air quality modeling.

- As we mentioned above, simulated meteorological fields are likely to be inadequate due to insufficient input data, particularly the absence of detail about the wind's vertical structure and temperature. These same data limitations will make it difficult to evaluate the meteorological modeling system's performance.

\section{c) Modeling Emissions}

There are many sound reasons for the use of models to estimate emissions from groups of similar sources that have complex activity patterns and emission factor-activity relationships (e.g. on-road motor vehicles, vegetation). Such models are typically developed from the measured emissions of individual sources under a range of environmental and/or operational conditions. Most prominent in the emission inventory developed for SWYTAF is the use of the BEIS2 model to estimate biogenic VOC emissions from the forests in southwest Wyoming; models are also used to predict on- and off-road motor vehicle emissions of several pollutants, including fine particles. The following issues are of significant concern if the current EarthTech/Air Sciences emission inventory is to be useful in determining air quality impacts of the petroleum industry in southwest Wyoming. More information on the emissions inventory can be found in Appendix V.

- The current modeling approach considers secondary organic aerosol production from only four species: toluene, xylene, alpha-pinene and beta-pinene. The current emission inventory speciates emissions of total organic compounds to estimate these four compounds. Secondary organic aerosol (SOA) can form from many additional organic compounds, some of which are prominent components of emissions from oil and gas operations. Both the chemical mechanism and the emissions inventory should include an assessment of SOA production from additional organic compounds.

- Biogenic sources have been estimated to contribute a large majority of the organic compounds that form secondary organic aerosol in southwest Wyoming [EarthTech, Inc. and Air Sciences, Inc., 1998]; as a result it is crucial that the biogenic VOC inventory be as accurate as possible and include uncertainty estimates. While it is impractical to measure directly the emissions of the varied biota in southwest Wyoming over a full growing season (emissions depend on growing season, temperature, moisture, atmospheric composition, and light), it is important to understand the limitations and uncertainties of the model predictions. These include uncertainties in measurements on which the model's emission factors are based, uncertainties in the parameterization of the emission factor-activity relationships (e.g. the effect of temperature), and the degree to which vegetation in southwest Wyoming is different than the vegetation used to develop model emission factors.

- The biogenic inventory estimates are presented for "high" and "moderate" emission canopies. These two estimates, which differ by nearly a factor of 3, were developed by selecting different forest type and tree species emission factors included in the BEIS2 model. The process of selecting appropriate BEIS2 forest categories requires an understanding of the forest and tree species represented by each BEIS2 category and knowledge of the forested 
areas of southwest Wyoming. Given the uncertainty about which categories are most appropriate, the biogenic inventory should be presented as a mean, "best-estimate" value with uncertainty bounds. The BEIS2 categories which were used to arrive at the mean, upper-, and lower-bound values should be documented for independent evaluation. The overall uncertainty of the biogenic inventory should include uncertainty in the individual forest or tree specie emission factors.

\section{d) Modeling Chemical Transformations}

Numerous gas and particle phase chemical transformations influence the formation rate of secondary pollutants and the chemical composition of the atmosphere. We identify specific concerns for both the gas phase and secondary organic aerosol transformations present in CALPUFF. Information detailing the chemical transformations represented in the CALPUFF model is limited to a few elementary gas phase reactions. In addition, limited means for representing secondary organic aerosol transformations is being developed for inclusion in the CALPUFF model. Additional detail concerning modeling atmospheric chemistry can be found in Appendix VI.

\section{i) Representation of Gas Phase Chemistry}

Gas phase chemistry describes the transformation of emitted pollutants to gaseous compounds that form visibility-impairing aerosols. In grid-based photochemical modeling, chemical mechanisms represent very complex atmospheric chemistry by simulating the dynamic transformations of a number of chemical species through a series of elementary reactions. The chemical mechanism is represented by coupled rate equations that describe the production and destruction of species in the atmosphere, both temporally and spatially. The rate equations, which are solved numerically, are coupled, nonlinear, and temperature dependent.

The treatment of gas phase chemistry employed in CALPUFF to describe the transformation of sulfur dioxide to sulfate, and nitrogen oxides to nitric acid and then to nitrate ${ }^{3}$, is based on two simplifying assumptions:

- the chemistry is linear

- reaction rates are independent of temperature.

These assumptions are problematic for the following reasons:

- Simple pseudo-first order expressions (i.e., linear in concentration) were developed for the assumed linear transformations. In the atmosphere, however, the transformations actually occur through a number of elementary reactions. Describing these chemical transformations requires the solution of highly coupled non-linear differential equations. There is no evidence to suggest that an assumption of linearity is warranted or predicts correct transformation rates.

- Chemistry based on knowledge extant in the early 1980s was used to derive the pseudo-first order expressions. The calculated nitrate and sulfate concentrations were assumed to react completely with ammonia $\left(\mathrm{NH}_{3}\right)$ to form ammonium sulfate $\left(\mathrm{NH}_{4} \mathrm{SO}_{4}\right)$ and ammonium nitrate

\footnotetext{
${ }^{3}$ The chemistry of these two transformations is: $\mathrm{SO}_{2} \rightarrow \mathrm{SO}_{4}{ }^{-2}$, and $\mathrm{NO}_{\mathrm{x}} \rightarrow \mathrm{HNO}_{3} \rightarrow \mathrm{NO}_{3}$
} 
$\left(\mathrm{NH}_{4} \mathrm{NO}_{3}\right)$ aerosols, an unwarranted assumption. Because the various assumptions are not substantiated and raise serious questions about accuracy of representation, we have concern about the approach adopted.

- The uncertainties in the $\mathrm{NH}_{3}$ concentrations used in the study are important. This is particularly important because $\mathrm{NH}_{3}$ may be a limiting reagent in the formation of $\mathrm{NO}_{3}{ }^{-1}$ and $\mathrm{SO}_{4}{ }^{-2}$ aerosols. This uncertainty should be given consideration, and if possible quantified, in future analyses conducted.

- The CALPUFF modeling approach was employed in the 1996 Mount Zirkel study to estimate $\mathrm{NH}_{4} \mathrm{SO}_{4}$ and $\mathrm{NH}_{4} \mathrm{NO}_{3}$ aerosols. Statistical bias (in percent) between measured and estimated concentrations, reported for four episodes, was:

\begin{tabular}{|l|l|l|l|l|l|}
\hline [otal PM-2.5 & Sulfate & Nitrate & Rrimary PM-2.5 & Elemental & Organic \\
& & & & Carbon & Aeroso \\
\hline+21 to -71 & +21 to -71 & +112 to -11 & +12 to -79 & -62 to -88 & -17 to -77 \\
\hline
\end{tabular}

The agreement between measured and estimated aerosol concentrations using this approach is random and poor. Thus, we are concerned that the simplistic approach to aerosol formation may produce significant errors in the current study as well.

\section{ii) Treatment of Secondary Organic Aerosol Formation}

We have the following concerns regarding efforts to estimate secondary organic aerosol formation:

- The yield of aerosol mass is the fraction of reacted organic species that produces aerosols. Yield formulae for secondary aerosols are used to calculate the mass of secondary organic aerosol when data are available that characterize emissions of organic compounds, their speciation, and their atmospheric reactivity. Currently, knowledge of organic aerosols and their optical properties is at a very primitive stage. It entails a leap of faith to estimate visibility based on aerosol mass data, particularly for organics.

- Visibility is estimated based on aerosol mass in the current modeling effort. Therefore, we reviewed available data on aerosol yields based on smog chamber experiments by Seinfeld and colleagues at Caltech. Extension of this work to the atmosphere has yet to be accomplished. However, were this extension valid, predicting secondary organic aerosol formation in the atmosphere would require knowledge of the following:

- The concentrations of individual organic compounds that contain more than six carbon atoms,

- The amount of each reactive organic gas (ROG) that reacts over time, 
- Yield formulae for each organic compound; the yield relationships should be determined in experiments that mimic the atmospheric chemistry of interest. This is crucial because the yield formulae are strongly influenced by the ambient chemistry.

- Although the EarthTech investigators reference the work of Seinfeld and colleagues, they do not adhere to this procedure. They consider four organic compounds to be sufficiently representative. They estimate the concentrations of these four compounds by considering VOCs from anthropogenic and biogenic sources with partitioning of the anthropogenics according to the prescription associated with the CB-IV chemical mechanisms. They reduce gas phase chemistry to a few elementary rates for the parent organic compounds, with gas phase concentrations of $\mathrm{OH}, \mathrm{NO}_{3}$, and $\mathrm{O}_{3}$ derived using linear chemistry and other approximations. Fitting parameters required in yield formulae were scaled from those determined in smog chamber experiments using relationships that have not been derived from scientific studies. In the report we raise a number of concerns about this approach, including partitioning the hydrocarbon emission inventory, treatment of the gas phase chemistry of the parent hydrocarbon that precedes aerosol formation, and derivation of the parameters in yield formula.

\section{e) Modeling Visibility}

There has been limited demonstrated ability to accurately model visibility impacts. To estimate visibility, the air quality model must provide detailed information about meteorological conditions and aerosol characteristics. Most work to date has focussed on gas phase chemistry. Research on aerosol formation in these models has recently begun in earnest. More detail can be found in Appendix II, but our primary findings include:

- Calculating visibility degradation for a complex mixture of aerosol species is a difficult task. The amount of information necessary to support such calculations is rarely, if ever, available. This information includes how the chemical composition of the aerosol varies both within particles of the same size and between particles of different sizes. Typically, a number of assumptions are employed to calculate the extinction resulting from a mixture of aerosol species. These assumptions facilitate the comparison of calculated and observed visibility conditions.

- While simplifying assumptions allow for the calculation of visibility from field measurements, it is much more difficult to assess how current visibility conditions will change due to removal of one or more of the species. The removal of a species can affect both the size and the chemistry of the remaining aerosol. Calculating the change in extinction requires information about the size and composition of the aerosol that is usually unavailable. Given these uncertainties, estimating the change in visibility resulting from emissions controls can result in a range of values that depend upon the assumptions made concerning the structure of the aerosol. It is important to make appropriate assumptions for the specific conditions in the area under study, and to realize that there may still be significant uncertainties associated with any estimated visibility change. 


\section{Plan, Evaluate, and Adapt}

Historically, most air quality efforts can be characterized by placing the majority of effort into monitoring and field measurement campaigns rather than careful planning and analysis activities. In the Rocky Mountain area, there have been carefully-planned measurement and analysis programs like the Mount Zirkel study. We suggest an effort that strives to achieve a balance between planning, measurement, and analysis. If each portion of this triad is carefully executed, the optimum tradeoff between extracting useful information and understanding and economy can be achieved. The details associated with a concerted study applied to the Rocky Mountain area are not touched upon in this report. Future project activities will include investigations into these issues.

\section{PLANNED PROJECT ACTIVITIES}

During the next reporting period, the study team will continue its investigation of modeling and analysis procedures employed to evaluate impacts on air quality and air-quality-related values associated with oil and gas development in southwestern Wyoming. Our efforts will include three broad areas of investigation:

Regulatory Setting: We have identified an initial list of key regulatory questions. We will conduct interviews to further examine the regulatory setting within which technical analyses are being carried out to identify outstanding issues, sources of conflicts, and possible means of resolution. Specifically, we will:

- Discuss regulatory issues with key personnel affiliated with the SWYTAF regulatory agencies, such as WDEQ, EPA, and DOE;

- Based on interviews, generate a list of important regulatory issues and questions;

- Using analyses of interview comments and other documentation, identify unresolved issues and their sources of dispute;

- Evaluate ongoing processes, such as interagency guidance efforts, that have the potential to resolve outstanding issues;

- Identify issues that are not likely to be resolved through ongoing processes;

- Suggest means for resolving outstanding issues.

Modeling Technical Details: In this report, we have discussed our concerns about the technical activities to date. Our particular concerns include the adequacy of the CALPUFF modeling approach, and the accuracy and uncertainty of key inputs, such as meteorological and emissions estimates. Our future efforts will include investigations aimed at developing a better understanding of the factors responsible for visibility changes and for assessing potential changes due to acid deposition in the Rocky Mountain area. At present, the CALPUFF model and associated data sets for southwest Wyoming have not been delivered to SWYTAF. Should there be interest in further characterization of that modeling system, the following list of potential activities contains tasks specific to CALPUFF. Other activities that we might pursue are included as well. 
- Obtain the SWYTAF modeling system and associated inputs and outputs for the final modeling runs when they become available;

- Review previous efforts to evaluate model performance. Determine lessons derived from applications experience, nature of past evaluations, including extent to which individual model components have been evaluated, and outcomes of these efforts;

- Identify a set of analyses to further assess the possible importance of theoretical limitations of the CALPUFF approach such as a limited intercomparison of sensitivity results from CALPUFF, a grid model with full nonlinear aerosol chemistry (such as SAQM-AERO), and other simpler approaches (such as box, trajectory, and/or observation-based techniques); this intercomparison will include an assessment of the consistency of the model responses to changes in precursor emissions;

- $\quad$ Further assess the adequacy of the emissions and meteorological inputs;

- Identify means for improved estimates of current and future emissions from oil and gas sources;

- Assess the appropriateness of assumptions made in deriving other key model inputs, such as boundary conditions;

- Identify additional diagnostic and model sensitivity work that may be needed to provide a better understanding of CALPUFF performance;

- $\quad$ Assess the use of current monitoring data for evaluating model performance;

- Identify alternative analysis approaches for corroborating the CALPUFF results;

- Identify possible means for improving the representation of aerosol formation and for estimating visibility degradation;

- Examine the need for and feasibility of adopting a grid-based modeling approach with improved representation of gas- and particle-phase physical and chemical processes.

Air Quality Assessment Process: A fundamental concern is the suitability of the current air quality assessment process, which attempts to discern air quality and visibility impacts through the use of modeling even though measurements are inadequate to appropriately characterize key atmospheric processes. Using the SWYTAF process as a case study, we will recommend alternative approaches that may provide a more sound basis for the conduct of such air quality assessments. Two of our specific tasks will include:

- $\quad$ Assess the feasibility of adopting a new approach for conducting air quality impact assessments of oil and gas developments based on a combined monitoring and modeling effort that is well-planned and highly concerted;

- Identify regulatory and technical issues that need to be addressed to facilitate the implementation of such an approach;

- Identify key areas where improved guidance is needed for the conduct of air quality assessments of oil and gas development activities. 


\section{BIBLIOGRAPHY}

Chu D., et al. (1996). The Red Desert Blues: The Industrialization of Southwest Wyoming. Friends of the Wild Wyoming Deserts, Greater Yellowstone Coalition, Sierra Club, The Wilderness Society, Wyoming Outdoor Council, Wyoming Wilderness Association, and Wyoming Wildlife Federation. Published April, 1996 at http://www.wocnet.org/wocnet/RedDesertB.html

EarthTech, Inc. and Air Sciences, Inc. (1998). 1995 Air Emissions Within the Southwest Wyoming Regional Modeling Domain, Vols 1-3, Draft Final Report. December, 1998.

Roth, P. et al. (1998). A Critical Review Regulatory Air Quality Modeling for Tropospheric Ozone. Prepared for the North American Research Strategy for Tropospheric Assessment (NARSTO) Sept. 1998 at http://www.cgenv.com/Narsto.

Rudolph, J. (1998). Southwest Wyoming Natural Gas Development: Air Quality Issues, Impacts, and Technology Opportunities. Barlow \& Haun, Inc. Geologists. Casper, Wy. Prepared for Gas Research Institute.

Watson, J.G. et al. (1996) Mt. Zirkel Wilderness reasonable Attribution Study of Visibility Impairment - Volume II: Results of Data Analysis and Modeling. Desert Research Institute, Reno, NV. 


\title{
APPENDIX I. REGULATIONS AND POLICY QUESTIONS
}

\author{
By James D. Fine \\ Environmental Energy Technologies Division, Lawrence Berkeley National Laboratory \\ Berkeley, California 94720-1740
}

\section{Table of Contents}

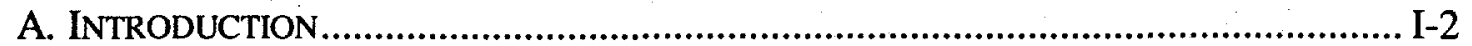

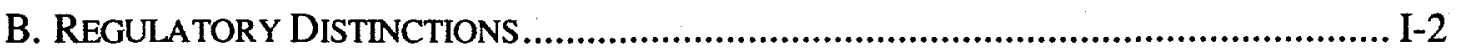

C. FEDERAL AND STATE ENVIRONMENTAL LAWS AND REGULATIONS....................... I-3

1. Environmental Impact Statements.............................................................. I-5

2. Prevention of Significant Deterioration (PSD) .............................................. I-5

3. Other Provisions of the Clean Air Act ......................................................... I-12

D. QUESTIONS ARISING FROM THE REGULATORY SETTING ................................... I-13

1. Decision Making Authority ............................................................. I-13

2. Impact Thresholds ...........................................................................I-14

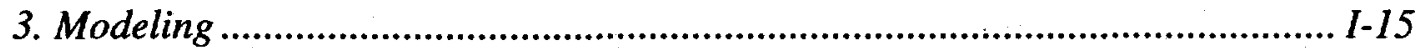

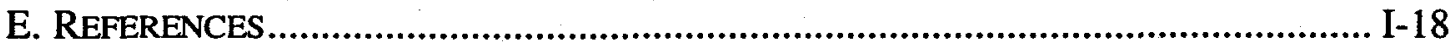

\begin{tabular}{ll} 
Acronyms & \\
\hline ATT & Air Technical Team, a working group of the Federal Leadership Forum \\
BACT & Best Available Control Technology \\
BART & Best Available Retrofit Technology \\
BLM & United States Department of the Interior Bureau of Land Management \\
CAA & Federal Clean Air Act \\
EIS & Environmental Impact Statement \\
EPA & United States Environmental Protection Agency \\
FLAG & Federal Land Managers' Air Quality Related Values Workgroup \\
FLF & Federal Leadership Forum \\
FLM & Federal Land Managers, including BLM, FWS, NPS, and USFS \\
IWAQM & Interagency Workgroup on Air Quality Modeling \\
LBL & Atmospheric Program of the Environmental Energy Technologies Division at Ernest \\
& Orlando Lawrence Berkeley National Laboratories \\
LTV & Long Term Visibility Plan \\
NAAQS & National Ambient Air Quality Standards \\
NEPA & National Environmental Policy Act \\
NOx & Nitrogen Oxides \\
NPS & United States Department of the Interior National Park Service \\
NSR & New Source Review \\
PAW & Petroleum Association of Wyoming \\
PSD & Prevention of Significant Deterioration \\
SIP & State Implementation Plan \\
SO & \\
SWYTAF & Sulfur Dioxide \\
USFS & Southwestern Wyoming Technical Air Forum \\
USFWS & United States Department of Agriculture Forest Service \\
WA & Wilderness Act \\
WAAQS & Wyoming Ambient Air Quality Standards \\
WAQS\&R & Wyoming Air Quality Standards and Regulations \\
WDEQ & Wyoming Department of Environmental Quality \\
\hline
\end{tabular}




\section{A. Introduction}

Although the Southwestern Wyoming Technical Air Forum (SWYTAF) is focused on the specific question of how to analyze the impacts of new air pollutants, its recommendations will be used by decision-makers balancing a broad set of technical, economic, political and social concerns. It is therefore useful to understand the regulatory setting, policy questions generated by this setting, and the relationships that policy questions have to the technical questions addressed by SWYTAF. Ultimately, the utility of these studies will depend on the decision-maker's ability to use technical information to inform policy decisions.

The efforts of SWYTAF are driven by the following policy question:

\section{$>$ WhAT, IF ANYTHING, SHOULD BE DONE TO LIMIT AIR POLLUTANT EMISSIONS FROM OIL AND GAS DEVELOPMENT?}

Encompassed within this rather generic question are increasingly specific and detailed queries about decision-making authority, scientific capability, the relative juxtaposition of social and environmental costs, available alternatives, etc.

In this appendix we discuss the regulatory setting in Wyoming with respect to air quality, visibility and acid deposition. We then identify important questions that derive from laws and regulations.

\section{B. Regulatory Distinctions}

Visibility is a characteristic of air quality, but there is a regulatory distinction between air quality and visibility. The Federal Clean Air Act (CAA) explicitly defines National Ambient Air Quality Standards (NAAQS) for six so called "criteria" air pollutants." Ambient concentrations of these pollutants, or air pollutants that lead to their formation, are measured to evaluate "air quality" in terms of conformance with or progress towards attaining the NAAQS.

Visibility is treated very differently in the CAA. It is referred to as one of many "air quality-related values." 2 Similarly, water quality is an air quality-related value that provides the impetus to evaluate acid deposition.

The distinction between air quality and air quality-related values is important because regulatory requirements for attaining and maintaining air quality (i.e., NAAQS) are very different, more explicitly defined, and in many ways more stringent, than requirements for preserving air quality-related values (e.g., visibility, water quality). For example, the CAA does not explicitly define what characteristics comprise air quality-related values,

\footnotetext{
${ }^{1}$ The six criteria air pollutants are lead, carbon dioxide, nitrogen dioxide, sulfur dioxide, ozone, and particulate matter.

${ }^{2}$ Other air quality related values include flora, fauna, soil, water, archaeological and paleontological cultural resources, and odor. Federal Land Managers are currently working together to define a common list of air quality related values (see discussion of the Federal Land Managers' Air Quality Related Values Workgroup below.)
} 
but it does specify criteria air pollutants, ambient air quality standards for them, and allowable impacts on their ambient concentrations from new emissions sources.

\section{Federal and State Environmental Laws and Regulations}

Numerous federal and state laws and regulations are relevant to air quality, visibility and acid deposition in Wyoming. The most important federal laws include the CAA, National Environmental Policy Act (NEPA), and Wilderness Act (WA). The parallel environmental review processes required by the CAA and NEPA are shown in Figure 1.

State level rules are delineated in the Wyoming Air Quality Standards and Regulations (WAQS\&R). ${ }^{3}$ Although the WAQS\&R derive from and incorporate by reference much of the CAA, they codify state authority by detailing and interpreting the CAA. For example, the WAQS\&R incorporate the NAAQS, thereby making them Wyoming Ambient Air Quality Standards (WAAQS).

Regulations associated with the CAA/WAQS\&R and NEPA require parallel review processes for projects seeking approval to become "major" emissions sources. ${ }^{4.5}$ The CAA's process is New Source Review (NSR); whereas NEPA calls for Environmental Impact Statements (EIS). The CAA and WAQS\&R rely on NSR to prevent the degradation of superior air quality and high air quality-related values. The EIS process calls for identification of the full range of potential environmental impacts associated with any project proposed for federal lands with the potential to cause significant harm.(42 USC 4371 et seq.).

The Wilderness Act of 1964 provides authority for Federal Land Managers (FLM) ${ }^{6}$ to take actions that protect and preserve wilderness areas. ${ }^{7}$

\footnotetext{
${ }^{3}$ Although Wyoming also has an Environmental Quality Act, NEPA requirements are more relevant because most oil and gas development is proposed for public lands managed by Federal agencies, namely the USFS and the BLM.

${ }^{4}$ Both the CAA and the WAQS\&R explicitly define a major source as any facility that has the potential to emit more than 250 tons per year of a pollutant for which there are state or federal air quality standards, or a specific type of facility capable of emitting 100 tons per year. Facilities subject to the 100 tons per year threshold include fossil-fuel fired steam electric plants, petroleum refineries, fuel conversion plants, chemical process plants, and fossil-fuel boilers (or combinations thereof) of more than two hundred and fifty million British thermal units per hour heat input, petroleum storage and transfer facilities with a capacity exceeding three hundred thousand barrels.

${ }^{5}$ EPA has required air quality impact analyses to include sources not meeting emissions thresholds for "major" sources because, in aggregate, they may impact air quality or air quality-related values. (EPA Region VIII memo, undated, reference number 8P2-A).

${ }^{6}$ Federal Land Managers include the U.S. Department of the Interior's Bureau of Land Management (BLM), Fish and Wildlife Service (FWS), and National Park Service (NPS), and the U.S. Department of Agriculture's Forest Service (USFS).

7 The Wilderness Act of 1964 provides authority for the USDA's Forest Service, and the USDOI's Bureau of Land Management, Fish and Wildlife Service and National Park Service to, "... to assure that an increasing population, accompanied by expanding settlement and growing mechanization, does not occupy and modify all areas within the United States and its possessions, leaving no lands designated for preservation and protection in their natural condition, it is hereby declared to ... secure for the American people of present
} 
Figure 1

Environmental Review Processes
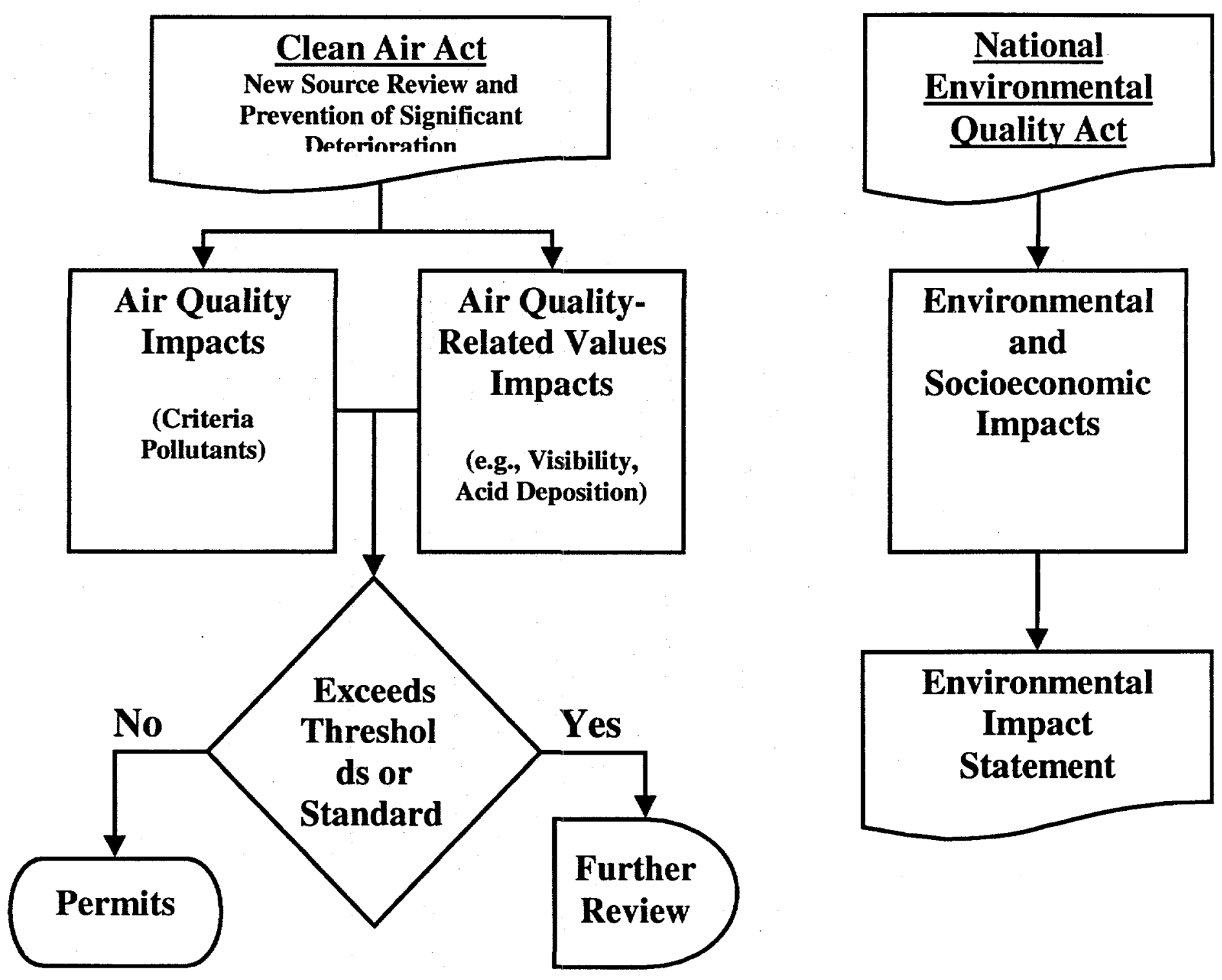

and future generations the benefits of an enduring resource of wilderness..." (P.L. 88-577,

September 3, 1964. U.S. Code Title 16, Chapter 23) 


\section{Environmental Impact Statements}

The National Environmental Policy Act requires evaluation of potentially significant environmental and socioeconomic impacts anticipated from any project on federal lands. The results of these analyses are compiled in an Environmental Impact Statement (EIS). Just as they are subject to NSR, all proposed oil and gas projects proposed on federal land must prepare an EIS. An EIS includes air quality and air quality-related values impact analyses, as well as analyses of project alternatives and cumulative impacts.

Until recently, air quality-related value impacts analysis was conducted using a screening-level simulation model. For example, the initial analyses for natural gas development projects in the Moxa Arch and Fontenelle areas, which are both in the Bureau of Land Management's Rock Springs District, Wyoming, were done using the ISCT3 model (Potter, Personal communication). More recently, however, projects have been evaluated using the CALPUFF modeling system. For example, CALPUFF is used to model impacts from the proposed Continental Divides, GWA II, South Braggs oil well projects (TRC, 1997). More recently, the EIS's for the Pinedale Anticline and Wyodak Coal Bed Methane are employing CALPUFF.

Modeling conducted for an EIS is not the same as modeling to support NSR evaluations. ${ }^{8}$ They differ in both the purposes of the modeling and the emissions considered. The EIS is primarily used for disclosure of impacts, since mitigation measures need only be considered, not required. The NSR process, however, ultimately results in the approval or denial of a permit to proceed with the project.

The emissions incorporated in EIS impact analyses include all current and foreseeable sources. Comparatively, the NSR modeling evaluation includes only the specific project if air quality-related values are being investigated, or all new sources of pollution since the first major point source was constructed.

Comprised of directors from the major FLM, the Federal Leadership Forum (FLF) convened in October 1998 to develop guidance for assessing the impacts of oil and gas development in an EIS. In addition to incorporating guidance provided by other interagency planning efforts discussed below, a working group of the FLF, the Air Technical Team, is addressing modeling questions such as what emissions to include in modeling, what constitutes "reasonably foreseeable development", and what comprises adequate model input data (Blett, Personal communication).

\section{Prevention of Significant Deterioration (PSD)}

When the CAA was amended in 1977, there was concern that strict rules in areas not meeting air quality standards would create incentives to locate new emissions where air quality is good. To ensure that areas with clean air remain that way the CAA

\footnotetext{
${ }^{8}$ Refer to Table D (Differing Modeling Protocol for EIS and PSD Analyses) for a summary of how EIS and NSR modeling differs.
} 
Amendments of 1977 introduced Prevention of Significant Deterioration (PSD) (P.L. 9595). Incorporated into the NSR program, PSD prohibits approval for proposed projects that are expected to cause unacceptable harm to air quality or air quality-related values in specially designated areas. The CAA classifies areas as Class I or II and specifies the associated threshold emissions levels that trigger PSD review requirements. The CAA identifies over 150 national parks and wilderness areas as Class I. Table A lists the eight Class I areas in Wyoming. Areas not designated as Class I are Class II by default. ${ }^{9}$

Table A

Lands in Wyoming Subject to PSD Requirements of the Clean Air Act ${ }^{10}$

\begin{tabular}{|l|}
\hline Bridger Wilderness $^{*}$ \\
\hline Fitzpatrick Wilderness \\
\hline North Absoroka Wilderness \\
\hline Savage Run Wilderness \\
\hline Teton National Park \\
\hline Teton Wilderness \\
\hline Washakie Wilderness \\
\hline Yellowstone National Park \\
\hline
\end{tabular}

As shown in Table B, a number of different types and quantities of pollutant emissions may trigger PSD. In addition to thresholds for projects within Class I areas, PSD review is also required for projects within $10 \mathrm{~km}$ of Class I areas if a project's emissions have the potential to increase 24-hour average pollutant concentrations by $1 \mu \mathrm{g} / \mathrm{m}^{3}$ within the Class I site.

Table B

Emissions Thresholds Triggering PSD Review (WAQS\&R Sect. $28 \$(a)(x x i)(A))$

\begin{tabular}{|l|c|}
\hline Pollutant & Threshold Emissions (Tons/Year) \\
\hline Carbon monoxide & 100 \\
\hline Nitrogen oxides & 40 \\
\hline Sulfur dioxide & 40 \\
\hline Particulate matter & 25 (particulate matter); \\
& 15 (PM ( $_{10}$ ) \\
\hline Ozone & 0.6 \\
\hline Lead & 0.007 \\
\hline Asbestos & 0.0004 \\
\hline Beryllium & (volatile organic compounds) \\
\hline
\end{tabular}

${ }^{9}$ The CAA also provide PSD rules for Class III areas but no such areas have been established.

${ }^{10}$ Class I areas in Wyoming are listed in Wyoming Air Quality Standards and Regulations, Section 28:

Visibility.

* The Bridger and Fitzpatrick Wilderness Areas are included in the SWYTAF modeling domain.

"Savage Run Wilderness does not have a mandatory Class I designation in the CAA. 


\begin{tabular}{|l|c|}
\hline Pollutant & Threshold Emissions (Tons/Year) \\
\hline Mercury & 0.1 \\
\hline Vinyl chloride & 1 \\
\hline Fluorides & 3 \\
\hline Sulfuric acid mist & 7 \\
\hline Hydrogen sulfide $\left(\mathrm{H}_{2} \mathrm{~S}\right.$ ) & 10 \\
\hline Total reduced sulfur (including $\mathrm{H}_{2} \mathrm{~S}$ ) & 10 \\
\hline Reduced sulfur compounds (including $\mathrm{H}_{2} \mathrm{~S}$ ) & 10 \\
\hline
\end{tabular}

PSD review requirements involve the following five steps for the project applicant:

1. demonstration that Best Available Control Technology (BACT) will be installed to control emissions,

2. provision of meteorological and ambient air quality monitoring data,

3. air quality impact analysis using dispersion models to determine if project emissions will cause violations of ambient air quality standards (i.e., NAAQS)

4. air quality-related values impact analysis using modeling to determine if project emissions will cause visibility impairment or unacceptable harm to other air quality related values,

5. public notification and solicitation of comments.(Wallach et al., 1991)

The protocol for conducting the air quality and air quality-related value impact analyses are defined by the U.S. Environmental Protection Agency (EPA). However, states have authority to use their discretion when interpreting and implementing EPA's protocol. This discretion can significantly influence the rigor required of PSD analyses. For example, although EPA provides guidance for modeling air quality impacts in Guideline on Air Quality Impact Models (40 CFR Pt. 51. Appendix W), states can require dispersion modeling with complex terrain or simple screening level models to evaluate the impacts of emissions.

\section{a) Air Quality Impact Analysis}

The WAQS\&R require project applicants to use dispersion models identified in EPA's Guidelines on Air Quality Models when modeling air quality impacts per PSD review. ${ }^{12}$ However, the regulations also grant the Wyoming Department of Environmental Quality (WDEQ) discretion to require that applicants modify or substitute the models selected by EPA. The SWYTAF effort is an exercise of that discretion.

\footnotetext{
${ }^{12}$ Wyoming Air Quality Standards and Regulations, Section 28: Visibility. § (b)(iv) states, "In general, the dispersion models defined in the EPA document, Guidelines on Air Quality Models may be used. However, due to the potential for complex terrain and meteorological situations in Wyoming, the Administrator may require appropriate modification or substitutions to those models defined in Guidelines on Air Quality Models"
} 
The WAQS\&R explicitly define acceptable air quality impacts associated with a proposed project. ${ }^{13}$ It establishes an allowable "increment" of impact on concentrations of air pollutants while prohibiting any impacts that cause a violation of NAAQS. ${ }^{14}$

As shown in Table C, smaller (i.e., more stringent) increments are ascribed to Class I areas. The incremental impacts must take into account not only project emissions but "all emissions not included in the baseline concentrations including, but not limited to, those emissions resulting from the instant application and all other permits issued in the area." Thus, a cumulative impact analysis is conducted whereby impacts of aggregate emissions from all past projects are considered against the allowable increment or standard. This analysis is essentially modeling to examine the extent to which a new project "uses up" an available increment that is partially consumed as each new source of emissions is constructed.

Table C

Allowable Incremental Air Quality Impacts Under PSD

\begin{tabular}{|l|c|c|c|}
\hline Pollutant & $\begin{array}{c}\text { Measurement } \\
\text { Averaging Period }\end{array}$ & $\begin{array}{c}\text { Class I } \\
\text { Threshold } \\
\left(\mu \mathrm{g} / \mathbf{m}^{3}\right)\end{array}$ & $\begin{array}{c}\text { Class II } \\
\text { Threshold } \\
\left(\mu \mathrm{g} / \mathbf{m}^{3}\right)\end{array}$ \\
\hline Sulfur Dioxide & Annual & 2 & 20 \\
\cline { 2 - 4 } & 24-Hour & 5 & 91 \\
\cline { 2 - 4 } & 3-Hour & 25 & 512 \\
\hline $\begin{array}{l}\text { Total Suspended } \\
\text { Particulates }\end{array}$ & Annual & 5 & 19 \\
\cline { 2 - 4 } & 24-Hour & 10 & 37 \\
\hline Nitrogen Oxides & Annual & 2.5 & 25 \\
\hline
\end{tabular}

The cumulative analysis for air quality impacts is distinctly different from air qualityrelated values impact analysis, where the impacts of only individual projects are modeled. It also differs, albeit more subtly, from the EIS cumulative impact analysis. The EIS analysis includes existing emissions sources, the proposed project, plus anticipated future projects. Differences between the modeling studies used in the EIS and the two-parts of PSD are shown in Table D.

${ }^{13}$ Wyoming Air Quality Standards and Regulations, Section 28: Visibility. § (b)(i)(A)(I) states, "A permit to construct ...shall be issued only if the ... predicted impact (over and above the baseline concentration) of emissions ... is less than the maximum allowable increment shown in Table [C] for the classification of the area in which the impact is predicted and if the ambient standard for the pollutant(s) is not exceeded."

${ }^{14}$ As of December 7, 1998, all areas of Wyoming met NAAQS except for high $\mathrm{PM}_{10}$ concentrations in Sheridan. (EPA website: http://www.epa.gov/airs/nonattn.html.) 
Table D

Modeling Protocol for EIS and PSD Analyses

\begin{tabular}{|c|c|c|c|}
\hline Characteristic & $\begin{array}{l}\text { Environmental } \\
\text { Impact Statement }\end{array}$ & PSD - Air Quality & $\begin{array}{l}\text { PSD - Air Quality- } \\
\text { Related Values }\end{array}$ \\
\hline Model Used & CALPUFF & CALPUFF & CALPUFF \\
\hline $\begin{array}{l}\text { Cumulative } \\
\text { Emissions } \\
\text { Modeled }\end{array}$ & $\begin{array}{l}\text { All past and foreseeable } \\
\text { future projects }\end{array}$ & All past projects & None $^{15}$ \\
\hline EPA Guidance & None $^{16}$ & $\begin{array}{l}\text { Guidelines on Air } \\
\text { Quality Models, } \\
\text { IWAQM Phase I }\end{array}$ & $\begin{array}{l}\text { Guidelines on Air Quality } \\
\text { Models, IWAQM Phase I }\end{array}$ \\
\hline $\begin{array}{l}\text { Interagency } \\
\text { Guidance } \\
\text { Efforts }^{17}\end{array}$ & FLF ATT $^{18}$ & $\begin{array}{l}\text { SWYTAF, } \\
\text { IWAQM }\end{array}$ & $\begin{array}{l}\text { SWYTAF, } \\
\text { IWAQM, } \\
\text { FLAG }\end{array}$ \\
\hline Relevant Laws & NEPA & $\begin{array}{l}\text { CAA, WAQS\&R, } \\
\text { Wilderness Act }\end{array}$ & $\begin{array}{l}\text { CAA, WAQS\&R, } \\
\text { Wilderness Act }\end{array}$ \\
\hline
\end{tabular}

\section{b) Air Quality-Related Values Impact Assessment}

Whereas allowable impacts to air quality are clearly delineated, no clear-cut rules are available for evaluating acceptable impacts on air quality-related values. The WAQS\&R require analysis of only visibility impairment, and impacts on soils and vegetation. ${ }^{19}$ No guidance about what constitutes an adverse impact to air quality-related values in general, or visibility in particular, is provided in either the CAA or the WAQS\&R. Instead, the CAA instructs EPA to establish rules governing PSD in terms of visibility (P.L. 101-549).

On April 22, 1999, Vice President Gore and the EPA announced regional haze (i.e., visibility) regulations. The rule requires every state to develop plans to achieve "natural visibility conditions" by the year 2064 through "reasonable progress targets". Backing away from proposed rules that set specific improvement targets of 1.0 deciview over either a 10-year or 15-year period (40 CFR Part 51. Docket No A-95-38; FRL-5862-7), the final rule leaves it to the states to define progress targets (40 CFR Part 51 Chapter I

\footnotetext{
${ }^{15}$ As discussed below, FLAG may propose guidelines that call for cumulative impact analysis involving all past projects.

${ }^{16}$ EPA believes that the guidance provided in Guidelines for Air Quality Models is adequate. Some FLM, however, disagree (Golden, Personal communication).

${ }^{17}$ SWYTAF = Southwestern Wyoming Technical Air Forum, IWAQM = Interagency Workgroup on Air Quality Modeling, FLAG = Federal Land Managers' Air Quality Related Values Workgroup.

${ }^{18}$ FLF = Federal Leadership Forum, ATT = Air Technical Team, a working subgroup of the FLF. The Forum is comprised of the directors of the EPA, USFS, BLM, and NPS.

${ }^{19}$ Wyoming Air Quality Standards and Regulations, Section 28: Visibility. § (b)(i)(B)(I) states, "an analysis of the impairment to visibility, soils and vegetation that would occur as a result of the facility or modification and general commercial, residential, industrial, and other growth associated with the facility or modification.".
} 
Subpart P). The regulations call for monitoring from the years 2000 and 2004 to establish baseline conditions from which progress plans are developed. ${ }^{20}$

The rules allow states to demonstrate that achieving the targets would be infeasible, due to either lack of suitable technology, or compliance costs. EPA's rules also call for States to consult with FLM and the EPA in developing alternative targets (Seitz, 1997). These new rules may ultimately provide the impetus to install BART on existing sources.

Although the new Federal regional haze rule provides no specific guidance in terms of deciview changes, the WDEQ has used "level of concern" increments established by the U.S. Forest Service (USFS) as measures of adverse impacts to visibility and lake chemistry (i.e., water quality). ${ }^{21}$ These increments are 0.5 deciview for visibility and a 10 percent decline in acid neutralizing capability for lakes with greater than $25 \mu \mathrm{EQ} / 1$ or 1 $\mu \mathrm{EQ} / 1$ for lakes with less than $25 \mu \mathrm{EQ} / 1$.

The choice of a 0.5 deciview significance threshold is one source of conflict amongst the regulated community, WDEQ and FLM. Project proponents argue that a more appropriate threshold for visibility is 1.0 deciview. In fact, 1.0 deciview has been used as threshold criteria by the Bureau of Land Management (BLM) and the Grand Canyon Visibility Transportation Commission. ${ }^{22}$

When EPA rewrote its NSR guidance in 1996, it called for FLM to identify air quality related values and threshold impact levels for all Class I areas. Although the CAA granted authority to FLM to protect air quality-related values, it provided no explicit guidance about how to do so. FLM developed their own methods that in some cases were internally (e.g., between BLM Districts) and externally (e.g., between USFS and BLM) inconsistent. In some cases, project applicants did not know what threshold level against which to evaluate project impacts. Worse yet, when impacts spanned more than one FLM jurisdiction, applicants were at times faced with multiple thresholds.

The Federal Land Managers' Air Quality Related Values Workgroup (FLAG) convened in April, 1997 to address these problems, focusing on three specific goals:

"1. define sensitive air quality related values,

2. identify the critical loads (or levels) and the criteria that define adverse impacts, and

3. standardize the methods and procedures for conducting air quality related value analyses." (NPS et al., 1997)

\footnotetext{
${ }^{20}$ The rules define baseline visibility impairment as the average impairment of the least and most impaired days.

${ }^{21}$ In this case, lake chemistry is a proxy for the water quality air quality-related value.

${ }^{22}$ In Wyoming, both the BLM and USFS evaluate project impacts on air quality-related values because many projects located on land's managed by BLM have the potential to impact USFS lands, specifically the Birdger and Fitzpatrick Wilderness Areas, and the Yellowstone and Teton National Parks.
} 
The guidance document produced by FLAG is currently undergoing internal review. Within the next few months it will be made available for public comment. The document explicitly addresses visibility, acid deposition and urban ozone. For example, the current guidance proposes a visibility impact threshold of five percent light extinction, which is essentially equal to 0.5 deciview. Guidance regarding modeling references the recommendations of EPA and other interagency workgroups (see the discussion of IWAQM below). It does, however, add one important interpretation of the CAA. FLAG concludes that FLM have authority to evaluate impacts that cause or contribute to adverse impacts on air quality-related values. Cumulative impact analyses, therefore, are deemed by FLAG to be appropriate. This differs dramatically from the current practice of modeling only the impacts of each proposed project. The cumulative impacts analysis proposed by FLAG will incorporate all past projects, but not anticipated future projects (Bunyak, Personal communication).

The Interagency Workgroup on Air Quality Modeling (IWAQM) was formed by EPA to provide guidance for modeling to estimate both air quality and air quality related values in Class I areas. Comprised of representatives from the EPA, USFS, NPS, and USFWS, it first established interim (i.e., Phase I) guidelines in 1995 for both near and far field impact analysis. In December 1998, IWAQM proposed Phase II guidelines that have now been peer reviewed and commented on by EPA. Thus, it appears that Phase II guidance is about to become the prevailing rule.

IWAQM breaks up modeling into two scales: Level I - impacts on receptors within 50 $\mathrm{km}$ of the emissions source; and, Level II - impacts beyond $50 \mathrm{~km}$. If the Level I analysis indicates significant impacts, then the Level II analysis is conducted.

The Phase I guidelines call for the use of the ISCT3 and MESOPUFF-II models for the Level I and II evaluations, respectively. Aside from the choice of model, one contentious guideline in Phase $I$ is the conservative requirement that visibility impacts be modeled assuming that $100 \%$ of emitted $\mathrm{SO}_{2}$ and $75 \%$ of emitted $\mathrm{NO}_{\mathrm{x}}$ is converted to $\mathrm{SO}_{4}$ and $\mathrm{NO}_{3}$, respectively. The Phase II guidance recommends the use of CALPUFF for both the Level I and II analysis, thereby allowing conversion rates to be modeled based on transport time. However, the cost and time savings benefits of ISCT3 assure that it will continued to be used as a screening level tool in both NSR and NEPA analyses.

States and FLM are already using CALPUFF in EIS analyses. This is the case in SW Wyoming for the Jonah II natural gas development project.

Peer review comments on IWAQM's Phase II guidance identified several concerns with CALPUFF, but IWAQM responded generally by stating that CALPUFF represented the best available science. EPA also acknowledged practical issues limiting modeling options, stating in one response,

"In making the recommendation, the EPA recognized that several concerns were being balanced.... [T]here was some concern that the computer resources for some states might be challenged." 
Finally, the SWYTAF is developing an approach for modeling impacts on air qualityrelated values. At first glance it appears that FLAG, IWAQM and SWYTAF all have the same charter - to establish modeling guidelines. The selection of CALPUFF by both IWAQM and SWYTAF provides further indication that these are parallel efforts. They are not.

The IWAQM guidance will establish national guidelines. SWYTAF will be detailing modeling in a specific region, agreeing on an emissions inventory (for 1995), and determining if the CALPUFF modeling system performs adequately for use in southwestern Wyoming. The real difference is in the details. Assumptions and inputs used in the SWYTAF study cannot be suggested by IWAQM.

In addition to identifying air quality related values and their allowable impact thresholds, FLAG will identify a method for evaluating air quality-related values by referring to EPA and IWAQM guidance. It may go one step further by recommending a process for evaluating model output (from CALPUFF or other model) with respect to thresholds. For example, FLAG may call for further modeling with a tool like MAGIC ${ }^{23}$ to translate acid deposition estimates generated by CALPUFF into estimates of lakes' lost acid neutralizing capability.

\section{Other Provisions of the Clean Air Act}

\section{a) Title IV Acid Rain Program}

In Title IV of the CAA, a program is established to reduce acid deposition nationwide by reducing emissions of both $\mathrm{SO}_{2}$ and $\mathrm{NO}_{\mathrm{x}}$ from power plants. The WDEQ estimates that the program has reduced annual $\mathrm{SO}_{2}$ emissions by 45,000 tons/year, which is 44 percent of 1985 emissions levels of 108,000 tons/year. Because these pollutants also contribute to visibility impairment and are generally located upwind of Wyoming's Class I areas, Title IV emissions reductions may be creating additional "margin" for project developers by reducing total emissions. For example, the Petroleum Association of Wyoming (PAW) has noted that since 1988, there have been over 1,800 new gas wells installed in southwestern Wyoming while visibility has improved (Blewitt and Clayson, 1998). These visibility improvements, if real, are likely due at least in part to SO2 emissions reductions from power plants.

\section{b) National Ambient Air Quality Standards}

The pursuit of NAAQS creates additional regulatory impetus to control emissions that may contribute to visibility impairment. The recently adopted NAAQS for urban ozone and ambient particulate matter less than 2.5 microns in diameter will result in emissions controls that, like the Acid Rain program, will contribute to improved visibility (Seitz, 1997).

\footnotetext{
${ }^{23}$ The Model Acidification of Groundwater Catchments (MAGIC) model simulates long-term effects of acid deposition on surface water chemistry. (B.J. Cosby and T.J. Sullivan. Model of Acidification of Groundwater in Catchments: Description of Model Structure and Calibration Procedures. January, 1998 Unpublished manuscript).
} 


\section{Questions Arising from the Regulatory Setting}

A web of minutia-laden but often ambiguous laws provide the impetus for and authority of SWYTAF. They generate the policy questions that frame SWYTAF's charter. Some of these questions have been resolved, while others remain untested or are pending resolution. These questions are discussed below.

\section{Decision Making Authority}

\section{$>$ WHAT AUTHORITY DOES EPA HAVE IN THE SWYTAF PROCESS?}

The EPA has two distinct programs for NEPA and Clean Air Act-related activities. Although the NEPA program staff are not currently involved with SWYTAF, some were initially. Representatives from the EPA Air program continue to participate substantively in both the SWYTAF Technical and Policy committees. This is no surprise given EPA's oversight authority.

The EPA is the oversees all permitting activities of the WDEQ Air Quality Division. EPA ultimately approves WDEQ's interpretation of laws and implementation of EPA guidance. Where EPA does not approve of WDEQ planning, it has power to override the state agency and to even take on planning responsibilities.

The CAA and, in turn, the WAQS\&R require the WDEQ Air Quality Division to prepare a plan for remedying any existing visibility impairment and preventing future impairment in Wyoming's Class I areas (P.L. 95-95 §169, WAQS\&R Sec. 28 \& (f) 169). The CAA calls for a State Implementation Plan (SIP) ${ }^{24}$ and a Long Term Visibility (LTV) plan. In 1988, the EPA approved WDEQ's Wyoming State Implementation Plan for Class I Visibility Protection. In 1995, WDEQ submitted a revised SIP/LTV that was not approved by EPA because it failed to adequately address potential impacts from anticipated oil and gas development (Golden, Personal communication). Disagreement over the appropriate modeling approach for developing this SIP/LTV was one impetus for the formation of SWYTAF. ${ }^{25}$

EPA's Air program therefore has a dual role of, first, helping to develop modeling methods for use in SIP planning (i.e., SWYTAF), and, second, reviewing and approving the modeling or other methods used in Wyoming's SIP/LTS.

\footnotetext{
${ }^{24}$ SIPs are better known as the CAA-required documents for planning how NAAQS will be met. See Section 110 of Title I in the federal Clean Air Act.

${ }^{25}$ In April 1997 the WDEQ submitted an interim SIP/LTS plan, Wyoming's Long Term Strategy for Visibility Protection, to satisfy both the WAQS\&R and CAA requirements until SWYTAF produces guidance for modeling. It concludes that no FLM has certified visibility impairment in any of Wyoming's Class I areas. Based on this conclusion, it finds that no emissions controls on existing facilities or other measures are necessary to improve current conditions. The SIP does, however, note the potential for visibility impairment from additional oil and gas development, disagreement about how to evaluate those impacts, and the role of SWYTAF in determining the "most appropriate tool and assumptions to be used in determining air quality impacts in Class I areas" (WDEQ, 1997).
} 
EPA has no direct regulatory control over WDEQ's decision to approve or deny an operating permit based on PSD review. WDEQ solicits comments on proposed projects from EPA as a courtesy. So long as the evaluation uses an EPA-approved model, such as CALPUFF, the EPA does not usually object (Golden, Personal communication).

\section{WHO HAS AUTHORITY TO DENY A PROPOSED PROJECT?}

The WAQS\&R include a provision to deny a permit if Federal Land Managers demonstrate that the project will cause "adverse impacts" in Class I areas. However, the WDEQ is given authority to override FLM findings (WAQS\&R Sect. 28. § (b)(iv)(A) and (b)(iv)(B)). Thus, the WAQS\&R set up a juxtaposition of the burden of proof. Whereas a project applicant must analyze project impacts on air quality-related values, the burden of demonstrating an unacceptable adverse impact lies with FLM. The stewardship responsibilities granted to the FLM by the Wilderness Act may create conflict between the FLM and the WDEQ. The FLM can argue that a project will harm air quality-related values, but the WDEQ ultimately decides if a project shall be approved.

In practice, decision-making authority established in the WAQS\&R is not as clear as the regulations suggest. For example, in March, 1977, the BLM established an emissions cap of 977 tons $\mathrm{NO}_{x}$ /year above emissions levels in May, 1996 for their Rock Springs District (located in SW Wyoming) (BLM, 1997a and 1997b). The cap was set to prevent a 0.5 deciview impairment of visibility the Bridger Wilderness, a Class I areas.

The cap was based on modeling analyses of two proposed projects: the Moxa Arch and Fontenelle gas development projects. Although these projects were evaluated in separate EIS's, their combined impacts were modeled. The WDEQ, natural gas industry and PAW subsequently challenged the authority of the BLM to set the cap. The Interior Board of Land Appeals found that indeed BLM was exceeding its authority and that only the WDEQ had authority to prohibit new projects. In response, BLM downgraded the cap to a "level of concern" threshold. As a "courtesy" to the BLM and USFS, the WDEQ now evaluates projects against the BLM-defined level of concern (Potter, Personal communication).

\section{Impact Thresholds}

\section{WHAT IS VISIBILITY IMPAIRMENT?}

There is more than one way to measure visibility impairment. Both deciview and light extinction measurements have been used by EPA, FLM and other agencies. Although there is now a general consensus to use the deciview measure, the most appropriate threshold value for the indicator remains a point of debate. Part of the reason for the debate is the complexity of measuring and evaluating visibility impairment, as discussed in Appendix II.

\section{WHAT CONSTITUTES AN UNACCEPTABLE IMPACT THRESHOLD FOR AIR QUALITY- RELATED VALUES?}

The CAA left it to the FLM to define thresholds. Using inconsistent methods, thresholds have been selected for many areas, by some FLM. The effort by FLAG is intended to 
develop a consistent method for establishing thresholds and evaluating impacts for all Class I areas.

WHAT FURTHER EVALUATIONS ARE REQUIRED ONCE SCREENING LEVEL ANALYSES INDICATE PROJECT EMISSIONS WILL VIOLATE AN IMPACT THRESHOLD?

Through the NEPA process, air quality modeling is conducted to establish a threshold level of concern, and then each project is evaluated independently against that level. If "permitted potential" emissions are projected to exceed the level of concern, the FLM is then responsible for examining more closely the project's potential to impact air quality related values. This examination may include monitoring to document impacts and/or additional modeling.

For example, the USFS modeling established a level of concern for the proposed Jonah Field II Natural Gas Development Project of 158.6 tons $\mathrm{NO}_{\mathrm{x}} /$ year. When permitted potential emissions were expected to exceed the level of concern, the BLM was charged with further evaluation. BLM in turn deferred to the SWYTAF modeling study, noting that the EIS modeling was done using the ISCT3 model, whereas SWYTAF will be using the more sophisticated CALPUFF model. The ISCT3 model is considered to be only a screening tool not explicitly designed to evaluate the potential long-range transport impacts from the proposed project. During the additional study phase to be conducted by BLM, WDEQ and USFS are serving as cooperating agencies, with no real oversight authority. EPA has even less role in this process, since it delegates air quality program responsibilities to states (i.e., WDEQ). Although EPA oversees and approves WDEQ activities, it cannot directly insert itself into the PSD evaluations unless State SIPs are deemed inadequate.

\section{WHAT OPTIONS ARE AVAILABLE TO PROHIBIT OR LIMIT PROJECT EMISSIONS?}

The WAQS\&R provides the WDEQ some flexibility in rejecting proposed projects. Once PSD cumulative impact analyses indicate that the available "increment" has been consumed and, in fact, visibility impairment exists, controls beyond BACT may be justified for all existing sources. This so call Best Available Retrofit Technology (BART) has not been required in Wyoming because the LTS concludes that no visibility impairment has been certified by FLM. Indeed, no such controls have been required anywhere in the country to date. However, the EPA's recently promulgated regional haze rules may provide further impetus to require BART.

\section{Modeling}

\section{WHY RELY ON MODELING?}

Regulations create requirements that can only be met through modeling. Demonstrating that the emissions of a proposed project will not cause impacts beyond allowable thresholds requires a simulation of future conditions. A model is the only feasible means of performing this demonstration. Consequently, guidance for meeting regulations specifically require modeling. For example, the CAA and WAQS\&R explicitly call for the use of models to evaluate air quality impacts in PSD. 
The technical questions that arise from the driving policy question require complex analytic techniques for evaluation. Model simulation is one example. Examining the sensitivity of environmental quality indicators, such as visibility, to insults, such as industrial pollutant emissions, involves analysis of nonlinear processes that are best simulated using models.

The third reason for modeling derives from the time and resource constraints faced by researchers and decision-makers alike. Although monitoring is useful and, in fact, essential, for evaluating technical questions, a desktop analysis using models can often be conducted in less time and at lower cost. For reasons discussed throughout this report, however, the money and time invested in modeling without monitoring, albeit relatively small, may yield few dividends.

\section{$>$ WHAT ASSUMPTIONS ABOUT EMISSIONS SHOULD BE USED IN MODELING?}

At first glance the choice of appropriate emissions baseline may appear to be a technical question (i.e., simply query what emissions exist). Any cumulative impact analysis must include both starting and ending points during which time emissions accumulate. The choice of ending point is not a technical question, but a policy issue. Similarly, regulations frequently "grandfather" in certain emissions, based on the belief that those who abided by the law in the past should not be penalized by a new law. However, PSD provides authority to require all existing sources to install retrofit emissions controls (i.e., BART) should the PSD increments be exhausted or the NAAQS be exceeded.

One contentious issue faced by SWYTAF is the accuracy of current emissions from oil and gas operations. The disagreement is between the WDEQ and PAW, with each arguing that their emissions inventory is more accurate (SWYTAF, 1998). At this point, the parties have agreed to split the difference. This is a clear case of politics influencing the modeling study. Emissions uncertainty is discussed in detail in Appendix V.

Another debated assumption is whether days with high humidity should be included in modeling studies because humidity itself can cause visibility impairment. If very humid days are not to be included in modeling, then some threshold humidity must be identified beyond which visibility is not a concern due to natural impairment.

\section{WHICH MODEL SHOULD BE USED?}

There appears to be a consensus amongst IWAQM, SWYTAF, and agencies such as EPA and WDEQ that the CALPUFF modeling system should be used to model the impacts of new emissions sources on air quality and air quality-related values in Class I areas. The Phase II guidance from IWAQM calls for CALPUFF, and it is now being used by SWYTAF and EIS analysts. The limitations discussed at length in this report raise the question, "Why has CALPUFF been selected?" There are at least three plausible and contributing reasons.

First, the EPA has approved CALPUFF. Given EPA's authority as the federal agency charged with approving the WDEQ Air Quality Division activities, it is logical that WDEQ would select a model endorsed by EPA. 
Second, acceptance of CALPUFF may be driven by an element of groupthink. Those charged with selecting a model for one study may lean toward CALPUFF simply because it is being used by others. For example, the Federal Leadership Forum currently developing guidance for addressing oil and gas impacts in Environmental Impact Statements will defer to the model recommended by IWAQM.

Last, CALPUFF is frequently referred to as the best available model. In IWAQM Phase I guidance the ISCT 3 model was used along with very conservative modeling assumptions about $\mathrm{SO}_{2}$ and $\mathrm{NO}_{x}$ conversion rates. CALPUFF is seen as an improvement over ISCT3, especially by project proponents who objected to the more conservative modeling using ISCT3.

Despite the apparent consensus that CALPUFF is the best model choice at this time, it is still relevant to question if it is adequate. Given the limitations of model formulation and input data, it is important to ask whether CALPUFF is sufficiently reliable to justify the decisions that derive from its use. Will it withstand, for example, the scrutiny that is likely to result should modeling justify extensive emissions controls?

The sociopolitical reality is that decisions with major private and public economic implications will rest on model output. From an environmental perspective, modeling will be relied upon to provide assurance that development will not compromise pristine natural resources. The current trajectory of SWYTAF, IWAQM and EPA, indicates that all of these decisions will be based on CALPUFF. If CALPUFF is not likely to provide the high degree of reliability necessitated by these important decisions, instead representing only the best available technology, then it is essential to recognize any shortcomings before important, irreversible decisions are made.

In the remainder of this report, we identify the reasons why CALPUFF might not be "good enough" to justify important policy decisions. Acknowledging that use of CALPUFF is imminent, we also identify actions that can improve the quality of the modeling study. 


\section{E. References}

Blett, T. United States Forest Service, Denver. Personal communication. April 15, 1999.

Blewitt, D. and T. Clayson. Presentation by the Petroleum Association of Wyoming at the Southwest Wyoming Technical Air Forum meeting. April 20, 1998.

Bunyak, J. National Park Service, Policy, Planning and Permit Review Branch of the Air Resources Division, Denver. Personal communication. March, 1999.

U.S. Bureau of Land Management. Record of Decision for Expanded Moxa Arch Area Natural Development Project Environmental Impact Statement. Department of the Interior. March 1997a.

U.S. Bureau of Land Management. Record of Decision for Fontenelle Natural Gas Infill Drilling Projects Environmental Impact Statement. Department of the Interior. March 1997b.

Clean Air Act Amendments of 1977. P.L. 95-95.

Clean Air Act Amendments of 1990. P.L. 101-549.

Chu D., et al. The Red Desert Blues: The Industrialization of Southwest Wyoming. Friends of the Wild Wyoming Deserts, Greater Yellowstone Coalition, Sierra Club, The Wilderness Society, Wyoming Outdoor Council, Wyoming Wilderness Association, and Wyoming Wildlife Federation. Pub. April, 1996 at http://www.wocnet.org/wocnet/RedDesertB.html)

U.S. Environmental Protection Agency. Guideline on Air Quality Impact Models. 40 CFR Pt. 51. Appendix W.

U.S. Environmental Protection Agency. Office of Air Quality Planning and Standards. Website: http://www.epa.gov/airs/nonattn.html.

U.S. Environmental Protection Agency. Memorandum. To Charles A. Collins, Administrator, Wyoming Department of Environmental Quality. From Richard Long, Director, Air Program, EPA Region VIII. Reference 8P2-A.

U.S. Environmental Protection Agency. Proposed Regional Haze Regulations. 40 CFR Part 51. Docket No A-95-38; FRL-5862-7. July 1997.

U.S. Environmental Protection Agency. Final Regional Haze Regulations. 40 CFR Part 51 Chapter I Subpart P. April 22, 1999. 
Golden, K. U.S. Environmental Protection Agency, U.S.E.P.A., Denver, Colorado. Personal communication. March, 1999.

National Environmental Policy Act. 42 USC 4371 et seq.

U.S. Forest Service-Air Quality Program. Briefing Statement. Federal Land Managers' Air Quality Related Values Workgroup (Flag). October 31, 1997.

Potter, D. Department of Environmental Quality, Cheyenne, Wyoming. Personal communication. February, 1999.

Rudolph, J. [Project Manager]. Southwest Wyoming Natural Gas Development: Air Quality Issues, Impacts, and Technology Opportunities. Barlow \& Haun, Inc. Geologists. Casper, Wy. Prepared for Gas Research Institute. July 1998.

Seitz. S. Testimony of before the Subcommittee on Forests and Public Land Management of the Committee on Energy and Natural Resources United States Senate. Office of Air Quality Planning and Standards, Office of Air and Radiation, U.S. Environmental Protection Agency. October 28, 1997.

Southwestern Wyoming Technical Air Forum. Record of Proceedings. SWYTAF Meeting December 2, 1998. Casper, Wyoming.

TRC Environmental Corp. and EarthTech, Inc. Air Quality Impact Assessment Protocol Continental Divide, GWAII and South Braggs Projects. December 16, 1997. Prepared for the BLM, Rawlins District.

Wallach, P. et al., The Clean Air Act: Strategies for the 1990's. Hale and Dorr, and TRC Environmental Consultants, Inc. (Pub.) April, 1991.

Wyoming Air Quality Standards and Regulations.

Wyoming Department of Environmental Quality Website: http://deq.state.wy.us/aqd.htm

Wyoming Department of Environmental Quality. Wyoming's Long Term Strategy for Visibility Protection. 1997 Draft Review Report. Air Quality Division. April, 1997.

Wilderness Act. P.L. 88-577. September 3, 1964. U.S. Code Title 16, Chapter 23) 


\section{APPENDIX II. UNDERSTANDING VISIBILITY}

By Melissa Lunden

Environmental Energy Technologies Division, Lawrence Berkeley National Laboratory Berkeley, California 94720-1740

Table of Contents

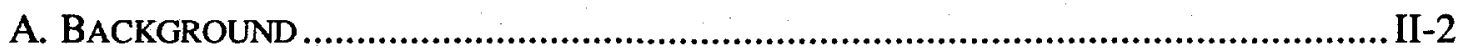

B. WHAT IS ExtINCTION?

C. Calculating the Extinction Coefficient: …..................................................6

D. THE VISIBILITY CONDITIONS IN WYOMING...................................................... II-10

E. ESTIMATING FUTURE IMPACTS OF VISIBILITY IN SW WYOMING..........................II-13

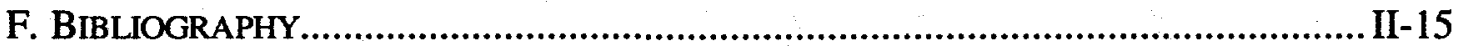




\section{A. Background}

To the average person, visibility degradation is the most readily perceived impact of air pollution. To residents of Los Angeles, the brown color of the air and the inability to make out even close landmarks serve as a much more potent reminder of poor air quality than physiological effects upon the observer, which are often harder to discern. While historically associated with the cities of London or Los Angeles, the problems of visibility degradation and its related pollutant load have increased to a global scale, including cities such as Athens, Paris, Mexico City, and Bangkok. In early 1999, the visibility in Hong Kong was reduced to $3000 \mathrm{ft}$ due to pollutants crossing the border from China. (New York Times, Feb. 1999) Ships in the harbor needed foghorns to safely navigate at midday on a sunny day.

The distance that one can see through the atmosphere depends on many factors, including the amount and quality of the light available, the characteristics of the object being observed, and the properties of the individual viewers eye. This distance, a measure of how transparent the atmosphere is to visible light, is called visibility. Visibility is reduced by the interaction of light with aerosol particles and gasses in the atmosphere. Both particles and gasses can absorb certain wavelengths of light, causing a discoloration of the sky and a change in the heat balance in the atmosphere, an important factor in climate change. However, light scattering by particles is the most important phenomena responsible for visibility reduction. This scattering decreases visibility by scattering light coming from the object out of the line of the observer and by scattering light from the sun and other parts of the sky into the line of sight of the observer. (See Figure 1.) Both physical processes lessen the contrast between the object and its background, making it more difficult to see objects at a distance.

Visibility is usually characterized by visual range, a quantity that describes how far an observer can see through the atmosphere. Visual range is defined as the greatest distance that a dark object can be seen against either the sky at the horizon or a white background [Seinfeld and Pandis, 1997]. Visual range is an intuitive measure that uses familiar distance units. It can be encountered in everyday situations such as the distance one can see on a foggy day or the visibility that is often reported at airports. No special tools are required to measure visual range - any sighted person can characterize the visual condition using familiar landmarks in any scene. However, the perceived visual range will vary with human judgment and perception. An alternative index is used by scientists to quantify visibility is the extinction coefficient, which is a measure of the degree to which pollutants present in the atmosphere effectively extinguish light. There is a direct relation between the concentration of pollutants in the atmosphere and the extinction coefficient, and the effect that any one constituent has on the total extinction can be calculated. This method, termed extinction budget analysis, allows for the assessment of how a change in the mixture of atmospheric constituents can change visibility. 


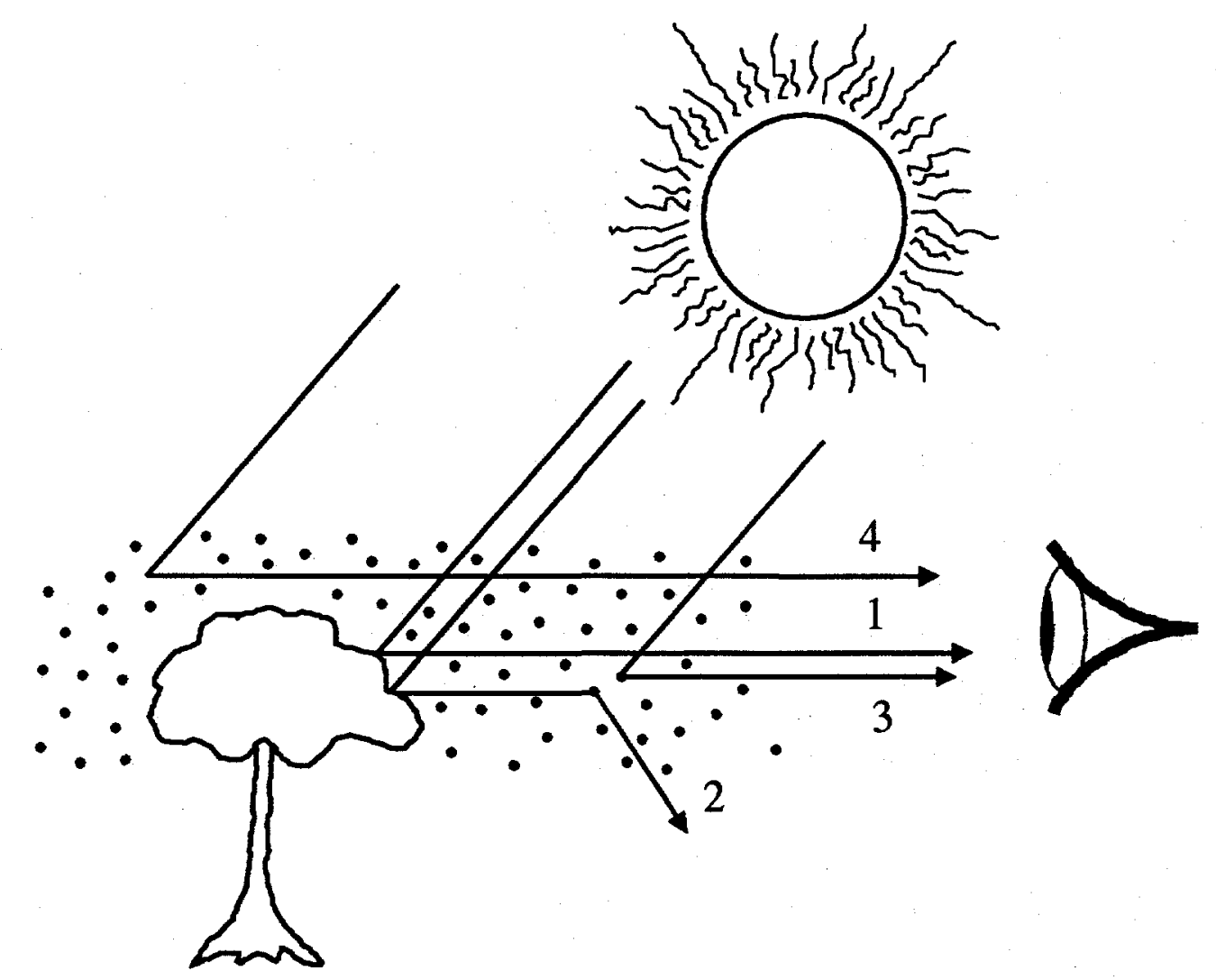

Figure 1 Particle interactions that contribute to visibility: (1) light from the target that reaches the observer; (2) light from the target that is scattered out of the line of sight of the observe; (3) airlight that is scattered into the line of sight of the observer; and (4) airlight that constitutes the horizon sky (Seinfeld and Pandis, 1997)

The visual range and the extinction coefficient are inversely proportional. However, neither is linearly related to the perceived change in the visual scene by a human observer. A particular change in the extinction coefficient can result in a scene change that is either unnoticeable or obvious. A new visibility index, called the deciview, has been developed to address this issue supposedly has the property of equal changes in deciview being equally perceptible, regardless of the baseline pollution level [Pitchford and Malm, 1994]. The newly developed visibility standard promulgated by the EPA targets specific visibility improvements in terms of deciviews.

The primary particulate substances that contribute to visibility reduction are sulfates, nitrates, organics, elemental carbon, and fine soil. Water can combine with the hygroscopic aerosol species, generally considered to be sulfates, nitrates, and organics, both increasing particle size and modifying particle optical properties. Thus, atmospheric water content is also an important factor in visibility. Elemental carbon (soot), fine soil, and some organic aerosols are directly emitted into the atmosphere. These are referred to as primary particles. Particles that consist of sulfates and nitrates are formed from SOx and NOx emitted in the gas phase, which transform in the atmosphere to form particles. 
In addition, some organic vapors that are released into the atmosphere can both form particles and condense onto existing particles. These particles are called secondary particles. Clearly, understanding the contributions of the mixture of atmospheric pollutants to visibility is complex. Any improvements in visibility will involve controls on both gaseous pollutants and directly emitted particles.

\section{B. What is Extinction?}

When visible radiation (light) hits a particle, it interacts with that particle, causing the energy in the light to either be absorbed by the particle or scattered in all directions. [Horvath, 1993; Seinfeld and Pandis, 1997]. The amount of energy that is scattered by the particle is proportional to the light that is incident upon the particle, $\mathrm{F}_{\mathrm{o}}\left(\mathrm{W} / \mathrm{m}^{2}\right)$

$$
E_{\text {scat }}=C_{\text {scat }} F_{0}
$$

where $C_{\text {scat }}$ is the single-particle scattering cross section and has units of $\mathrm{m}^{2}$. The corresponding expression for absorption uses an absorption cross section, $\mathrm{C}_{\mathrm{abs}}$. The combined effect of scattering and absorption is called extinction. Since all of the energy incident on the particle is either scattered or absorbed, the cross section for extinction, $\mathrm{C}_{\mathrm{ext}}$, is simply the sum of the scattering and absorption cross sections,

$$
C_{e x t}=C_{s c a t}+C_{a b s}
$$

Since the scattering and absorption cross sections have the units of an area, it is useful to normalize the cross section by the area of the particle. This dimensionless value, $Q=$ $\mathrm{C} / \mathrm{A}$, is called either the scattering or absorption efficiency depending upon which cross section is used. The extinction efficiency is a sum of the scattering and absorption efficiencies, similar to Eq. (2). This efficiency is the amount of light attenuated versus the amount of light incident on the particle, in effect the shadow cast by the particle, and can be either greater than or less than one.

The physics of absorption and scattering of light by spherical particles is described by Mie theory, a complex mathematical formalism [Bohren and Huffman, 1983]. The key properties that affect scattering and absorption are the wavelength of the incoming light, the particle size, the particle concentration, and the optical properties of the particle. The optical properties are determined by the particle refractive index, which characterize how the photons in the light interact with the material of the particle. This interaction can be thought of as a slowing down the light when inside the material. The refractive index has two parts, one of which describes the attenuation (or absorption) of light in the material. Particle shape can also affect scattering behavior, but mathematical solutions are only available for the most simple shapes. For this reason, the particles are assumed spherical, a good assumption for most particles except elemental carbon, fine soil, and larger coarse aerosols.

Mie theory is valid for all particle sizes; gas molecules are effectively small particles, and the same calculation holds for both gasses and particles. However, there is an important simplification of Mie theory in the case of gas molecules and very small particles, which is called the Rayleigh limit. (For light in the visible spectrum, small particles correspond to sizes less than $0.1 \mu \mathrm{m}$.) In the Rayleigh regime, light of shorter wavelengths (blue) is 
scattered more effectively than longer wavelengths (red). This effect is the reason the sky is blue. An ideal atmosphere that contains no particles is called the Rayleigh atmosphere, where scattering is solely due to the gasses normally found in the atmosphere. The Rayleigh atmosphere represents the naturally occurring amount of extinction against which any additional extinction from to anthropogenic sources can be judged.

To calculate scattering from an ensemble of particles, it is usually assumed that the total light scattering and absorption is the sum of that from individual particles [Seinfeld and Pandis, 1997]. This assumption is acceptable for the atmosphere, which has relatively low particle concentrations. The fractional reduction of light intensity, F, over an atmospheric layer of depth $\mathrm{dz}$ can be expressed as

$$
d F=-b_{e x t} F d z
$$

where $b_{\text {ext }}$ is extinction coefficient. The extinction coefficient is a product of the extinction cross section, $\mathrm{C}_{\mathrm{ext}}$, and the number concentration of particles, $\mathrm{N}$,

$$
b_{e x t}=C_{e x t} N
$$

and has units of inverse distance, $\mathrm{m}^{-1}$. The solution of Eq. (3) yields an exponential decay of light intensity with distance through the atmosphere

$$
F / F_{0}=\exp \left(-b_{e x t} z\right)
$$

where $F_{0}$ is the intensity of the light at $z=0$, i.e. either at the top of the atmosphere or from the object that is being observed. Just like the extinction cross section, the extinction coefficient can also be expressed as the sum of a scattering and an absorption coefficient,

$$
b_{e x t}=b_{s c a t}+b_{a b s}
$$

Each of these individual scattering and absorption coefficients can be decomposed into contributions from the gas and particle components of the atmosphere;

$$
\begin{aligned}
& b_{a b s}=b_{a g}+b_{a p} \\
& b_{s c a t}=b_{s g}+b_{s p}
\end{aligned}
$$

where $b_{a g}$ and $b_{a p}$ are the extinction due to absorption by gasses and particles respectively and $b_{\mathrm{sg}}$ and $b_{\mathrm{sp}}$ are the extinction due to scattering by gasses and particles.

In everyday viewing situations, visibility is usually thought of as a loss of contrast between objects in a scene rather than a decrease in light intensity. Contrast, often described as a black object being viewed against a white sky, is defined as the difference in light intensity between the background and the object

$$
C=\frac{F_{b}(x)-F(x)}{F_{b}(x)}
$$

where $F_{b}(x)$ and $F(x)$ are the intensities of the background and object, respectively. Contrast decreases exponentially with distance through the atmosphere, just like the decrease in light intensity in Eq. (5), 


$$
C(x)=\exp \left(-b_{e x t} x\right)
$$

were $b_{\text {ext }}$ is the same extinction coefficient as discussed above. While the ability to perceive contrast depends upon the individual observer, typical people can detect a 0.02 or greater contrast change in a scene. This value is usually used in visual range calculations and when substituted into Eq.9, gives the following expression for visual range

$$
x_{V R}=3.912 / b_{\text {ext }} .
$$

This is called the Koschmeider equation. Notice that the visual range and the extinction coefficient are inversely proportional.

The visual range in the southwest Wyoming area is approximately $150 \mathrm{~km}$, which corresponds to an extinction coefficient, $b_{e x t}$, of $26 \mathrm{Mm}^{-1}$ [Sisler, 1996]. The Rayleigh extinction for the same area is $10 \mathrm{Mm}^{-1}$, which corresponds to a maximum visual range of $391 \mathrm{~km}$. Large cities that are more heavily polluted can have extinction coefficients of around $150 \mathrm{Mm}^{-1}$, which would correspond to a visual range of $26 \mathrm{~km}$. During a heavily polluted day in Hong Kong in early 1999 the visual range was reported to be $3000 \mathrm{ft}$, resulting in an extinction coefficient of $4000 \mathrm{Mm}^{-1}$ !

\section{Calculating the Extinction Coefficient:}

The relationship of the extinction coefficient to the ambient aerosol is complex. The chemical composition of the particles may vary with particle size, or between particles of the same size. Individual particles are not necessarily chemically pure. Particle populations are often described as either externally or internally mixed. In an externally mixed aerosol, each particle in the mixture is chemically pure with a unique diameter and species. In an internally mixed aerosol, each particle is composed of many chemical species, and the mixture of species can change with particle size. Most aerosols in the atmosphere are a combination of both internally and externally mixed.

To calculate the extinction coefficient for any aerosol is conceptually quite simple; sum the contributions from every particle in the mix according to each particles extinction cross section, similar to Eq.(4) above. For a mixture of particle in the atmosphere this sum can be expressed at the integral over the particle size distribution

$$
b_{e x t}=\int \frac{\pi D^{2}}{4} Q_{e x t}(m, D, \lambda) n(D) d D
$$

where $D$ is the particle diameter, $Q_{\text {ext }}$ is the scattering efficiently, and $n(D)$ is the size distribution. However, the chemical complexity of atmospheric aerosols makes the evaluation of Eq. (11) quite difficult. The value of the extinction efficiency, Q, for a particle of any specific size can differ because particles of the same size can have quite different chemical compositions.

There has been a large amount of research concerning how to simplify Eq. (11) so that extinction coefficients can by calculated more easily than summing the contribution from every particle in the atmosphere [Ouimette and Flagan, 1982; White, 1986]. This amount of detail concerning the aerosol present in the atmosphere is rarely available. Clearly, if 
we could assume that the aerosol was externally mixed, the calculation would be much easier because the contributions from each species would be independent, and the only variable would be particle size. This simplification is also acceptable for internally mixed aerosols if the index of refraction is not a function of composition or size. Moreover, it is more convenient to calculate properties based upon total particle mass instead of number or volume, because aerosol mass is what is typically measured at air quality monitoring stations. This mass based formulation is formed by converting from a number based to a mass based particle size distribution. When assuming an externally mixed aerosol and using a mass based scattering efficiency, Eq. (11) simplifies to

$$
b_{e x t}=\sum_{\text {species }, i} \alpha_{i} m_{i}
$$

where $m_{i}$ is the total measured mass of each species and $\alpha_{i}$ is called the specific mass scattering (or absorption) efficiency,

$$
\alpha_{i}=\int \frac{3}{2 D \rho} Q_{e x t, i}(m, D, \lambda) n_{m, i}(D) d D
$$

and $n_{m, i}$ is now the mass distribution of the aerosol.

The expression presented in Eq. (12) is the most widely used method to calculate extinction from aerosol mass measurements. Routine aerosol monitoring programs were not designed to measure, and in most cases cannot measure, whether an aerosol is internally or externally mixed. Moreover, except for some special visibility characterization studies, the size distribution of most species is not measured, meaning that the specific mass scattering efficiency cannot be calculated with the full rigor of (13) [Sisler, 1996]. Therefore, $b_{e x t}$ is apportioned by assigning a constant specific mass extinction efficiency for each individual species (sulfate, nitrate, etc.) and calculating the extinction using the simple sum in Eq. (12). The value of $\alpha_{i}$ for each species is usually determined by a couple of methods. The first uses intensive visibility studies where statistical methods are used with a large amount of data to determine the best values for each species. The other uses multilinear regression models with $b_{\text {ext }}$ as the dependent variable and the measured aerosol mass measurements as the independent variable. The different values determined by these methods can vary significantly. This result is not surprising given the rather severe restrictions required to use Eq. (12). However, there are accepted ranges for the value of $\alpha_{i}$, and most visibility calculations use a value in this range.

Another significant factor in calculating the extinction of hygroscopic aerosols is the amount of water present in the atmosphere [Tang et. al, 1981; Malm and Kreidenweis, 1997]. Sulfates, nitrates, and some organic species gain water, which causes the particle to grow in size and can change the optical properties of the particle. Of these two, the change in scattering due to an increase in particle size is the most significant. In general, the larger the value of the relative humidity, the larger the particle size and the greater the scattering of the aerosol. A scheme has been developed by Tang et al. (1981) where the relative increase in the scattering coefficient over that expected in a dry aerosol can be calculated, 


$$
f(R H)=b_{\text {scat }}(R H) / b_{\text {scat }}(0 \%) .
$$

This function is highly non-linear with relative humidity, as shown in Figure 2. The extinction coefficient for hygroscopic particles are calculated by multiplying the dry scattering coefficient by the Tang RH factor,

$$
b_{e x t, i}=f(R H) \alpha_{i} m_{i}
$$

Therefore, as relative humidity increases visibility will decrease, even for the same ambient aerosol concentration. This effect is most obvious on a hazy, overcast day, but can also be significant on sunny days. At relative humidities above $80 \%$, this increase in scattering can be very significant. Therefore, it is important not only to know the concentrations of the aerosols in the atmosphere but also the meteorological conditions, including any long term trends in the meteorological variables at the location of interest.

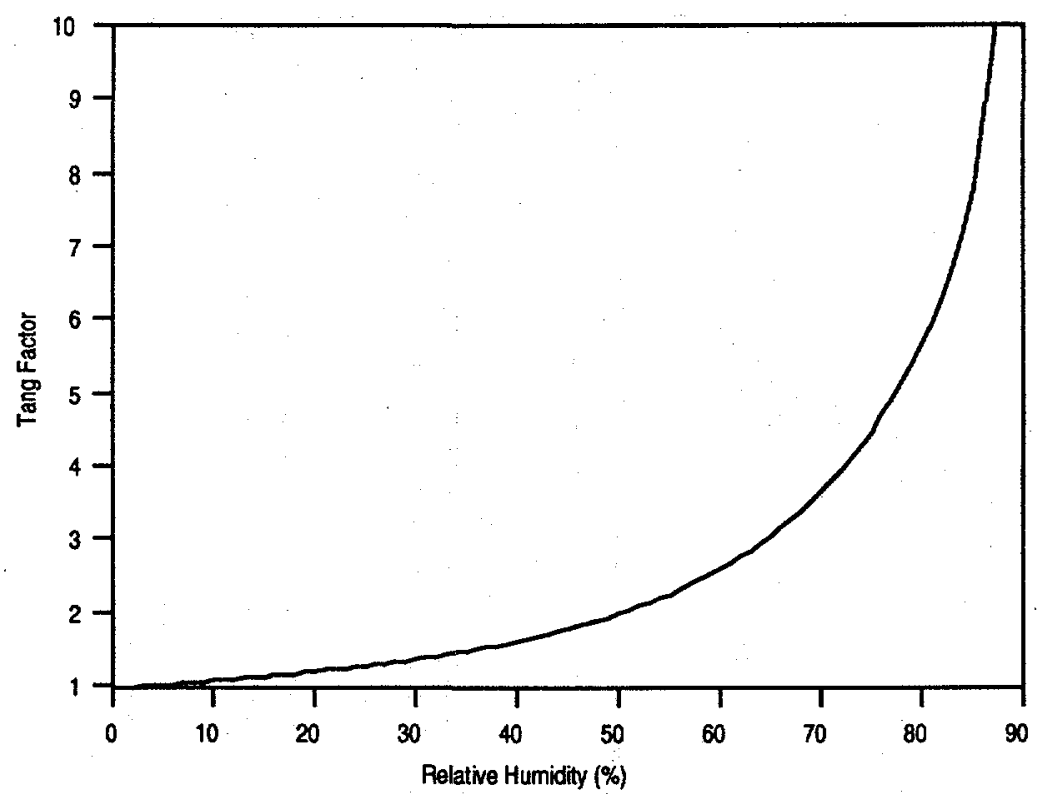

Figure 2 The Tang relative humidity factor, $\mathrm{f}(\mathrm{RH})$, for ammonium sulfate plotted as a function of relative humidity. The fitting parameters for this function were taken from the IMPROVE report [Sisler et al, 1996].

Equation (12) can provide reasonable values for visibility from measurements. However, estimating the change in $b_{\text {ext }}$ resulting from the removal (or addition) of a specific chemical species is different problem from that of assigning the fraction of the measured extinction to individual chemical species [White, 1986; Malm and Kreidenweis, 1997]. The change in extinction that results from a change in the aerosol species composition, $\mathrm{C}_{\mathrm{i}}$, can be written mathematically as

$$
e_{p}=\delta_{e x t} / \delta C_{i}
$$

This partial derivative depends on changes in chemical composition as well as any change in the aerosol size as a result of the addition or removal of species. This 
derivative is termed the species partial mass extinction (or scattering) efficiency, and is quite dependent upon the composition and the microstructure of the aerosol. For instance, assumptions about whether the aerosol is internally or externally mixed can drastically affect how a change in chemical composition will affect the extinction coefficient.

An example of the difficulty in determining the change in $b_{\text {ext }}$ from changes in the aerosol species concentrations can be seen in Figure 3, taken from Malm and Kreidenweis (1997). The right hand side of the figure shows the calculations of extinction for both an external and internally mixed aerosol which both consist of same amounts of species one and two. In the externally mixed aerosol, the particle mass is simply multiplied by the mass scattering efficiency and added to achieve a total scattering of $60 \mathrm{Mm}^{-1}$. In the internally mixed aerosol, the specific mass scattering efficiency is the mass weighted average of the two species; the total scattering for this case is also $60 \mathrm{Mm}^{-1}$. However, when species two is removed, the calculated particle scattering differs, as shown in the left hand side of the figure. The case of the externally mixed aerosol is straightforward; the removal of $5 \mathrm{mg} \mathrm{m}^{-3}$ of species two, which contributed $30 \mathrm{Mm}^{-1}$ to the total extinction, results in an partial scattering efficiency of $3 \mathrm{~m}^{2} \mathrm{~g}^{-1}$, which is the same as that attributed to species one in figure 1-A. However, the removal of species two from the internally mixed aerosol changes the particle size, resulting in a new specific mass scattering efficiency for species one of $2 \mathrm{~m}^{2} \mathrm{~g}^{-1}$. The new total aerosol scattering of 20 $\mathrm{Mm}^{-1}$ gives a partial scattering efficiency for species two of $8 \mathrm{~m}^{2} \mathrm{~g}^{-1}$, which differs from the nominal value of $3 \mathrm{~m}^{2} \mathrm{~g}^{-1}$ when the species is present by itself. This simple example shows some of the difficulties encountered when trying to assess how the change in pollutant load will change visibility. Other complication arise when changes in the aerosol chemistry affects the degree of hygroscopicity of the resulting mixture.

This apportionment issue is an active area of research in the visibility community. The expression presented in Eq. (12) is often the only one that can be used, due to the type of measurement data available. Fortunately, reconstructing extinction coefficients from mass measurements has been shown to not terribly sensitive to the particulars of the aerosol microstructure. Therefore, for a specific measurement methodology, the measured and reconstructed extinction can be compared statistically given a large enough data set, and that some reasonable values for the specific mass scattering efficiencies can be calculated. These values should provide a reasonable estimate of extinction for that measurement program. 


\begin{tabular}{|c|c|c|c|c|c|}
\hline & & \multicolumn{2}{|c|}{ Figure 3a } & \multicolumn{2}{|c|}{ Figure $3 b$} \\
\hline & & species 1 & species 2 & species 1 & species 2 \\
\hline mass & \multirow{6}{*}{ 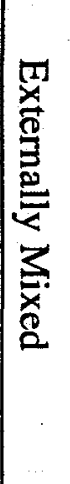 } & $10 \mu \mathrm{g} \mathrm{m}^{-3}$ & $2 \mu \mathrm{g} \mathrm{m}^{-3}$ & $10 \mu \mathrm{g} \mathrm{m}^{-3}$ & \\
\hline aerosol type & & 0 & & D & \\
\hline species density & & $2 \mathrm{~g} \mathrm{~cm}^{-3}$ & $1 \mathrm{~g} \mathrm{~cm}^{3}$ & $2 \mathrm{~g} \mathrm{~cm}^{3}$ & \\
\hline $\begin{array}{l}\text { mass scattering } \\
\text { efficiency }\end{array}$ & & $3 \mathrm{~m}^{2} \mathrm{~g}^{-1}$ & $6 \mathrm{~m}^{2} \mathrm{~g}^{-1}$ & $3 \mathrm{~m}^{2} \mathrm{~g}^{-1}$ & \\
\hline particle scattering & & $30 \mathrm{Mm}^{-1}$ & $30 \mathrm{Mm}^{-1}$ & $30 \mathrm{Mm}^{-1}$ & \\
\hline total scattering & & \multicolumn{2}{|c|}{$60 \mathrm{Mm}-1$} & \multicolumn{2}{|c|}{$30 \mathrm{Mm}-1$} \\
\hline mass & \multirow{5}{*}{ 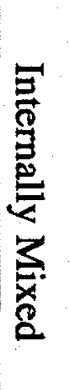 } & \multicolumn{2}{|c|}{$15 \mu \mathrm{g} \mathrm{m}-3$} & \multicolumn{2}{|c|}{$10 \mu \mathrm{g} \mathrm{m}-3$} \\
\hline aerosol type & & & & \multicolumn{2}{|c|}{0} \\
\hline species density & & \multicolumn{2}{|c|}{$1.66 \mathrm{~g} \mathrm{~cm}^{-3}$} & \multicolumn{2}{|c|}{$2 \mathrm{~g} \mathrm{~cm}^{-3}$} \\
\hline $\begin{array}{c}\text { specific mass scattering } \\
\text { efficiency }\end{array}$ & & \multicolumn{2}{|c|}{$4 \mathrm{~m}^{2} \mathrm{~g}^{-1}$} & \multicolumn{2}{|c|}{$2 \mathrm{~m}^{2} \mathrm{~g}^{-1}$} \\
\hline total scattering & & \multicolumn{2}{|c|}{$60 \mathrm{Mm}^{-1}$} & \multicolumn{2}{|c|}{$20 \mathrm{Mm}^{-1}$} \\
\hline
\end{tabular}

Figure 3 (a) Schematic diagram contrasting mass scattering efficiencies associated with external and internal mixing; (b) mass scattering efficiencies upon removal of species two demonstrating the sensitivity of partial mass scattering efficiencies.

\section{The Visibility Conditions in Wyoming}

Examination of the long-term trends in aerosol mass concentrations at the Bridger Wilderness IMPROVE monitoring site give the only quantitative information available concerning visibility in the area. This data has been collected since 1988, and supplies both aerosol mass and extinction budgets. The data can provide information about both the types of aerosol in the area as well as the trends in the aerosol load for the past few years.

The aerosol fine mass budget is presented in Table 1 and is based upon the average of the years 1988 to 1995 [Sisler, 1996]. Coarse mass (particles above $2.5 \mathrm{~mm}$ in diameter) accounted for $58 \%$ of the aerosol collected at Bridger. The trends observed over the 7year data period show a decrease in the organic carbon fraction of the mass budget, while the remainder of the species show little change in their atmospheric concentration. It should be noted that the concentration of organic carbon is strongly related to the number of forest fires in the area. It is, thus, difficult to determine the effect that any increases in anthropogenic organic emissions had on this fraction due to the difficulty deconvoluting 
out the influence of forest fires. The Bridger region also has a large amount of fine soil relative to other areas of the United States, which is typical of areas in the west and southwest.

Table1

Aerosol Mass Budget for the Bridger Wilderness Area from Averaged IMPROVE Data from 1988 to 1995

\begin{tabular}{ll}
\hline Aerosol Species & Aerosol mass \% \\
\hline \hline Organic Carbon & $17.0 \%$ \\
Sulfate & $13.1 \%$ \\
Fine Soil & $7.8 \%$ \\
Nitrate & $2.5 \%$ \\
Elemental Carbon & 1.5 \\
Coarse Mass & $58.0 \%$ \\
\hline
\end{tabular}

Seasonally, the sulfate, organic carbon, elemental carbon, and fine soil fractions of the aerosol mass are larger in the summer than in the winter. Nitrates are the only fraction that is larger in the winter than in the summer. The seasonal variation in soil and particularly organics is much larger than the variation within the other species.

Each species contribution to the extinction budget will differ from its mass concentration because the species have different specific mass extinction efficiencies. Recall that the extinction coefficient, $b_{\text {ext }}$, can be calculated by summing the contribution, on a mass basis, from each species in the atmosphere;

$$
b_{e x t}=\sum_{s p e c i e s, i} \alpha_{i} m_{i}
$$

Based on experimentally determined specific mass scattering efficiencies (based on both literature values and statistical analysis of the IMPROVE data set), Eq.(17) can be written as follows

$$
\begin{aligned}
b_{\text {ext }} & =3 f(R H)[\text { Sulfate }]+3 f(R H)[\text { Nitrate }]+4[\text { Organic Carbon }] \\
& +1[\text { FineSoil }]+0.6[\text { CoarseMass }]+b_{a b s}+b_{R a y}
\end{aligned}
$$

In this expression, $3 f(R H)$ is the specific mass scattering efficiency for sulfate, and [Sulfate] is the measured mass concentration of sulfate in $\mu \mathrm{g} / \mathrm{m}^{3}$, with a similar interpretation for the other terms. The function $f(R H)$ is the Tang correction factor that accounts for the increase in scattering due to the water that has condensed on to hygroscopic aerosol components, sulfate and nitrate. The Rayleigh extinction, $b_{\text {Ray }}$, for the Bridger Wilderness area is $10 \mathrm{Mm}^{-1}$. 
Table 2

Aerosol Extinction Budget for the Bridger Wilderness Area from Averaged IMPROVE data from 1988 to 1995

\begin{tabular}{ll}
\hline Aerosol Species & Fine Mass \% \\
\hline \hline Organic Carbon & $16.2 \%$ \\
Sulfate & $17.5 \%$ \\
Fine Soil & $1.9 \%$ \\
Nitrate & $3.4 \%$ \\
Absorption & $13.8 \%$ \\
Coarse Mass & $8.3 \%$ \\
Rayleigh Scattering & $39.0 \%$ \\
\hline
\end{tabular}

Table 2 shows how each species contributes to the extinction budget based on the specific mass scattering efficiencies given in Eq. 18 and the mass budget presented in Table 1. Note that sulfate and nitrate contribute a larger amount to the extinction budget than the mass budget. This is due to the effect of water on light scattering in these species. Both fine soil and coarse mass, which make up a significant fraction of the aerosol, greatly decrease in significance in the extinction budget. Absorption by elemental carbon, organic carbon, and fine soil accounts for $13.8 \%$ of the extinction budget. It is worth noting that a large percent of the extinction is due to Rayleigh scattering, which indicates a relatively clean atmosphere.

Table 3 lists the measured aerosol concentrations in $\mu \mathrm{g} / \mathrm{m}^{3}$ for the Central Rocky Mountain region of the IMPROVE network from their summary report of 1996. (Spatial and Seasonal Patterns and Long Term Variability of the composition of the Haze in the United States: an Analysis of Data from the IMPROVE Network published by the IMPROVE consortium.) In this report, the monitoring sites were grouped into regions based on regional similarities in order to make trends in the data more apparent. The Central Rocky Mountain district includes Bridger Wilderness Area, Rocky Mountain National Park, Weminuche Wilderness Area, Yellowstone National Park, and Great Sand Dunes National Monument. While the data are not specific to the Bridger Wilderness, they are characteristic of the area and can be used to both understand how visibility is calculated from mass concentration and what changes in visibility may be expected from changes in particulate loading.

Table 3

Seasonal average aerosol concentrations from the IMPROVE data for the Central Rocky Mountain Region from the IMPROVE data averaged from 1988 to 1995 .

\begin{tabular}{lllllllll}
\hline & $\begin{array}{l}\text { Fine } \\
\text { Mass }\end{array}$ & Sulfate & Nitrate & Organics & E.C. & Soil & $\begin{array}{l}\text { Coarse } \\
\text { mass }\end{array}$ & Total \\
\hline \hline Spring & 3.3 & 0.9 & 0.2 & 1.1 & 0.1 & 0.9 & 5 & 11.5 \\
Summer & 4 & 1 & 0.2 & 1.8 & 0.2 & 0.8 & 5.7 & 13.7 \\
Fall & 3.1 & 0.8 & 0.2 & 1.4 & 0.2 & 0.5 & 3.9 & 10.1 \\
Winter & 2.1 & 0.6 & 0.2 & 1 & 0.1 & 0.5 & 2.8 & 7.3 \\
\hline
\end{tabular}


Table 3 lists the measured seasonal aerosol concentration for the region in $\mu \mathrm{g} / \mathrm{m}^{3}$. There is more aerosol mass during the summer. Organics, sulfate, and coarse mass all play a role in the seasonal variation of the measurement. The organic fraction is the species that contributes the most to the seasonal variation of the fine mass measurement. Table 4 lists the seasonal average reconstructed total light extinction coefficient. As expected, the total extinction is larger in the spring and summer. However, it is perhaps unexpected that the fine aerosol contribution to scattering is larger in the spring than in the summer, even though the fine particle mass is greater. It appears that you can pollute more yet not affect the visibility! The answer lies in relative humidity. A lower relative humidity in the summer means that the hygroscopic aerosols (sulfate and nitrate) will not contribute as much to the scattering coefficient on a mass basis, almost offsetting the additional scattering due to the increased organic fraction. The effect can be seen in Table 5, which lists the amount that each species contributes to the total light extinction. The Tang RH factor decreases from 3.5 to 2.5 when the relative humidity decreases from $65 \%$ and $49 \%$. Thus, the contribution from scattering from sulfates and nitrates significantly decreases from spring to summer, while that contributed by organics has increased. However, the amount of light absorbed has increased, which is a large function of the organic and elemental carbon fractions.

Table 4

The Seasonal Average Extinction Coefficient for the Central Rocky Mountain Region from the IMPROVE data of 1988 to 1995

\begin{tabular}{lllllll}
\hline & $\begin{array}{l}\text { Total Ext. } \\
\mathrm{Mm}^{-1}\end{array}$ & $\begin{array}{l}\text { Fine Scat. } \\
\mathrm{Mm}^{-1}\end{array}$ & $\begin{array}{l}\text { Coarse Scat. } \\
\mathrm{Mm}^{-1}\end{array}$ & $\begin{array}{l}\text { Abs. } \\
\mathrm{Mm}^{-1}\end{array}$ & \% Aerosol & $\mathrm{RH}$ \\
\hline \hline Spring & 33.9 & 15.8 & 3.9 & 4.3 & 71 & 65 \\
Summer & 34 & 13.7 & 4.3 & 6.1 & 71 & 49 \\
Fall & 29.5 & 12.3 & 2.9 & 4.4 & 66 & 55 \\
Winter & 22.9 & 8.6 & 1.9 & 2.4 & 56 & 58 \\
\hline
\end{tabular}

Table 5

Species Contributions to the Seasonal Average Extinction Coefficient (in $\mathrm{Mm}^{-1}$ ) for the Central Rocky Mountain Region from IMPROVE data of 1988 to 1995.

\begin{tabular}{llllll}
\hline & Sulfate & Nitrate & Organics & Absorptivity & Soil \& Coarse \\
\hline \hline Spring & 9.1 & 2.2 & 4.4 & 4.3 & 3.9 \\
Summer & 5.4 & 0.9 & 7.4 & 6.1 & 4.3 \\
Fall & 5.6 & 1.1 & 5.6 & 4.4 & 2.9 \\
Winter & 3.6 & 1.0 & 4.0 & 2.4 & 1.9 \\
\hline
\end{tabular}

\section{E. Estimating Future Impacts of Visibility in SW Wyoming}

It should be possible, based on the extinction budget for the Central Rocky Mountain area detailed above, to estimate what increases in specific aerosol components will do to the 


\section{APPENDIX III. AIR QUALITY MONITORING IN WYOMING}

By Melissa Lunden

Environmental Energy Technologies Division, Lawrence Berkeley National Laboratory Berkeley, California 94720-1740

Table of Contents

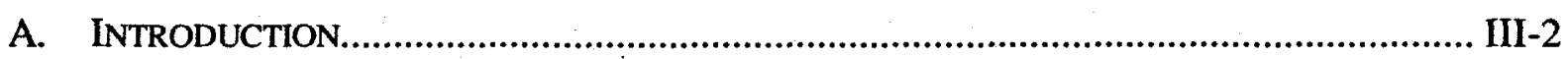

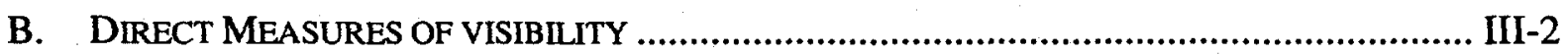

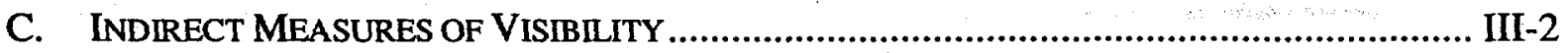

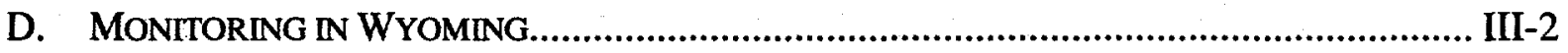

1. IMPROVE (Interagency Monitoring of Protected Visual Environments)...............III-3

2. CASTNet (Clean Air Status and Trends Network) ............................................. III-4

3. NADP (National Atmospheric Deposition Program/National Trends Network)...... III-5

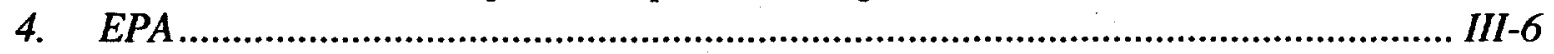




\section{A. Introduction}

Visibility is usually monitored using a combination of two measures. The first is direct optical monitoring of the local visibility. The second method involves measuring the concentration and composition of aerosols in the same area. The two elements are crucial to understanding the specific pollutant issues affecting the visibility of a particular area. The caveat to this statement is that direct source/receptor models of visibility are tricky, as discussed in separate section, and a priori predictions of changes in visibility due to the change in emissions is similarly difficult.

\section{B. Direct Measures of visibility}

Transmissometers measure the irradiance at a wavelength of $550 \mathrm{~nm}$ of the light that have traveled over a finite path in the atmosphere, usually 0.5 to 10 kilometer. Basically, a light source of know intensity is passed through the atmosphere to a detector. The transmittance of the path is calculated by dividing the amount of light reaching the detector by the intensity of the light source. This is a direct measure of the total extinction by scattering and absorption of the light in the atmosphere through which the beam is passed. The measurement can be affected by local atmospheric conditions, and degradation in the optics due to exposure to the atmosphere, e.g. dirt on the lenses.

Nephelometers measure the scattered light over a specific wavelength band of visible light from an enclosed volume of air. Air from the atmosphere is passed into the atmosphere, and the total scattering from that sample is measured. The instruments historically underestimate scattering due to modification of the sample as it passes into the chamber (usually by heating and/or drying), particle loss in the sampling train, and an optical geometry that truncates some of the scattering angles that can be detected. Newer instruments have been designed to limit these effects.

\section{Indirect Measures of Visibility}

The indirect measure of visibility is accomplished by particle sampling and analysis. This is most often achieved using filter measurements. The filters collect particle mass which can either be directly weighed to determine particle mass, or the filter can be analyzed after collection for specific chemicals of interest. The sampling system usually consists of a size selective inlet, a device that provides the proper particle size cutoff based on the flow rate, and the collection substrates. The sampling substrate employed depends upon the specific chemical information desired. For instance, organics are sampled onto quartz filters. Problems associated with filter sampling arise from sampling biases due to particle interaction with the sampling system. An particularly problematic example of this is the evaporation of nitrate particles collected on filters, resulting in a measurement that is lower that the atmospheric concentration.

\section{Monitoring in Wyoming}

The following is a summary of the monitoring that is available in the state of Wyoming. This review mentions the organization that is responsible for the monitoring location, its location, and what data is being collected. 


\section{IMPROVE (Interagency Monitoring of Protected Visual Environments)}

\section{Who participates in the IMPROVE network?}

IMPROVE is a monitoring network established as part of the Federal Implementation Plans (FIPs) for states without approved visibility provisions in their State Implementation Plans with the goal of monitoring regional haze in as many of the Class I visibility-protected areas as possible. It is a collaborative program which includes the EPA, the National Park Service (NPS), the US Forest Service (USFS), the Fish and Wildlife Service (FWS), and the Bureau of Land Management (BLM), the State and Territorial Air Pollution Program Association (STAPPA), the Western States Air Resources Council (WESTAR), and the Northeast States for Coordinated Air Use Management (NESCAUM).

The network is coordinated and operated by the Desert Research Institute in Nevada and Air Resource Specialists, in Ft. Collins, Colorado. DRI has extensive experience operating large monitoring networks and intensive monitoring studies. Their work is considered top notch.

\section{Site locations}

IMPROVE has been collected data since 1987. There are currently 30 monitoring sites in the IMPROVE network, as well as 37 IMPROVE protocol sites operated by the NPS, the USFS, and the FWS. Not all of the sites have the full configuration of optical and aerosol monitoring equipment. Three of these sites are in Wyoming in Yellowstone NP, in Bridger WA, and near Centennial (in the Medicine Bow National Forest). The Bridger site is an IMPROVE site. The Yellowstone and Centennial locations are operated by the NPS and the USFS respectively, using the IMPROVE protocol.

\section{Optical and Aerosol Data}

The routine monitoring approach involves aerosol and optical monitoring. The aerosol monitoring measures the mass concentrations (in $\mu \mathrm{g} / \mathrm{m}^{3}$ ) and the chemical composition of the collected particles. The optical monitoring measures either the light-extinction coefficient $\left(b_{e x t}\right)$ using a transmissometer or the light-scattering coefficient $\left(b_{\text {scat }}\right)$ using a nephelometer. The aerosol samples are collected twice a week, on Wednesday and Saturday from midnight to midnight (24-hour samples). The optical monitoring equipment run throughout the week, providing hourly averaged samples. Meteorological data is also collected at each site.

\section{Aerosol}

The aerosol sampler collects four simultaneous samples; one $\mathrm{PM}_{10}$ samples on a Teflon filter and three $\mathrm{PM}_{2.5}$ samples on Teflon, nylon, and quartz filters. The substrates and the species measured for each substrate is shown in Table 1 . 
Table 1. Substrates and Species Measured For Each Substrate

\begin{tabular}{|l|l|l|}
\hline Module & Filter Media & Analyses \\
\hline A & Teflon & $\begin{array}{l}\text { Gravimetric analysis for mass }<2.5 \mu \mathrm{m} \\
\text { LIPM for optical absorption } \\
\text { PIXE for elements Na to Pb } \\
\text { PESA for H }\end{array}$ \\
\hline B & Nylon (denuded) & Ion chromatography for NO3 and SO4 \\
\hline C & Quartz & TOR for organic and light-absorbing C \\
\hline D & Teflon & Gravimetric analysis for mass $<10 \mu \mathrm{m}$ \\
\hline
\end{tabular}

The module A Teflon filters are analyzed for sulfur and other elements by Particle Induced X-ray Emission (PIXE) and for hydrogen by Proton Elastic Scattering Analysis (PESA). The coefficient of light absorption is also determined using a Laser Integrating Plate Method (LIPM) which involves a direct measurement of the absorption of a laser beam by a sample.

The module $\mathrm{C}$ quartz substrates are analyzed by Thermal Optical Reflectance (TOR) combustion for organic and elemental carbon. Briefly, TOR involved heating a sample through a series of temperature increases (in helium, and later in oxygen), converting the carbon to $\mathrm{CO}_{2}$ using an oxidizer, and reducing the $\mathrm{CO}_{2}$ to methane, which is quantified by passage through a flame ionization detector.

\section{Optical}

The optical monitoring is accomplished using either a transmissometer or a nephelometer. A transmissometer measures irradiance, at a wavelength of $550 \mathrm{~nm}$, of a light source after the light has traveled over a finite atmospheric path. The measured irradiance is used to calculate the extinction, $b_{\text {ext. }}$ The transmissometer used in the IMPROVE network is an OPTEC, Inc., LPV-2 instrument. An integrating nephelometer measures the scattering of light over a defined band of visible wavelengths from an enclosed volume of air, from which $b_{\text {scat }}$ is calculated. The instrument used in the IMPROVE network is an OPTEC Inc. NGN-2 ambient integrating nephelometer.

\section{Meteorological}

Air temperature and relative humidity are sampled at 30 minutes past the hour. The measurements are collocated with the optical instrumentation.

\section{CASTNet (Clean Air Status and Trends Network)}

CASTNet was established in 1987. The majority of the monitoring stations are operated under contract to the EPA's Office of Air and Radiation. Some of the sites are operated by the NPS in cooperation with the EPA. The network provides atmospheric data on acid rain, tropospheric (ground-level) ozone and other forms of atmospheric pollution, and is the nation's primary source for atmospheric data to estimate dry acidic deposition and to provide data on rural ozone levels.

At present, it is not clear what organization or organizations runs the sites under contract to the EPA. The filter analyses are done by QST in Florida, and it is likely that they are also in charge of site operations. 


\section{Site Locations}

There are 71 monitoring stations across the U.S. 67 measure dry-deposition, 18 wet-deposition, 48 ozone, and 9 visibility. Of the 67 that measure dry deposition, 48 form the core of the network and were formerly known as the National Dry Deposition Network. The three CASTNet sites in Wyoming are collocated with the IMPROVE sites, namely Yellowstone NP, Bridger WA, and Centennial. The Bridger and Centennial sites are CASTNet dry deposition sites, and the Yellowstone location is a NPS/EPA dry deposition site.

\section{Data Collection}

The dry deposition stations measure atmospheric concentrations of sulfate, nitrate, ammonium, sulfur dioxide, and nitric acid, and continuous ozone levels. Each site is equipped with a temperature-controlled shelter, an ozone analyzer, meteorological sensors, and a filter pack sampling system. The filter packs are exposed for 1-week intervals (Tuesday to Tuesday). The concentration data are collected with open-faced, 3-stage filter packs that contain a Teflon filter for collection of particulate, a nylon filter for nitric acid and a base-impregnated cellulose filter for sulfur dioxide.

\section{NADP (National Atmospheric Deposition Program/National Trends Network)}

NADP is a national network of precipitation monitoring sites. It is a cooperative effort between many organizations, including the State Agricultural Experiment Stations, the U.S. Geological Survey, the U.S. Department of Agriculture, and other governmental and private entities. (These are numerous, and include the Department of the Interior, the EPA, NASA, the NSF, and the DOE.) The purpose of the network is to collect data on the chemistry of precipitation for both geographical and long-term trends.

The network is coordinated by the Natural Resource Ecology Laboratory at Colorado State University in Fort Collins, CO and the Illinois State Water Survey in Champaign, IL.

\section{Site Locations}

There are 200 sites in the continental United States, Alaska, and Puerto Rico. There are eight active sites in Wyoming, with locations shown in Table 2. 
Table 2. NADP Monitoring Sites in Wyoming

\begin{tabular}{|l|l|l|l|}
\hline Station & \multicolumn{1}{|c|}{ Location } & \multicolumn{1}{|c|}{$\begin{array}{c}\text { Dates of } \\
\text { Operation }\end{array}$} & \multicolumn{1}{|c|}{ Operator } \\
\hline Snowy Range & Albany Co. & $4 / 22 / 86-$ Present & USFS \\
\hline Brooklyn Lake & Albany Co. & $9 / 22 / 92-$ Present & USFS \\
\hline Sinks Canyon & Freemont Co. & $8 / 21 / 84-$ Present & BLM \\
\hline South Pass City & Freemont Co. & $4 / 3085-$ Present & $\begin{array}{l}\text { SO Phosphates } \\
\text { Ltd./USFS }\end{array}$ \\
\hline Pinedale & Sublette Co. & $1 / 26 / 82-$ Present & BLM \\
\hline Gypsum Creek & Sublette Co. & $12 / 26 / 84-$ Present & Exxon/USFS \\
\hline Newcastle & Weston Co. & $8 / 11 / 81$ - Present & BLM \\
\hline $\begin{array}{l}\text { Yellowstone, } \\
\text { Tower Falls }\end{array}$ & Park Co. & $6 / 5 / 80-$ Present & NPS \\
\hline
\end{tabular}

\section{Data Collection}

The precipitation at each station is collected weekly and sent to a Central Analytical Laboratory. where it is analyzed for hydrogen (acidity as $\mathrm{pH}$ ), sulfate, nitrate, ammonia, chloride, and base cations (such as calcium, magnesium, potassium and sodium).

\section{EPA}

Administered by the EPA, these are the monitoring sites that the states are required to establish in order to measure the concentration of the six criteria air pollutants. The monitors on the network are called the State and Local Air Monitoring Stations (SLAMS). The administration of the sites and the data is coordinated through the Office of Air Quality Planning and Standards (OAQPS), Information Transfer and Program Integration Division (ITPID) at the EPA.

\section{Site Locations}

The SLAMS network currently only monitors for $\mathrm{PM}_{10}$ in Wyoming. (It is assumed that some assessment was performed for the other criteria air pollutants, and the state was found to be in compliance. We do not know if this is performed on a regular basis.) There are 11 SLAMS monitors in Wyoming. Their locations are listed in Table 3. 
Table 3. SLAMS Monitoring Sites in Wyoming

\begin{tabular}{|l|l|l|}
\hline County & City & Type \\
\hline Albany Co & Laramie & Commercial \\
\hline Fremont Co & Lander & Commercial \\
\hline Fremont Co & Lander & Residential \\
\hline Laramie Co & Cheyenne & Residential \\
\hline Natrona Co & Casper & Commercial \\
\hline Park Co & Cody & Residential \\
\hline Sheridan Co & Sheridan & Commercial \\
\hline Sheridan Co & Sheridan & Commercial \\
\hline Sweetwater Co & 25 Miles WNW Of Green River & Desert \\
\hline Sweetwater Co & Rock Springs & Residential \\
\hline Teton Co & Town Square, Jackson & Residential \\
\hline
\end{tabular}

Data Collection

We assume that each site is require to use one of the Federal Reference Method $\mathrm{PM}_{10}$ monitors, or an equivalent method. There are several types being manufactured, but it is unclear which type of monitor being used at each location. Soon, many of these sites will be required to monitor $\mathrm{PM}_{2.5}$ as well. 


\section{APPENDIX IV. AN INITIAL REVIEW OF METEOROLOGICAL PHENOMENA, DATA, AND MODELING FOR SOUTHWEST WYOMING AIR QUALITY ASSESSMENTS}

\section{By Steven D. Reynolds}

Envair, 12 Palm Avenue, San Rafael, California 94901-2222

Table of Contents

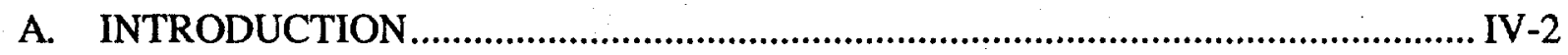

B. OVERVIEW OF KEY METEOROLOGICAL PHENOMENA ……............................ IV-3

C. AVAILABLE METEOROLOGICAL DATA ......................................................... IV-4

D. AVAILABLE METEOROLOGICAL MODELING APPROACHES ......................... IV-4

1. Diagnostic Approaches.................................................................................... IV-5

2. Prognostic Approaches.......................................................................................

E. SELECTION OF METEOROLOGICAL MODELS FOR SW WYOMING ............... IV-6

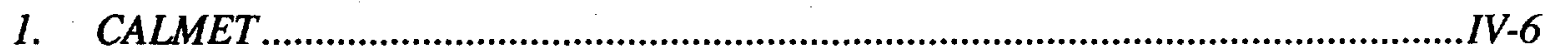

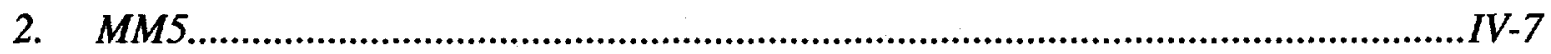

F. SUITABILITY OF THE METEOROLOGICAL MODELING APPROACH ............. IV-8

G. RECOMMENDATIONS FOR FURTHER STUDY ............................................... IV-9

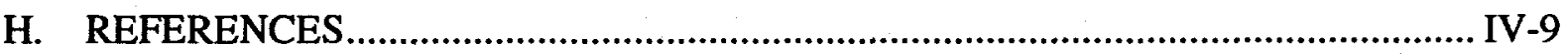




\section{A. INTRODUCTION}

In a study sponsored by the U.S. Department of Energy, the Ernest Orlando Lawrence Berkeley National Laboratory (LBNL) is providing technical support for efforts to assess air quality impacts of oil and gas exploration and development in southwest Wyoming. Key objectives of this work are:

- To determine the impacts on air quality and visibility of current oil and gas production and planned oil and gas development (OGD) in Wyoming,

- To assess the air quality and visibility benefits of alternative emissions control strategies, and

- To evaluate and improve the reliability of the estimates made.

Oversight for the air quality assessment work is being provided by the Southwest Wyoming Technical Air Forum (SWYTAF), which includes representatives from the Wyoming Department of Environmental Quality, Forest Service, Environmental Protection Agency, Bureau of Land Management, industry, environmental organizations, and tribes. The SWYTAF identified the modeling system and assumptions to be used in determining air quality impacts in Class I areas due to long range transport of pollutants from the proposed oil and natural gas developments. In particular, it was decided to employ the CALPUFF/CALMET modeling system, which is being adapted for application in southwest Wyoming by EarthTech, Inc.

Given that a modeling approach has been selected and modeling efforts have proceeded apace, the purpose of the present LBNL study is to contribute in the following areas:

- To evaluate modeling efforts, considering the need for evaluating performance and assessing the reliability of model estimates, and

- To suggest analyses that may prove beneficial in assessing the current and potential future severity of the air quality and visibility problems.

This document provides an initial assessment of key meteorological issues associated with the conduct of the air quality assessments, including

- Current understanding of important meteorological phenomena in the area,

- Available meteorological measurements at the surface and aloft to support modeling,

- Possible meteorological modeling approaches,

- The suitability of the meteorological modeling approach being adopted to support air quality modeling, and

- Recommendations for further study. 


\section{B. OVERVIEW OF KEY METEOROLOGICAL PHENOMENA}

The measurements and analyses conducted as part of the Mt. Zirkel Wilderness Area (MZWA) Reasonable Attribution Study of Visibility Impairment (Watson et al., 1996) provide insights into the meteorological phenomena that influence air quality and visibility in the southwest Wyoming area. The Mt. Zirkel study collected meteorological, air quality and visibility measurements in northwestern Colorado from December 1994 through November 1995 to determine the frequency and intensity of visibility impairment in the MZWA. Of particular concern are sources in the Yampa Valley, which is west of the MZWA and contains the Hayden and Craig coal-fired generating stations, and more distant emitters in Colorado, southern Wyoming, western Utah, and outlying areas. The measurement program included an annual monitoring network, intensive studies during the winter, summer, and fall, and selected emissions measurements.

Radar profiler measurements up to $3000 \mathrm{~m}$ AGL and RASS virtual temperature measurements up to $900 \mathrm{~m}$ AGL were analyzed to provide a climatology of winds and mixing conditions aloft. This information was then used to develop a generalized conceptual model of the atmospheric processes that mix and transport emissions from the Yampa Valley sources. Observed plume behavior was divided into three stages, based on data shown in Figure 1. A schematic drawing illustrating the three stages of plume behavior is shown in Figure 2. Key elements of the three stages may be summarized as follows (Watson et al., 1996):

- Stage 1-Drainage Flow. At about 1900 MST, the westerly flow that persists during the afternoon changes to easterly flow as the cold air from the surrounding valleys and mountains drains into the Yampa Valley. This drainage flow deepens from about $300 \mathrm{~m}$ AGL by 2300 MST to about $450 \mathrm{~m}$ AGL by 0700 MST. The mixing depth is quite shallow at night, but the thermal buoyancy allows the plumes from the power stations to ascend into the stable air in the drainage flow. An inversion typically exists at the top of the flow and traps the plume in the drainage flow. Brisk easterly winds at 200 to $400 \mathrm{~m}$ GL transport emissions to the west at Hayden.

- Stage 2 - Transition. This stage begins near sunrise when the convective boundary layer starts growing. Plume rise data suggest that between 0600 and 0700 MST, the plume ascends higher and reaches up to $600 \mathrm{~m}$ AGL. As the plume rises, it is initially carried westward by the downslope flow and then transported eastward by the prevailing synoptic flow aloft. A bifurcation of the plume may occur as it ascends through these two wind regimes with emissions transported in two directions.

- Stage 3-Coupling. As the day continues, the drainage flow ends at about $1000 \mathrm{MST}$ and the convective boundary layer (CBL) continues deepening and reaches $1600 \mathrm{~m}$ AGL by 1400 MST. Low-level winds couple with the synoptic flow aloft as aloft air mixes downward and low-level air upward, causing the valley emissions to start flowing up the valley. Rigorous mixing in the CBL tends to dilute and mix emissions from the plumes throughout the developing boundary layer. As the CBL grows, these diluted emissions are mixed with any background air that was transported into the region aloft during the nighttime and early morning. In addition, surface-based anthropogenic pollutants would also be mixed upwards into the developing boundary layer. Thus, the aloft air in the boundary layer could contain a 
mix of pollutants from various sources. By $1200 \mathrm{MST}$, the mixed layer typically grows to about $1300 \mathrm{~m}$ AGL, and the air with its background and local pollutant burden would now be transported eastward.

The conceptual model developed by Watson et al. (1996) illustrates the complexity of the wind flow and mixing conditions that are likely to occur in the southwest Wyoming area. The success of planned air quality and visibility modeling efforts in southwest Wyoming will be contingent on the availability of suitable measurements and the ability of the meteorological modeling system to adequately represent these transport phenomena.

\section{AVAILABLE METEOROLOGICAL DATA}

An electronic database containing meteorological and air quality measurements collected during 1995 in Wyoming and the immediately surrounding area has been assembled by Air Resources Specialists (ARS, 1997). This database is intended to support the application of the CALMET/CALPUFF modeling system. Sources of data include the Department of Interior Remote Automatic Weather Stations; IMPROVE, U.S. Forest Service Visibility Program, National Park Service Gaseous Pollutant Monitoring Program, Wyoming State Department of Transportation sites, National Dry Deposition Network, industrial sites, and special studies (e.g., Mount Zirkel Reasonable Attribution Visibility Study). Surface and upper air meteorological data collected by the National Weather Service were not included in the database.

The ARS team examined available QA/QC protocols to determine which data would be included or excluded from the database. ARS made qualitative observations of the data through wind rose plots and other visual techniques as well as conversations with on-site personnel as to the general quality of the data.

Watson et al. (1996) analyzed the meteorological measurements collected during 1995 in the Mt. Zirkel study and found them reasonably representative of conditions encountered in other years, except that May was exceptionally stormy. No more than 6 percent of the days during the study showed major deviations from long-term averages for temperatures, cloud-cover, or rainfall. However, May was the wettest on record for the upper Yampa Valley. While similar analyses should be conducted in the southwest Wyoming area, there is some indication that the 1995 period may be a reasonable choice for air quality assessments.

\section{AVAILABLE METEOROLOGICAL MODELING APPROACHES}

Various techniques have been employed over the past three decades to develop the meteorological inputs required by air quality models. Such inputs may include threedimensional, time dependent wind and temperature fields as well as prescriptions of cloud cover, UV radiation intensity, vertical mixing, and moisture content. In early urban-scale photochemical modeling work, a skilled meteorologist prepared hourly wind streamline, isotach, and mixing height maps based on a subjective interpretation of available wind measurements and temperature soundings (Reynolds et al., 1974). These maps were digitized to provide the gridded input fields required by the air quality model. This labor-intensive approach was abandoned in the mid-1970s in favor of automated input preparation procedures. To expedite the preparation of meteorological inputs, diagnostic approaches were developed and applied in urban modeling studies. Updated versions of these techniques are still in use today. Over the past decade, prognostic meteorological models have seen increasing application in urban and regional 
modeling studies. With the most complete representation of atmospheric physics, the scientific community often prefers these models for air quality applications.

\section{Diagnostic Approaches}

In diagnostic wind modeling, the kinematic details of the flow are estimated by solving the mass conservation equation. Dynamic interactions such as turbulence production and dissipation and the effects of pressure gradients are parameterized. Various diagnostic wind models have been developed, such as those described by Fosberg et al. (1976) and Yocke (1981). In recent years, attempts have been made to combine the best features of objective analysis and pure diagnostic wind modeling. The current release of the EPA's UAM-IV includes the Diagnostic Wind Model (DWM) as the suggested wind field generator for this urban-scale photochemical model. The DWM (Douglas et al., 1990) is representative of this class of hybrid objective/diagnostic models. The DWM combines the features of the Complex Terrain Wind Model (CTWM) (Tesche and Yocke, 1976) and the objective wind interpolation code developed at the California Institute of Technology (Goodin et al., 1980). The CALMET model (Scire et al., 1998) combines the DWM with a comprehensive micrometeorological and boundary layer model to produce a complete set of meteorological fields for air quality models.

Among the advantages of the diagnostic modeling approach are their intuitive appeal and modest computing requirements. The method generally reproduces the observed wind values at the monitoring locations and provides some information on terrain-induced airflows in regions where observations are absent. In addition, one may calibrate diagnostic model parameters for a particular locale based on site-specific field measurements. However, there are several disadvantages. Diagnostic models cannot represent complex mesoscale flow circulations, unless these features are well-represented by surface and aloft observations. Often the vertical velocities produced by a diagnostic model are unrealistic and in regions of complex terrain, local horizontal flow velocities may often be an order of magnitude too high (Tesche et al., 1987).

Since the diagnostic model is not time dependent, there is no inherent dynamic consistency in the winds from one hour to the next. That is, calculation of the flow field at hour 1200 , for example, is not influenced by the results of the 1100 hour winds. This is a particular problem in situations involving secondary circulations such as land-sea or land-lake breezes that take several hours to develop and whose three-dimensional character is poorly characterized by even the most intensive sampling networks.

\section{Prognostic Approaches}

In prognostic meteorological modeling, atmospheric fields are computed based on numerical solutions of the coupled, nonlinear conservation equations of mass, momentum, energy, and moisture. Derivations of these equations are presented extensively in the literature (Pielke, 1984; Seinfeld, 1986). Many prognostic models have been developed for computing mesoscale wind fields and have been applied to a variety of problems, including the study of land-sea and landlake circulations.

Prognostic wind models are attractive because they explicitly address the various physical processes governing atmospheric flows. Consequently, they have the potential for describing a number of wind regimes that are particularly relevant to air pollution modeling; such as flow reversal, daytime upslope flows, wind shear, and other mesoscale thermally-induced circulations. 
Drawbacks of prognostic models include the need to gather detailed data for model performance testing and significant computational costs. Prognostic models may require as much or more computer time that regional-scale photochemical models.

\section{E. SELECTION OF METEOROLOGICAL MODELS FOR SW WYOMING}

The CALPUFF/CALMET modeling system was selected by the SWYTAF for use in the Southwest Wyoming Air Quality Study. At this time we have not ascertained the basis for the SWYTAF's selection of this modeling system. However, CALMET would be an obvious candidate meteorological model to pair with an application of the CALPUFF air quality model. Note that this pair of models has also been recommended for the determination of air quality impacts from the Continental Divide, GWA II, and South Baggs natural gas field development projects (TRC, 1997).

The development of meteorological inputs for the CALPUFF application in the Southwest Wyoming Air Quality Study involves the combined use of both the CALMET diagnostic model and the MM5 prognostic model. Although MM5 represents the state-of-the-science in meteorological modeling, it was deemed impractical to apply this model on a fine spatial grid sufficient to resolve important terrain-induced features in the flow fields. Instead, MM5 is being applied to a nested domain with 60 and $20 \mathrm{~km}$ grid resolutions. The MM5 results are then used as inputs to the CALMET model, which is being applied on a grid with $4 \mathrm{~km}$ horizontal resolution.

\section{CALMET}

CALMET is a diagnostic meteorological model that contains parameterized treatments of terrain effects and separate boundary layer modules for water and land surfaces. The model can be executed for relatively long simulation times (one or more years) with relatively modest computational requirements.

The diagnostic wind field module employs a two step procedure to compute wind fields. First, an initial-guess wind field is adjusted for the kinematic effects of terrain, slope flows, and terrain blocking effects to produce a Step 1 wind field. The second step involves the application of an objective analysis procedure to introduce observational data into the Step 1 wind field to produce a final wind field. As an option, gridded prognostic wind field estimates can also be used by CALMET. The prognostic flow fields may better represent regional flows and certain aspects of sea breeze and slope/valley circulations. MM5 prognostic data can be introduced into CALMET in three ways: (1) as a replacement for the initial guess wind field, (2) as a replacement for the Step 1 field, or (3) as "observations" in the objective analysis procedure.

The techniques used in developing the Step 1 wind field may be briefly described as follows (Scire et al., 1998):

- Kinematic effects of terrain. The approach of Liu and Yocke (1980) is employed to evaluate kinematic terrain effects. Domain-scale winds are used to compute a terrain-forced vertical velocity, subject to an exponential, stability-dependent decay function. The kinematic effects of terrain on the horizontal wind components are evaluated by applying a divergenceminimization scheme to the initial guess wind field. A divergence minimization scheme is 
applied iteratively until the three-dimensional divergence is less than a threshold value.

- Slope flows. CALMET employs the shooting flow parameterization of Mahrt (1982). Shooting flows are buoyancy-drived flows, balanced by advection of weaker momentum, surface drag, and entrainment at the top of the slope flow layer. The slope flow is parameterized in terms of the terrain slope, distance to the crest and local sensible heat flux. The thickness of the slope flow layer varies with the elevation drop from the crest.

- Blocking effects. The thermodynamic blocking effects of terrain on the wind flow are parameterized in terms of the local Froud number (Allwine and Whiteman, 1985). If the Froud number at a particular grid point is less than a critical value and the wind has an uphill component, the wind direction is adjusted to be tangent to the terrain.

The resulting Step 1 wind field is further modified through the introduction of observational data using an objective analysis procedure. An inverse-distance-squared interpolation scheme is employed which weighs observational data heavily in the vicinity of the observation site, while the Step 1 wind field dominates the interpolated wind field in regions where no observations are available. The resulting wind field is subject to smoothing, an optional adjustment of vertical velocities based on the O'Brien method, and divergence minimization to produce the final Step 2 wind field.

CALMET employs two boundary layer models for application to grid cells that are situated over land or water.

- Overland Boundary Layer Model. Over land surfaces, the energy balance method of Holtslag and van Ulden (1983) is used to compute hourly gridded fields of the sensible heat flux, surface friction velocity, Monin-Obukhov length, and convective velocity scale. Mixing heights are determined from the computed hourly surface heat fluxes and observed temperature soundings using a modified Carson (1973) method based on Maul (1980). Gridded fields of PGT stability class and optional hourly precipitation rates are also determined by the model.

- Overwater Boundary Layer Model. The aerodynamic and thermal properties of water surfaces suggest that a different method is best suited for calculating the boundary layer parameters in the marine environment. A profile technique, using air-sea temperature differences, is used in CALMET to compute the micro-meteorological parameters in the marine boundary layer.

An upwind-looking spatial averaging scheme is optionally applied to the mixing heights and three-dimensional temperature fields to account for important advection effects.

\section{MM5}

The PSU/NCAR mesoscale model is a limited-area, hydrostatic or nonhydrostatic, terrainfollowing sigma-coordinate model designed to simulate or predict mesoscale and regional-scale atmospheric circulation. It has been developed at Penn State and NCAR as a community mesoscale model and is continuously being improved by contributions from users at several 
universities and government laboratories.

The Fifth-Generation NCAR / Penn State Mesoscale Model (MM5) is the latest in a series that developed from a mesoscale model used by Anthes at Penn State in the early 70's. Since that time, it has undergone many changes designed to broaden its usage. These include (1) a multiple-nest capability, (2) nonhydrostatic dynamics, which allows the model to be used at a few-kilometer scale, (3) multitasking capability on shared- and distributed-memory machines, (4) a four-dimensional data-assimilation capability, and (5) more physics options.

MM5 is supported by several auxiliary programs, which are referred to collectively as the MM5 modeling system. As described by EarthTech (1997), these programs are being used in the following manner to support the southwest Wyoming air quality modeling.

- TERRAIN - Geophysical Data Preprocessor. TERRAIN is used to provide a horizontal interpolation of terrain elevations onto the chosen modeling domain. Pertinent geophysical data sets are archived on the NCAR Masstore and TERRAIN must be run on the NCAR's Crays. Data sets with resolutions of 5 and 10 minutes are used to derive terrain elevations and land use categories, respectively.

- DATAGRID - Meteorological Analysis Preprocessor. DATAGRID accesses meteorological analyses archived on the NCAR Masstore and horizontally interpolates them to the model grids. The NMC Global Analysis data set with a $2.5^{\circ} \times 2.5^{\circ}$ resolution has been selected for the southwest Wyoming study.

- RAWINS - Surface and upper-air observations Preprocessor. RAWINS improves the meteorological analyses on the mesoscale grid by objective analysis of surface and upper-air observations. It provides fields for initial and boundary conditions on pressure levels, and provides three-dimensional fields for analysis-nudging four dimensional data assimilation (FDDA). The data sets consist of the NMC operational global surface (3- and 6-hourly) and upper-air (twice-daily) observations.

- INTERP - Sigma coordinates transformation Preprocessor. INTERP operates as a "frontend" preprocessor transforming fields produced on pressure levels by RAWINS to fields in sigma coordinates for input to MM5. It also operates as a "back-end" processor transforming the MM5 output fields (produced on sigma levels) back to fields on pressure levels. These fields can then serve as inputs to CALMET.

For the southwest Wyoming study, MM5 is being run on a $24 \times 22$ grid with $60 \mathrm{~km}$ resolution that covers much of the Western US. Within this grid is nested a $25 \times 19$ grid with $20 \mathrm{~km}$ resolution encompassing the southwest Wyoming study domain.

\section{F. SUITABILITY OF THE METEOROLOGICAL MODELING APPROACH}

The combined use of CALMET and MM5 is a pragmatic means for developing meteorological inputs for air quality and visibility modeling. The approach might be improved by a full nested grid application of MM5 to the $4 \mathrm{~km}$ horizontal grid resolution being employed in CALMET. However, it is unclear that significantly more reliable meteorological fields would result from such an approach. It is clear that considerably more computing time would be required to 
develop the meteorological inputs required for annual air quality modeling.

A key issue influencing the adequacy of the simulated meteorological fields is the availability of suitable input data. Of particular concern is the absence of information on the vertical structure of the wind and temperature fields in key areas of the southwest Wyoming study domain. The potential complexity of the meteorological fields can be surmised from a review of the Mt. Zirkel study where particular measurement efforts were undertaken to characterize such phenomena. Whether the meteorological modeling system is performing adequately may be difficult to ascertain given the paucity of suitable independent measurements in southwest Wyoming. Further insight into model performance characteristics can be gained by reviewing the recent MM5 application and performance evaluation work conducted as part of the SARMAP study in central California. The SARMAP MM5 application benefited from the availability of a very rich database for supporting the evaluation of a prognostic meteorological model.

\section{G. RECOMMENDATIONS FOR FURTHER STUDY}

To provide further insight into the suitability and adequacy of the meteorological modeling approach being implemented in southwest Wyoming, we suggest the following activities:

- Acquire and review the meteorological database that has been assembled for southwest Wyoming modeling activity.

- Review previous CALMET model applications and performance evaluation studies.

- Review the MM5 performance evaluation work conducted in the SARMAP and other studies.

- Review the procedures and assumptions employed in developing CALMET/MM5 inputs for southwest Wyoming and the resulting performance evaluation results.

- Acquire the CALMET/MM5 modeling system developed for the southwest Wyoming study.

- Conduct further CALMET/MM5 performance assessments using independent measurements in southwest Wyoming (if available).

\section{H. REFERENCES}

Allwine, K. J. and C. D. Whiteman (1985). MELSTAR: A Mesoscale Air Quality Model for Complex Terrain: Volume I - Overview, Technical Description and User's Guide. Pacific Northwest Laboratory, Richland, WA.

ARS (1997). Southwest Wyoming Regional CALPUFF Modeling Analysis - Preparation of MeteorologicaV/Air Quality Database for CALPUFF/CALMET Modeling. Air Resource Specialists, Inc., Fort Collins, CO.

Carson, D. J. (1973). The Development of a Dry, Inversion-Capped, Convectively Unstable Boundary Layer. Quart. J. Roy. Meteor. Soc., 99: 450-467. 
Douglas, S. G. et al. (1990). User's Guide for the Urban Airshed Model, Volume III: User's Manual for the Diagnostic Wind Model (Version 1.1). EPA-450/4-90/007C, U.S. Environmental Protection Agency, Research Triangle Park, NC.

EarthTech (1997). Southwest Wyoming Air Quality Study Proposal. EarthTech, Inc., Concord, MA.

Fosberg, M. A. et al. (1976). Estimating Airflow Patterns Over Complex Terrain. Research paper RM-162, U.S. Forest Service, Ft. Collins, CO.

Goodin, W. R. et al. (1980). An Objective Analysis Technique for Constructing ThreeDimensional, Urban-Scale Wind Fields. J. Appl. Meteorol., 19:98-108.

Holtslag, A. A. M. and A. P. van Ulden (1983). A Simple Scheme for Daytime Estimates of the Surface Fluxes from Routine Weather Data. J. Clim. and Meteor., 22: 517-529.

Liu, M. K. and M. A. Yocke (1980). Siting of Wind Turbine Generators in Complex Terrain. J. Energy, 4: 10-16.

Mahrt, L. (1982). Momentum Balance of Gravity Flows. J. Atmos. Sci., 39: 2701-2711.

Maul, P. R. (1980). Atmospheric Transport of Sulfur Compound Pollutants. MID/SSD/80/0026/R, Central Electricity Generating Bureau, Nottingham, England.

Pielke, R. A. (1984). Mesoscale Meteorological Modeling. Academic Press, New York, NY.

Reynolds, S. D. et al. (1974). Mathematical modeling of photochemical air pollution--Part III. Evaluation of the model. Atmos. Environ., 8:563-596.

Scire, J. S. et al. (1998). A User's Guide for the CALMET Meteorological Model (Version 5.0 DRAFT). EarthTech, Inc., Concord, MA.

Seinfeld, J. H. (1986). Atmospheric Chemistry and Physics of Air Pollution. John Wiley and Sons, New York, NY.

Tesche, T. W. and M. A. Yocke (1976). Numerical Modeling of Wind Fields Over Mountainous Regions in California. Conference on Sierra Nevada Meteorology, AMS, June 19-21, South Lake Tahoe, CA.

Tesche, T. W. et al. (1987). Performance Evaluation of Four Grid-Based Dispersion Models in Complex Terrain. Atmos. Env., 21: 233-256.

TRC (1997). Air Quality Impact Assessment Protocol: Continental Divide, GWA II and South Baggs Projects. Draft Report prepared by TRC Environmental Corporation and EarthTech, Inc. for the U.S. Department of the Interior, Bureau of Land Management, 
December 16, 1997.

Watson, J. G. et al. (1996). Mt. Zirkel Wilderness Area Reasonable Attribution Study of Visibility Impairment -- Volume II: Results of Data Analysis and Modeling. Desert Research Institute, Reno, NV.

Yocke, M. A. (1981). A Three-Dimensional Wind Model for Complex Terrain. PhD Dissertation, University of California, Berkeley, CA. 


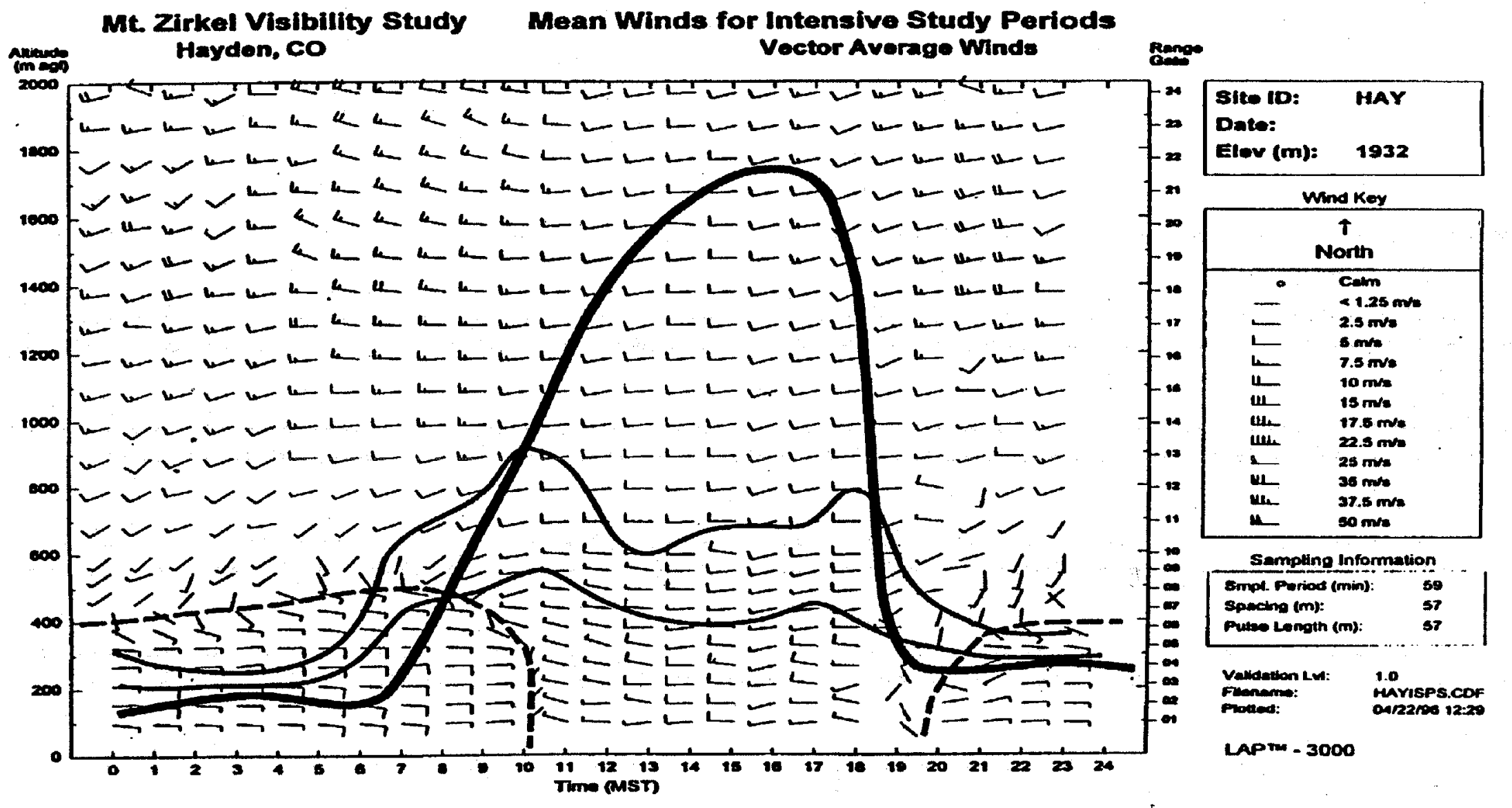

Figure 1. Time-height cross sections of averaged winds at Hayden, Colorado, for the intensive study days in 1995 . The thick solid line denotes the mixing height estimates from CALMET; the thin solid lines denote the plume heights from the two Hayden units. The easterly winds associated with the drainage flow are indicated by the thin-dashed line. (Source: Watson et al., 1996). 


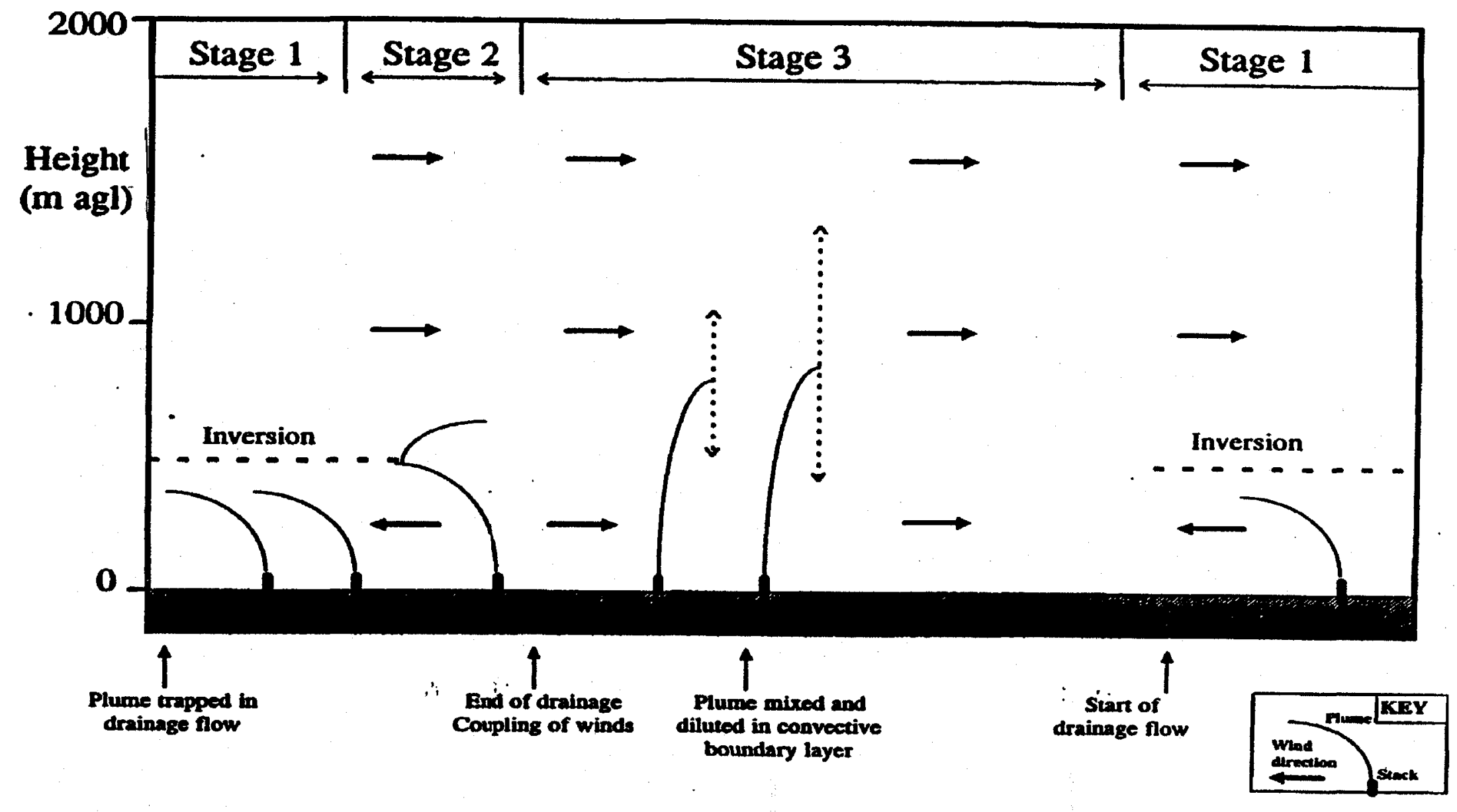

Figure 2. Schematic showing plume behavior based on the analyses of aloft wind and temperature data, mixing depth and plume heights, and time lapse video. (Source: Watson et al., 1996). 


\section{APPENDIX V. EMISSIONS ESTIMATES}

By Brett Singer

Environmental Energy Technologies Division, Lawrence Berkeley National Laboratory Berkeley, CA 94720

Table of Contents

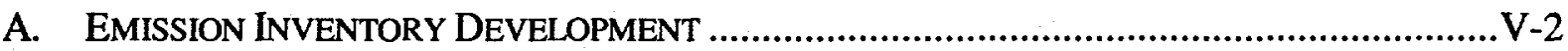

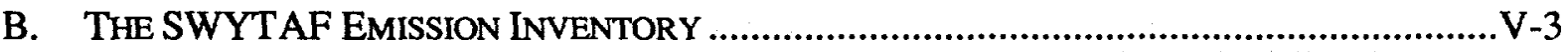

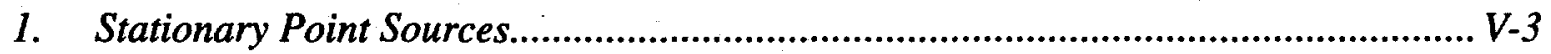

2. Stationary Area Sources ............................................................................... V-3

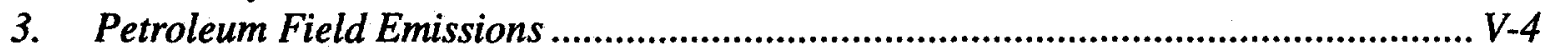

4. Mobile Source Emissions ........................................................................................ V-4

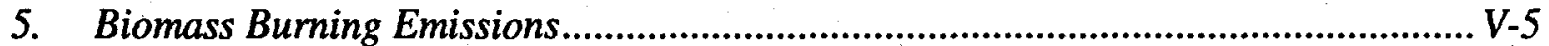

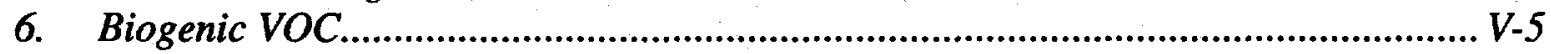

C. PRELIMINARY EVALUATION OF THE SWYTAF EMISSION INVENTORY ......................... V-5

1. Inventory of VOC with Secondary Organic Aerosol Formation Potential................. V-5

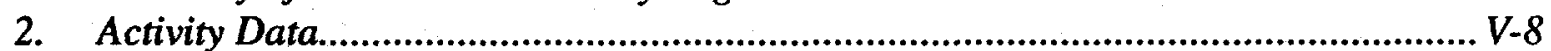

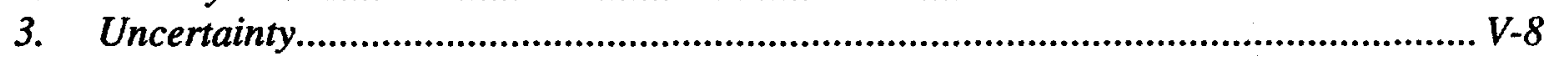

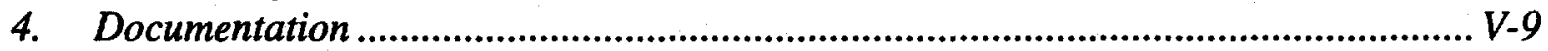

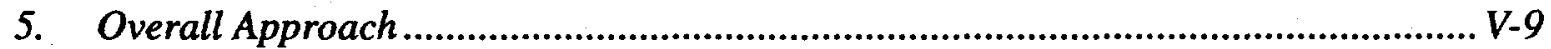

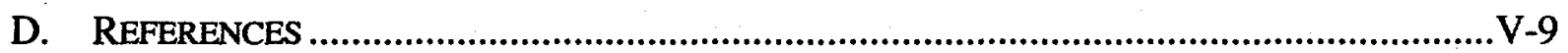




\section{A. Emission Inventory Development}

An emission inventory is developed by identifying and quantifying emissions from all significant sources of each pollutant in the geographic area of concern. Sources may include a wide array of processes, some related (anthropogenic) and others unrelated to human activity. Examples of anthropogenic pollutant sources include internal combustion engines, solvent evaporation from consumer products, and myriad industrial processes. Examples of "natural" air pollutant sources are trees (organic compounds), farm animals (ammonia and methane), and forest fires $\left(\mathrm{CO}, \mathrm{NO}_{\mathrm{x}}\right.$, organic compounds, and particulate matter). Source emissions are typically estimated as the product of an emission factor and an activity rate. Emission factors are expressed as pollutant mass emitted per unit of activity. Activity may be expressed in many forms: an amount of fuel consumed (e.g. for combustion processes), an amount of material processed, or an amount of time over which the activity occurs. The magnitude, location, and timing of emissions from each source are important parameters in an emission inventory. Emissions may be considered to occur at a single point or over a finite area; they may be relatively constant with time, or vary according to diurnal, weekly and seasonal patterns.

The best emission factor data are provided by continuous emission monitors (CEMs), which measure emissions directly and continuously. CEM data are typically available for a limited range of pollutants and processes, often at larger industrial facilities. In lieu of directly measured data, emissions for a given source may be estimated using emission factors measured from other similar sources. The U.S. EPA's AP-42 database includes emission factors for a wide range of sources; these data are available via the Internet at www.epa.gov/ttn/chief/. The actual emissions of any single source may differ considerably from the AP-42 values, and may depend on operating conditions, control equipment, and the specific characteristics of the source (age, technology, working condition). AP-42 emission factors are intended to represent the average inuse source, but may be biased because sources are typically sampled when they are in goodrepair.

For some sources, emission factors are developed using models that allow for the selection of specific source characteristics, operating schedules, and/or environmental conditions. These models include the Biogenic Emission Inventory System (BEIS), which estimates organic compound emissions from vegetation, and MOBILE for estimating on-road motor vehicle emissions.

Two important aspects of emission inventory development are (a) validation of estimates for the largest sources and (b) estimation of uncertainty. The importance of validating emissions estimates from the largest sources can be understood by considering the effect of uncertainty in large and small source estimates. A factor of 2 error in a source estimated to contribute only $1 \%$ of total emissions will have a small effect, whereas the same relative error in a source estimated to contribute $60 \%$ of total emissions will have significant consequences to the overall inventory. Uncertainty estimates provide important information when using an emission inventory for air quality modeling and help to identify sources for which the emission estimation methodology and/or data need to be improved. Development of an emission inventory for predictive air quality modeling typically involves the adjustment of a current, baseline inventory assuming some future growth or control of emissions sources. 


\section{B. The SWYTAF Emission Inventory}

EarthTech, Inc. and Air Sciences, Inc. have developed an emission inventory for the purpose of atmospheric transport and photochemical modeling of the Southwest Wyoming region (EarthTech/Air Sciences, 1998). The inventory attempts to quantify and attribute to their sources all local and upwind emissions of nitrogen and sulfur oxides $\left(\mathrm{SO}_{\mathrm{x}}\right.$ and $\left.\mathrm{NO}_{\mathrm{x}}\right)$, particulate matter with aerodynamic diameters less than 2.5 and 10 microns $\left(\mathrm{PM}_{2.5}\right.$ and $\left.\mathrm{PM}_{10}\right)$, ammonia, and volatile organic compounds (VOC). VOC emissions are speciated to consider xylene, toluene, $\alpha$-pinene and $\beta$-pinene. Nitrogen and sulfur oxides are tracked because they can contribute to acid deposition and the formation of atmospheric aerosol. Emitted particulate matter is of direct concern for visibility effects, while ammonia and the four organic compounds can react in the atmosphere to form, condense, or partition onto aerosol particles. The following paragraphs provide a brief overview of the approaches and data used to develop the SWYTAF emission inventory. Concerns about the current inventory are summarized in the following section.

\section{Stationary Point Sources}

This category includes large sources with buoyant plumes. Emissions result mainly from combustion sources including boilers, turbines, incinerators/flares, diesel engines, heaters, calciners and furnaces, i.e. sources which are typically located at industrial facilities. Sources were identified from state permits for air pollutant emissions. Facility-related emissions with non-buoyant plumes are considered as area sources; this group includes surface mines in Wyoming. The Wyoming Department of Environmental Quality provided data about major sources (>100 tons/year) and 37 minor sources permitted to operate in Wyoming. The Utah Division of Air Quality provided information about major sources in Utah. Emissions from point sources in Utah were subtracted from county-level emissions totals; the remaining countylevel emissions are treated as non-buoyant area sources. Idaho sources were identified from Idaho databases, a Pocatello regional inventory, and local industry; the initial list was reviewed and updated by the Idaho DEQ.

Actual, as opposed to permitted, emissions levels are estimated for each source. Emissions were estimated using EPA's AP-42 emission factors, continuous emission monitoring (CEM) data, and/or facility operating records. Emissions from periods of control system ineffectiveness are tracked separately as "upset" events. CEM and upset data are time-resolved; other emissions are considered constant with time. Toluene and xylene emissions are estimated as a fraction of total VOC based on the emission source or process (Table 2-3, Vol. 1, EarthTech/Air Sciences, 1998).

The bottom-up inventory of individual sources was reconciled with previous source-by-source estimates and top-down inventories of total emissions in each county.

\section{Stationary Area Sources}

These include (a) point sources at small facilities with no plume rise, (b) all anthropogenic ground-level emissions in Utah (estimated by county) and (c) ground-level emissions in Wyoming cities. The Utah county and Wyoming city inventories include emissions from motor vehicle use and retail motor fuel distribution and sale (e.g. fuel vapor loss at gas stations). Other processes include the combustion-related sources described above, mining, construction, residential wood burning, and solvent emissions from consumer goods. Emissions for many of 
the processes were estimated using EPA AP-42 emission factors and estimates of source activity. In some cases, such as with solvent emissions, activity was estimated from the known population and estimates of per-capita product use. Motor vehicle emissions were estimated by converting gram-per-mile emission factors predicted by EPA's MOBILE-5B model into gram-per-gallon factors and multiplying by the estimated amount of fuel used in each area. Utah county-level emissions were provided by Utah's Department of Environmental Protection. VOC speciation of $10 \%$ toluene and $4 \%$ xylene was assumed for county-wide VOC emissions.

\section{Petroleum Field Emissions}

This category includes all emissions related to petroleum well set-up and petroleum extraction, but does not include emissions from transmission or processing of petroleum products. The following emissions processes are represented: diesel engine use during drilling, construction, and compression of gas up to pipeline pressure; burning of gas during well development (flaring); clearing of liquids from wellheads (blowdown); flashing and dehydration. Flashing results when pressurized hydrocarbon liquids from a natural gas well vaporize as they are reduced to atmospheric pressure; this process occurs after the hydrocarbon liquids have been separated from liquid water and natural gas. Dehydration is the process of removing water vapor from natural gas after the gas has been separated from liquid water and hydrocarbon liquids; trace quantities of hydrocarbons are removed with the water vapor and later may be released to the atmosphere.

Emissions from diesel engines during well drilling were estimated using AP-42 emission factors and assumptions about engine operating time per well. $\mathrm{NO}_{\mathrm{x}}$ was estimated using the AP-42 emission rate per quantity of fuel burned. Flaring emissions were estimated by assuming a gas consumption rate, VOC content and combustion efficiency. Flashing, dehydration, and miscellaneous other production-related emissions estimates were provided by the Petroleum Association of Wyoming (PAW). Blowdown emission factors were estimated by the contractor, based on assumptions about gas pressure, composition, and production rates. The number of blowdown events per year for all wells was assumed to be the same as those at Amoco's Moxa and Wamsutter fields.

Well locations were determined from Wyoming Oil and Gas Conservation Commission (WOGCC) records. Well activity is tracked by $20-\mathrm{km}$ square grid cells. VOC emissions are speciated by process to estimate emissions of toluene and xylene; speciation data are based on measurements at Moxa and Wamsutter wells (Table 4-1, Vol. 1 of EarthTech/Air Sciences, 1998). Average emission factors from all reporting wells (PAW data) were applied to all producing wells (WOGCC data). Emissions were assumed to occur continuously, even though some of the processes occur sporadically.

\section{Mobile Source Emissions}

Mobile sources include on-road and off-road car, truck, and motorcycle use and railroad emissions. Emissions from vehicle use in urbanized areas of Wyoming and all areas of Utah are accounted for in the area source estimates described above. Separate emissions estimates were made for major roads in non-urban areas of Wyoming and for vehicle use on unpaved roads near the Wilderness areas. Major roadway and railroad emissions were assigned to a series of 4-km square grid cells. On-road vehicle emission factors (in units of gram-per-mile) were predicted 
using EPA's MOBILE-5B model and multiplied by travel estimates for each roadway segment; travel was estimated from traffic count data provided by the Wyoming Department of Transportation. Emission factors and travel were resolved by vehicle type. All motor vehicle emissions were resolved by hour of day. VOC emissions were also resolved by month to account for temperature effects. Total travel estimates are resolved by month to account for higher loads during the summer tourist season. Toluene and xylene emissions were estimated as a fraction of total VOC (see Table 1).

Emission factors for particulate matter were estimated using EPA's PART5 model, which attempts to account for particle emissions from tire wear and roadway surfaces. Similar procedures were used to estimate emissions from unpaved roads based on traffic count data from the U.S. Forest Service and AP-42 emission factors for particulate matter. Railroad emissions were estimated using EPA's AP-42 emission factors together with assumptions about fuel use rate per amount of material hauled.

\section{Biomass Burning Emissions}

An inventory of emissions from prescribed burns and wildfires was developed from records of burned acreage, estimated biomass per acre, and emission factors per amount of biomass.

\section{Biogenic VOC}

Emissions of organic compounds from vegetation were estimated using the Biogenic Emission Inventory System (BEIS2) model (Geron et al, 1994). The model requires that the user specify up to three plant species and/or forest type for each parcel of land in an area, along with a daily temperature cycle. The model includes algorithms for determining the temperature and solar radiation at various levels of a forest canopy. The model adjusts emission factors for each species according to the temperature and solar radiation exposure of the biomass. Biogenic emissions were aggregated using a grid system that was optimized to include the finest resolution in the mountainous regions of Bridger and Fitzpatrick Wilderness areas.

\section{Preliminary Evaluation of the SWYTAF Emission Inventory}

The task of developing a complete, detailed emission inventory for any area is daunting. Overall, it appears that the contractors have done a good job of identifying the major sources of pollutant emissions in southwest Wyoming and have used standard scientific approaches to estimate emissions from most processes. The current documentation provides adequate information for a third-party review of many of the methods used to develop the emissions estimates. Despite these strengths, there are a number of issues that should be considered for improvement of the emission inventory; these are outlined below.

\section{Inventory of VOC with Secondary Organic Aerosol Formation Potential}

The current modeling approach considers secondary organic aerosol (SOA) formation from only four hydrocarbon species: toluene, xylene, $\alpha$-pinene, and $\beta$-pinene. The first two are emitted primarily from anthropogenic activities while the latter two are emitted from biogenic sources. The contractor justifies the narrow focus on toluene and xylene from anthropogenic sources by citing test chamber observations that organic compounds with six or fewer carbon atoms have little propensity to form secondary organic aerosol (EarthTech, 1998; Odum et al, 1996; Odum et al, 1997). 
One problem with this approach is that anthropogenic VOC emissions, especially those which result from combustion processes, can include many organic compounds larger than xylene (which has 2 methyl groups attached to a benzene ring for a total of 8 carbon atoms). This is acknowledged in the EarthTech/Air Sciences emission inventory documentation; for example, Table 3.10 of Vol. 2 indicates that "C $\mathrm{C}_{8}+$ heavies" comprise $4.7 \%$ of VOC emitted during oil and gas production-related processes. Emissions from gasoline and diesel-powered engines can include aromatics larger than xylene, naphthalenes (two connected benzene rings with substituents), polycyclic aromatic hydrocarbons (PAH), and alkanes with 11 or more carbon atoms. These compounds have substantial potential for SOA formation, with yields comparable to, or greater than those of toluene and xylene (Odum et al, 1996; Odum et al, 1997). As an example of VOC speciation from a well-characterized combustion source, Table 1 shows the total hydrocarbon weight fractions of SOA precursors measured from on-road vehicle populations; the weight fractions assumed by EarthTech/Air Sciences are shown for comparison.

Table 1. Organic compound speciation for on-road vehicles.

\begin{tabular}{|c|c|c|c|c|}
\hline Source & $\begin{array}{l}\text { EarthTech } \\
\text { gasoline }^{\mathbf{1}}\end{array}$ & $\begin{array}{c}\text { EarthTech } \\
\text { diesel }^{1}\end{array}$ & $\begin{array}{l}\text { On-road } \\
\text { gasoline }^{2}\end{array}$ & $\begin{array}{c}\text { On-road } \\
\text { diesel }^{3}\end{array}$ \\
\hline $\mathrm{C}_{7}-\mathrm{C}_{8}$ aromatics ${ }^{4}$ & 0.14 & 0.142 & $0.16-0.19$ & $0.09 \pm 0.02$ \\
\hline $\mathrm{C}_{9}$ aromatics & - & - & $0.06-0.10$ & $0.08 \pm 0.02$ \\
\hline $\mathrm{C}_{10}+$ aromatics & - & - & $0.03-0.04$ & $0.13 \pm 0.05$ \\
\hline Naphthalenes & - & - & $0.06 \pm 0.03$ & $0.15 \pm 0.03$ \\
\hline $\mathrm{C}_{11}+$ alkanes & - & - & - & $0.18 \pm 0.06$ \\
\hline
\end{tabular}

Anthropogenic emissions of higher molecular weight organic compounds may be estimated with the same procedure used to estimate toluene and xylene emissions, i.e. by combining total organic compound emissions estimates with accurate speciation data. Care should be taken to ensure that the speciation data are relevant to the current gasoline and diesel fuels used in Wyoming since organic compound speciation depends heavily on fuel composition and properties. Application of this approach may require assumptions about sources for which full VOC speciation data are unavailable, but such assumptions are already needed to estimate toluene and xylene emissions from many sources in the current inventory. The uncertainty resulting from these assumptions should be estimated and documented in the inventory estimates. Available speciation data may understate emissions of semi-volatile compounds, since the accurate quantification of semi-volatile compounds requires additional analytical techniques beyond those typically used to speciate VOC emissions (Zielinska et al, 1996). As a result, accurate speciation data for semi-volatile compounds are available for very few sources. This lack of data creates additional, unavoidable uncertainty in modeling of SOA formation.

\footnotetext{
${ }^{1}$ Reproduced from Table 5-10 of Volume 1: CALPUFF Modeling Inventory (EarthTech, 1998).

2 Based on measurements at the Ft. McHenry (MD), Tuscarora mountain (PA), and the Caldecott (Oakland, CA) tunnels in early- to mid-1990s. These fractions represent primarily exhaust, but include some running evaporative emissions. References: Sagebiel et al, 1996; Kirchstetter et al, 1996.

${ }^{3}$ Based on measurements at the Ft. McHenry and Tuscarora mountain tunnels (Sagebiel et al, 1996).

${ }^{4}$ Includes Toluene, Xylenes, and Ethylbenzenes.
} 
The current biogenic inventory estimates emissions of $\alpha$-pinene and $\beta$-pinene, both of which have large SOA formation potential, but does not include other SOA precursors emitted by vegetation. The exclusive focus on monoterpene emissions probably results because the BEIS2 model has been developed from extensive measurements of isoprene and monoterpene emissions from varied plant species, while only limited data are available to describe and quantify other VOC emitted by plants. Nevertheless, biogenic emissions of other VOC species may contribute significantly to SOA formation. BEIS-2 includes a category called "other VOC". Some effort should be made to estimate emissions of this potentially large source of SOA precursors and to estimate the uncertainty in the inventory of SOA precursors resulting from uncertainty in estimating "other VOC" from biogenic sources.

\section{a) Biogenic VOC Emissions Estimates}

The current inventory suggests that biogenic emissions are by far the largest source of secondary organic aerosol precursors: as such, it is essential that the biogenic VOC inventory be estimated as accurately as possible. Monoterpene emission estimates of the BEIS2 model depend upon plant species, light intensity, humidity, and daily temperature profiles. The EarthTech/Air Sciences report notes that the choice of forest types can have a large effect on total emissions estimates. Table 7-3 of Vol. 1 provides emission inventory estimates based on "moderate" and "high" emission canopy scenarios; ostensibly, these result from selecting different BEIS2 categories which are thought to represent the forests in Wyoming. Domain-wide monoterpene emissions from the "high emission canopy" scenario are about three times those of the "moderate emission canopy" scenario. No results are given for a "low emission canopy" and it is unclear whether such a scenario was investigated. The current inventory appears to be based on the "high emissions" scenario, but no justification is given for this choice.

The choice of daily temperature profile is also important since monoterpene emission rates depend non-linearly on temperature (Guenther et al, 1993). Use of average winter and summer daily temperature profiles will not capture day-to-day emissions variability and may not even produce accurate estimates of seasonal-average emissions. Biogenic emissions are currently considered as a constant source, but should perhaps, be assigned some temporal variability.

Biogenic emissions of isoprene demonstrate a seasonal dependence that is not captured currently in the BEIS2 model (Goldstein et al, 1998). Isoprene emissions were not detected from deciduous trees in Massachusetts until 2 weeks after leaf out. The emissions reached a peak at 4 weeks after leaf out, then remained constant for approximately 65 days. It is not known if monoterpene emissions follow the same seasonal pattern, but the importance of a seasonal effect might be considered, especially in the modeling of springtime SOA formation.

From the discussion above (and in the inventory documentation itself), it is clear that the choice of input parameters has a potentially large effect on the biogenic emission inventory. The inventory should be based on the best estimate of the BEIS 2 categories that represent the forested areas of Wyoming. The selection of forest/species types should be documented and the uncertainty that results from this selection process should be included as uncertainty bounds around the biogenic VOC inventory. Uncertainty in the biogenic emission inventory should also reflect the uncertainty of emission factors reported for each forest, the uncertainty in land coverage for each forest type, and the uncertainty that results from daily and yearly temperature 
fluctuations. Uncertainty in the emission factors alone is estimated to be about $\pm 50 \%$ (Guenther et al., 1994, Winer et al, 1995). When compared to field measurements, BEIS2 predictions show good overall agreement but can differ by more than a factor of 2 from measured emissions at individual forest sites (Geron et al, 1994).

Isoprene is not included in the inventory of biogenic emissions because it has little observed potential for secondary organic aerosol formation. Isoprene and many of the compounds which are lumped into the "other VOC" category by BEIS2 are atmospherically reactive and can be important drivers of atmospheric photochemistry in non-urban areas. Since secondary organic aerosol formation is determined not only by aerosol yields, but also by initial reaction rates and pathways for the emitted species, estimates of biogenic isoprene and other VOC emissions are important components of the emission inventory.

b) Oil and Gas Field Emissions

SWYTAF was formed to evaluate potential air quality impacts of oil and gas industry expansion in Wyoming; emissions associated with oil and gas extraction are therefore among the most important elements of the emission inventory. Oil and gas emissions estimates should be based upon directly measured emissions and activity data from a large number of local sources. Accurate organic compound speciation is also critical, as outlined above. Radian's companion report identifies some concerns about the current inventory methodology for oil and gas emissions, although for many processes there is insufficient data provided to evaluate the methods and assumptions used. Appropriate uncertainty estimates should be included with all calculated emission factor estimates.

c) Emission Factors for Other Processes

Concerns about emissions estimates for additional sources and processes must be balanced against the estimated importance of these sources. Nevertheless, the widespread use of AP-42 emission factors and the mobile source emission factors predicted by MOBILE are both of concern. AP-42 emission factors are not of uniform quality or direct relevance to in-use emissions from any given source. The assumption of an average speed of $60 \mathrm{mph}$ on remote highway stretches probably leads to an underestimate of motor vehicle emissions, since emissions of $\mathrm{CO}, \mathrm{HC}$, and $\mathrm{NO}_{\mathrm{x}}$ all increase at speeds above $60 \mathrm{mph}$. The assumption of an average speed of $40 \mathrm{mph}$ to estimate in-city emissions will also result in an underestimate of $\mathrm{CO}$ and $\mathrm{HC}$ emissions if the actual average speed in cities in towns is much lower than $40 \mathrm{mph}$.

\section{Activity Data}

The SWYTAF emission inventory was developed for calendar year 1995 using activity data specific to that year. For some emission sources, such as wildfires, it would be wise to consider activity data from additional years to determine if emissions during 1995 were typical of other years. This is especially relevant for estimating petroleum field emissions in future years.

\section{Uncertainty}

The current emission inventory contains no formal estimate of uncertainty, despite the acknowledged uncertainty in BEIS2 estimates of biogenic emissions and the highly uncertain emission factors used to estimate emissions from many additional processes. Uncertainty estimates should be based on uncertainty in emission factors and activity data for each source 
category. For sources estimated using models, total uncertainty depends on the uncertainty in the emission factor algorithms and uncertainty in the model input data (i.e. data about source characterization and/or or operating schedules).

\section{Documentation}

It is essential that all aspects of a scientific study be well documented so that others may review the work that has been done. The current inventory documentation provides a brief description of each process (summarized above), but the actual emission factors and activity estimates are not provided in many cases. In some cases, e.g. Utah counties and some petroleum field processes, the contractors used previous emission estimates; all efforts should be made to obtain and make available a full description of the methodologies used to arrive at these emissions estimates. Many of the tables in the emission inventory documentation are poorly annotated and the headings are cryptic; efforts should be made to identify such data in a way that will be meaningful to a third party reader/reviewer.

\section{Overall Approach}

The goal of SWYTAF is to evaluate potential environmental impacts of increasing emissions related to the oil and gas industry. Uncertainty in the current emission inventory estimates for all local sources complicates the analysis of both the base case (1995) and scenarios based on projected emissions increases. One approach to dealing with uncertainty in the emission inventory is to model using lower-bound emission estimates for all other sources and upperbound estimates for oil and gas industry emissions. If increasing oil and gas emissions under such a scenario yields an insignificant decrease in air quality, then it may be argued that additional refinement of inventory estimates is unnecessary. Of course, this approach assumes use of an appropriate air quality model and the accurate assessment of upper-bound emissions estimates from oil and gas industry sources and lower-bound estimates of other sources.

\section{References}

EarthTech, Inc. (1998) Development of a Secondary Organic Aerosol Production Module. Attch 8. Record of Proceedings, SWYTAF Meeting, Casper, Wyoming, April 201998.

EarthTech, Inc. and Air Sciences, Inc. (1998) 1995 Air Emissions Within the Southwest Wyoming Regional Modeling Domain, Vols 1-3, Draft Final Report. December 1998.

Geron, C.D., A.B. Guenther, and T.E. Pierce. (1994) An improved model for estimating emissions of volatile organic compounds from forests in the eastern United States. Journal of Geophysical Research 99: D6: 12,773-12,791.

Goldstein, A.H., M.L. Goulden, J.W. Munger, S.C. Wofsy, and C.D. Geron. (1998) Seasonal course of isoprene emissions from a midlatitude deciduous forest. Journal of Geophysical Research 103: D23: 31,045-31,056.

Guenther, A.B., P.R. Zimmerman, and P.C. Harley. (1993) Isoprene and monoterpene emission rate variability: model evaluations and sensitivity analyses. Journal of Geophysical Research 98: D7: $12,609-12,617$. 
Guenther, A., P. Zimmerman, and M. Wildermuth. (1994) Natural volatile organic compound emission rate estimates for U.S. woodland landscapes. Atmospheric Environment 28: N6: 1197-1210.

Kirchstetter, T.W., B.C. Singer, R.A. Harley, G.R. Kendall, and W. Chan. (1996) Impact of oxygenated gasoline use on California light-duty vehicle emissions. Environmental Science \& Technology 30: N2: 661-670.

Odum, J.R., T. Hoffman, F. Bowman, D. Collins, R.C. Flagan, and J.H. Seinfeld. (1996) Gas/particle partitioning and secondary organic aerosol yields. Environmental Science \& Technology 30: N8:2580-2585.

Odum, J.R., T.P.W. Jungkamp, R.J. Griffin, H.J.L. Forstner, R.C. Flagan, and J.H. Seinfeld. (1997) Aromatics, reformulated gasoline, and atmospheric organic aerosol formation. Environmental Science \& Technology 31: N7:1890-1897.

Sagebiel, J.C., B. Zielinska, W.R. Pierson, and A.W. Gertler. (1996) Real-world emissions and calculated reactivities of organic species from motor vehicles. Atmospheric Environment 30: N12: 2287-2296.

Winer, A.M, L. Chinkin, J Arey, R. Atkinson, J. Adams, and J. Karlik. (1995) Critical Evaluation of a Biogenic Emission System for Photochemical Grid Modeling in California. Final Report to the California Air Resources Board, Contract No. 93-725. December 8, 1995.

Zielinska, B., J.C. Sagebiel, G. Harshfield, A.W. Gertler, and W.R. Pierson. (1996) Volatile organic compounds up to $\mathrm{C} 20$ emitted from motor vehicles; measurement methods. Atmospheric Environment 30: N12: 2269-2286. 


\section{APPENDIX VI. MODELING ATMOSPHERIC CHEMISTRY TO ESTIMATE AEROSOLS}

\section{By Nancy J. Brown}

Environmental Energy Technologies Division, Lawrence Berkeley National Laboratory Berkeley, California 94720-1740

Table of Contents

A. INTRODUCTION VI-2

B. TREatment of Chemistry IN Photochemistry Models: VI-2

C. NITRATE AND SULFATE CHEMISTRY VI-4

1. Treatment of Nitrate \& Sulfate Chemistry in the CALPUFF Modeling System. VI-4

2. Predictions of $\mathrm{NO}_{3}$ and $\mathrm{SO}_{4}^{-2}$ Chemistry in the Mount Zirkel Study. VI-5

3. Issues Related to Modeling of Sulfate and Nitrate Chemistry in Wyoming. VI-5

D. SECONDARY ORgANIC AEROSOL CHEMISTRY VI-6

1. Background. $V I-6$

2. Aerosol Yield Model of Seinfeld and Colleagues . $V I-7$

3. Biogenic SOA Precursors. VI-9

4. Treatment of SOA Formation by EarthTech $V I-9$

5. Issues Related to Modeling of SOA Formation VI-11

E. BIBLIOGRAPHY VI-13 


\section{A. Introduction}

Aerosols scatter and absorb light and thus attenuate visibility. Quantifying the attenuation so that visibility degradation might be assessed requires knowledge of the various types of atmospheric aerosols, their concentrations, and their optical properties. Aerosol size, aerosol composition, and information regarding whether or not the aerosol is hygroscopic or hydrophobic are important data for the calculation of optical properties. Given the particle size distribution and chemical composition, Mie theory allows for the calculation of aerosol optical properties after making a number of assumptions.

The CALPUFF model has been chosen by SWYTAF to help them assess the visibility changes that would result from future oil and gas exploration and production. To address visibility, CALPUFF computes quantities related to sulfate aerosols, nitrate aerosols, and secondary organic aerosols (SOA). The phrase "related to" is chosen purposefully to indicate that the model calculations do not include the determination of many of the quantities required for the calculation of optical properties and attenuation. This portion of the report provides a brief overview of what is required to estimate nitrate and sulfate concentrations and what may be required to quantify the atmospheric formation of organic aerosol from gas-phase organic compound emissions. We briefly review the manner in which chemistry is frequently treated in regulatory modeling, and cite examples of some chemical mechanisms used for photochemical modeling.

We also describe the EarthTech effort to estimate nitrate, sulfate, and SOA formation with the CALPUFF model. The discussion is given in the context of using the model results to estimate visibility degradation. Visibility and its dependence on aerosol properties are discussed elsewhere in this report.

\section{B. Treatment of Chemistry in Photochemistry Models:}

Transformation of emissions to pollutants of concern in the atmosphere involves complex chemistry that is described by chemical mechanisms that contain a number of species reacting via elementary reactions to form products. The chemical mechanism is used to generate the set of coupled rate equations that describe temporally and spatially the production and destruction of species in the atmosphere. The rate equations are solved numerically using a variety of solvers, each specific to a particular model. It is the solution of these differential equations, the so-called chemical rate equations, that requires the bulk of the computational effort in photochemical modeling.

Although our knowledge of all the pertinent elementary reactions is incomplete, there are three reaction mechanisms that are widely used to describe tropospheric photochemistry. These are the Carbon Bond IV (CB-IV), Lurmann, Carter, Coyner (LCC) and SAPRAC97 mechanisms. The primary function of these alternate representations is to describe the tropospheric chemistry of $\mathrm{NO}_{\mathrm{x}}\left(\mathrm{NO}+\mathrm{NO}_{2}\right)$ and volatile organic compounds (VOCs) involved in the photochemical formation of $\mathrm{O}_{3}$. The mechanisms have been built by using rate data for elementary reactions, devising lumping schemes based on measured rates and chemical functionality, and modeling smog chamber data determined for a variety of conditions in many laboratories. The CB-IV and LCC mechanisms each describe chemistry for approximately 50 species, whereas SAPRAC-97 includes about 100. 
Because of the extensive acid precipitation research program supported by the Federal government in the 1970s and 80s, there is considerable knowledge about emissions and atmospheric transformation of sulfur-containing compounds. Sulfur emissions include $\mathrm{SO}_{2}$ from combustion sources and reduced sulfur compounds from natural sources. This research has also contributed to our knowledge of the formation of nitrous and nitric acid from $\mathrm{NO}_{\mathrm{x}}$ emitted by combustion sources. There are quite detailed gas and aqueous phase chemical mechanisms describing the transformation of $\mathrm{SO}_{2}$ to $\mathrm{SO}_{4}{ }^{-2}$ and $\mathrm{H}_{2} \mathrm{SO}_{4}$ (sulfuric acid) as well as acidification chemistry for nitrogenous species. This chemistry is featured in grid-based models describing regional phenomena and acidification in particular. Two models frequently used are the Regional Oxidant Model (ROM2.2) and the Acid Deposition and Oxidants Model (ADOM).

Our knowledge of atmospheric chemistry is incomplete, and even the most detailed chemical mechanisms use steady-state approximations and functional lumping to treat reactivity of organic species. In the latter case, compounds that have similar structures but somewhat different reaction rates are assumed to react at an average rate, in a similar manner.

The atmospheric chemistry described here is highly coupled and highly non-linear in all cases. Much of it is based on our understanding of chemistry representative of urban environments. Selection of the most important chemical species and reactions depends upon the chemical content of the inventory. For example, in regions with a preponderance of biogenic organic compound emissions, the formation of ozone may be more influenced by isoprene reactions than by reactions involving VOC associated with mobile sources.

There are uncertainties associated with photochemical modeling in urban, rural, and regional areas. Uncertainties in chemistry result from omission of important reaction pathways from the mechanism, and insufficiently accurate kinetic data for reactions that are important. Uncertainty also results from the incomplete description of nighttime chemistry, which is responsible for a large fraction of $\mathrm{NO}_{3}$ formation.

During modeling, spatially- and temporally- dependent chemical transformations are described by solving the chemical rate equations associated with the chemical mechanism in a particular grid cell. The modeling results themselves and their validation through comparison with smog chamber data and atmospheric observations have confirmed chemistry behaves in a non-linear manner.

A striking example of the non-linearity of atmospheric chemistry can be illustrated by examining the relative roles of VOCs and $\mathrm{NO}_{\mathrm{x}}$ in ozone formation. This can be best understood in terms of competition for the hydroxyl radical $(\mathrm{OH})$. When the instantaneous $V O C / \mathrm{NO}_{\mathrm{x}}$ ratio is low, $\mathrm{OH}$ reacts predominately with $\mathrm{NO}_{2}$, removes reactive radical species, and retards $\mathrm{O}_{3}$ formation. Under these conditions, a decrease in $\mathrm{NO}_{x}$ increases $\mathrm{O}_{3}$ formation. In contrast, at a sufficiently low concentration of $\mathrm{NO}_{x}$ or a higher $V O C / \mathrm{NO}_{\mathrm{x}}$ ratio, a decrease in $\mathrm{NO}_{\mathrm{x}}$ favors peroxy-peroxy reactions. This inhibits $\mathrm{O}_{3}$ formation because it removes reactive radicals from the system. The size of the radical pool in the first case is diminished by increasing $\mathrm{NO}_{\mathrm{x}}$ and, in the second, by decreasing it. Because the removal rates of $\mathrm{NO}_{\mathrm{x}}$ and free radicals depend in a complex manner on the concentrations of VOCs and $\mathrm{NO}_{\mathrm{x}}, \mathrm{O}_{3}$ production does not increase linearly with an increase in precursor concentrations. Another important example of the nonlinearity of atmospheric chemistry is to consider the number of $\mathrm{NO}_{2}$ molecules that are 
required to produce $\mathrm{O}_{3}$ in urban, rural, and maritime environments. They are considerably different.

The $\mathrm{NO}_{3}$ (nitrate) chemistry is coupled with the $\mathrm{NO}_{\mathrm{x}}-\mathrm{O}_{3}$ chemistry and is somewhat less studied. It is dominated by nighttime chemistry, interacts with VOC chemistry, and is often heterogeneous. Needless to say, it is also non-linear.

\section{Nitrate and Sulfate Chemistry}

\section{Treatment of Nitrate \& Sulfate Chemistry in the CALPUFF Modeling System.}

CALPUFF includes an option for parameterizing chemical transformation effects using a five species scheme $\left(\mathrm{SO}_{2}, \mathrm{SO}_{4}{ }^{\circ}, \mathrm{NO}_{\mathrm{x}}, \mathrm{HNO}_{3}\right.$, and $\left.\mathrm{NO}_{3}{ }^{-}\right)$that is employed in the MESOPUFF II (Scire et al., 1984) model. It requires a set of user-specified diurnally varying transformation rates. The model contains a linear, psuedo-first order scheme to treat the chemistry. Another option is available; the RIVAD/ARM3 method treats the same species but considers $\mathrm{NO}_{x}$ as two species, $\mathrm{NO}$ and $\mathrm{NO}_{2}$, and assumes an equilibrium between gaseous $\mathrm{HNO}_{3}$ and $\mathrm{NH}_{4} \mathrm{NO}_{3}$ aerosol. User-specified diurnal concentration profiles are often used to evaluate transformation rates for the first order rate expressions. In particular, if the MESOPUFF II chemical scheme is used to simulate the following chemical transformations:

$$
\mathrm{SO}_{2} \rightarrow \mathrm{SO}_{4}^{-2} \text { and } \mathrm{NO}_{\mathbf{x}} \rightarrow \mathrm{HNO}_{3} \rightarrow \mathrm{NO}_{3} \text {, }
$$

then estimates of ambient $\mathrm{O}_{3}$ concentrations are required to compute the hourly conversion rates for these chemical transformations.

CALPUFF provides two options for the ozone data. The first uses a single, typical value for the background $\mathrm{O}_{3}$ concentration, while the second option allows for use of hourly $\mathrm{O}_{3}$ data from one or more monitoring stations. Using the second option, a 24-hour cycle of transformation rates ( 1 per hour per each transformation) is derived that is based on $\mathrm{O}_{3}$ diurnal profiles. The transformation rate expressions were obtained by statistically analyzing hourly transformation rates determined from a photochemical model. The chemical model, the $\mathrm{RHC} / \mathrm{NO}_{\mathrm{x}} / \mathrm{SO}_{\mathrm{x}}$ model of Atkinson et al (1982), was used to conduct box model calculations for a range of ambient conditions that were assumed to be representative of those spanned by a year. The results were used to determine daytime hourly conversion rates by numerical fitting. Variables considered were total solar radiation intensity, $\mathrm{O}_{3}$ concentration, an atmospheric stability index, and $\mathrm{NO}_{x}$ concentration. Calculations to evaluate the conversion rates appear to have been performed independent of local Wyoming ambient conditions. Evaluating the expressions for the transformation rates requires $\mathrm{O}_{3}$ concentrations. In the current study, $\mathrm{O}_{3}$ profiles that were measured as a function of time at four locations in Wyoming in 1995 were averaged and used as a surrogate to mimic the reactivity characteristics of the Wyoming atmosphere.

One can also choose the RIVAD/ARM3 chemical scheme to compute transformation rates that are used. In this scheme, sulfate and nitrate concentrations are calculated using steady-state expressions for $\mathrm{OH}$ and $\mathrm{O}\left({ }^{1} \mathrm{D}\right)$ (an electronically excited oxygen atom) concentrations. Wyoming photochemical flux is not calculated specifically and is only considered indirectly in the calculation of the $O\left({ }^{1} \mathrm{D}\right)$ concentration. (The steady state expression for $O\left({ }^{1} D\right)$ presented is proportional to the cosine of the solar zenith angle.) 
The aqueous-phase oxidation of $\mathrm{SO}_{2}$ to sulfates $\left(\mathrm{SO}_{4}{ }^{-2}\right)$, is assumed to have a constant rate of $0.2 \%$ per hour.

\section{Predictions of $\mathrm{NO}_{3}$ and $\mathrm{SO}_{4}{ }^{-2}$ Chemistry in the Mount Zirkel Study.}

The Mount Zirkel study was an extensive field measurement campaign that focused on apportioning the contributions of various aerosol sources to visibility degradation. Both source and receptor models were applied for source apportionment during selected episodes. Plume dispersion and conversion of

$$
\begin{aligned}
& \mathrm{SO}_{2} \rightarrow \mathrm{SO}_{4}^{-2} \\
& \mathrm{NO}_{\mathbf{x}} \rightarrow \mathrm{HNO}_{3} \rightarrow \mathrm{NO}_{3},
\end{aligned}
$$

followed by subsequent reaction of each with $\mathrm{NH}_{3}$ was used to estimate $\mathrm{NH}_{4} \mathrm{SO}_{4}$ and $\mathrm{NH}_{4} \mathrm{NO}_{3}$ aerosols with the CALMET/CALPUFF modeling system. No attempt was made to model the chemistry of SOA. The individual contributions of motor vehicles and forest fires to SOA could not be separated. For one episode, it was estimated that organic aerosols contributed $13 \pm 20 \%$ toward visibility degradation. They concluded that the CALMET/CALPUFF plume chemistry modeling system often underestimated measured PM-2.5 and extinction due to the neglect of source contributions from outside the emissions domain, inaccurate emissions estimates, and inadequate mechanisms for determining aqueous phase conversion of $\mathrm{SO}_{2} \rightarrow \mathrm{SO}_{4}{ }^{-2}$. Chemical transformations were treated (except for SOA) much as they are in the Wyoming study; the chemistry was treated as linear and first-order conversion rates were derived. Unfortunately, no temperature dependence was considered for the chemistry. The region investigated around Mount Zirkel experiences large temperature variations that will result in significant changes to the local chemical transformations. This is due to that fact that reaction rates generally depend exponentially upon temperature. This exponential temperature dependence of reaction rates is a large source of non-linearity. The conversion rate selected to describe the $\mathrm{SO}_{2} \rightarrow \mathrm{SO}_{4}{ }^{-2}$ transformation was too slow, especially for conditions when a plume passes through a fog. It is also important to note that the description of the chemistry employed was based on studies for the eastern United States.

When statistical bias (\%) was reported between measured and CALPUFF predicted

\begin{tabular}{|c|c|c|c|c|c|}
\hline otapM25 & Snfiate & Nitrate & Pinan DM-25 & $\begin{array}{l}\text { Eemental } \\
\text { istoon }\end{array}$ & $\begin{array}{l}\text { Trganc } \\
\text { erosol }\end{array}$ \\
\hline+21 to -71 & +21 to -71 & +112 to -11 & +12 to -79 & -62 to -88 & -17 to -77 \\
\hline
\end{tabular}
species concentrations, the following ranges in bias for four episodes were reported:

The average statistical bias reported here is defined as the percent difference between the CALPUFF and measured PM2.5 concentrations averages over six aerosol measurement sites and averaged over the duration of each modeling period.

\section{Issues Related to Modeling of Sulfate and Nitrate Chemistry in Wyoming.}

What is the justification for treating this complex chemistry as linear?

Modeling $\mathrm{NO}_{2}$ formation with detailed chemical mechanisms has shown that $\mathrm{NO} / \mathrm{NO}_{2}$ ratios vary substantially temporally and well as spatially. It is important to capture this variation in the model since $\mathrm{NO}_{2}$ reactivity is critical in atmospheric chemistry and its 
rate is important for determining the $\mathrm{NO}_{\mathrm{y}}$ chemistry. (The designation $\mathrm{NO}_{\mathrm{y}}$ is used to denote the total reactive nitrogen pool.) $\mathrm{NO}_{\mathrm{y}}$ chemistry is important in aerosol and acidification chemistry, as well. What is the justification for not describing the $\mathrm{NO}_{\mathrm{y}}$ formation chemistry in a detailed manner? What are the implications of the very simplified treatment of chemistry?

Many reaction rates are highly temperature dependent, and the dependence is most frequently exponential (highly non-linear!). The model is being run to simulate a full year's conditions and during a calendar year in Wyoming there are wide variations in temperature. What is the justification for not including the temperature dependence of all reaction rates in the model? What are the implications of this?

Sulfate chemistry is based on a box model derived for conditions representative of the eastern United States. What is the justification for treating the $\mathrm{SO}_{2}$ transformation processes in Wyoming using "eastern" chemistry? What are the implications of this approximation?

Why was relatively old chemistry (1982) used in the box model calculations? Our understanding of atmospheric chemistry has advanced significantly since then; why not use a more modern chemical mechanism?

What is the state of knowledge regarding emitted and ambient $\mathrm{NH}_{3}$ concentrations in the modeling domain? What are the anticipated uncertainties in the ambient $\mathrm{NH}_{3}$ concentration? How do the uncertainties affect modeled concentrations of $\mathrm{NH}_{4} \mathrm{NO}_{3}$ and $\mathrm{NH}_{4} \mathrm{SO}_{4}$ aerosols?

\section{Secondary Organic Aerosol Chemistry}

\section{Background}

Formation of SOA is important because it has been estimated that SOA can contribute up to $50 \%$ of particle mass in urban areas. The contribution of SOA to particle mass in rural areas is not well characterized, but has been shown to be significant in the region surrounding Atlanta. The aerosol mass yield is the fraction of the reacted organic that has formed aerosol mass. Yield formulae for secondary aerosols can be used to provide estimates of the mass of secondary organic aerosol if there are robust data regarding organic mass emissions, their speciation, and a chemical description regarding their atmospheric reactivity. However, when samples of SOA are analyzed for chemical composition only, 20-30\% of the compounds are identified. Moreover, there have been few studies of SOA formation and aerosol mass yields and these frequently are based on compounds believed to be important in the Los Angeles emission inventory and to mobile source emissions, in particular. Therefore, our current knowledge of organic aerosols is at a primitive stage. Furthermore, our knowledge of the optical properties of these organics is seriously deficient. Therefore, it is quite a leap of faith to go from aerosol mass data to visibility. Since this is done in the current modeling effort in SW Wyoming, a brief review of aerosol yield modeling is presented.

In contrast with nitrate and sulfate, our knowledge of the chemistry of secondary organic aerosol (SOA) formation is not well understood. Aerosol formation modeling requires more than a chemical description because aerosol formation and growth involves many physical processes, including nucleation (gas-to-particle conversion), coagulation, condensation/evaporation, and the partitioning of organic compounds between the 
particle (liquid) and gas-phases. Aerosol concentrations are also affected by emissions of primary particles and removal through wet and dry deposition processes. SOA production from a given VOC depends on: (1) the abundance and reactivity of the given compound; (2) the abundance of radicals in the atmosphere; (3) the nature of its reaction pathways; (4) the volatility and gas-to-particle partitioning properties of its products; (5) the ambient aerosol mass concentration; and (6) temperature.

There are two separate steps involved in the production of secondary organic aerosol. In the first step, the organic aerosol compound is emitted and/or produced in the gas phase from reactions of a parent compound with other species. Important species that most frequently react with organic species are $\mathrm{OH}, \mathrm{O}_{3}$, and $\mathrm{NO}_{3}$. Next, the organic compound product partitions between the gas and particle phases, forming secondary organic aerosol. The partitioning is a physicochemical process that may involve interactions among the various compounds present in both phases. An accurate model of SOA would include a complete description of all the gas phase and heterogeneous reactions as well as the correct description of the gas-to-particle conversion processes. Included also would be the many physicochemical parameters involved in partitioning complex mixtures between two (or perhaps three) phases.

An SOA formation model that ultimately would be used to compute visibility should be able to predict size/composition relationships, hygroscopicity, and shape because these characteristics affect the optical properties. Simple yield formula, if applied appropriately, would reveal the extent to which the gas phase organic is converted to aerosol. To apply the yield formulae in a reacting atmosphere would require that rate equations be solved for the organic compound. Reactions of the oxidizing species with organic compounds lead to the formation of other organics that subsequently react with the oxidizing species. Hence, evaluation of aerosol yield would require the solution of the species rate equations where the aerosol model is coupled to the gas phase chemistry to compute the total organic reactivity as a function of time.

\section{Aerosol Yield Model of Seinfeld and Colleagues}

Research by Seinfeld, Flagan, and colleagues at Caltech has resulted in a simplified model for SOA formation. The model is based on smog chamber studies involving single hydrocarbons, simple mixture of hydrocarbons, and more complex mixtures consisting of the vapors from research grade gasolines. Smog chamber data are fit with the following expression

$$
Y=\frac{\Delta M_{o}}{\Delta R O G}
$$

where $\Delta \mathrm{M}_{\mathrm{o}}$ and $\triangle \mathrm{ROG}$ are the amounts of organic aerosol mass formed and reactive organic gas (ROG) reacted, respectively. This formula is useful in determining the amount of aerosol mass that is formed when a given amount of ROG reacts. A second formula has been derived that is useful for individual compounds.

$$
Y=M_{o} \sum_{i} \frac{\alpha_{i} K_{i}}{1+K_{i} M_{o}}
$$


The yield, $Y$, is not constant but is a function of, $\mathrm{M}_{\mathrm{o}}$, the organic aerosol mass concentration; $\alpha_{\mathrm{i}}$, the mass-based stoichiometric coefficient for the reaction generating product "i"; and $K_{i}$, the partitioning coefficient for distribution of product between the gas and aerosol phases. This formula is useful when the organic compound forms both volatile and non-volatile products. If the partitioning constant for product " $i$ " is large, the dependence on $\mathrm{M}_{\mathrm{o}}$ cancels, and the equation for yields is just the sum of the $\alpha_{\mathrm{i}}$ for the various products.

Experience with the smog chamber results revealed that $\mathrm{i}=2$ is adequate for each compound and that the fitting parameters $\left(\alpha_{1}, \mathrm{~K}_{\mathrm{oml}}\right)$ and $\left(\alpha_{2}, \mathrm{~K}_{\mathrm{om} 2}\right)$ are determined by minimizing the squared residuals between the data and theoretical line generated by the equation. In other words they are not physical constants associated with physicochemical processes, but are fitting parameters. The so-called gas-particle partitioning coefficients do, however, correlate with vapor pressures in the semi-volatile range and the $\alpha$ 's have some relationship to chemical stoichiometry in the smog chamber. The two sets of parameters are highly dependent on conditions in the smog chamber. This so-called twoproduct formula was found suitable for 17 individual aromatic species and 8 individual biogenic species based on over 100 smog chamber experiments. The chemical composition of the air in the smog chamber experiments was typical of urban conditions.

Studies with binary mixtures showed that the yield formula derived individual species in a mixture could be used to determine the mass of the organic aerosol formed. The two contributions to organic aerosol mass, when added, summed to the amount of total aerosol mass.

Studies with the complex mixture gasoline showed that the organic aerosol mass $\left(\mathrm{M}_{\mathrm{o}}\right)$ correlated with the aromatic content of the gasoline. Separate experiments were required to determine the yield values corresponding to the amount of SOA formed for the individual parent compounds found in gasoline. The yield values were then multiplied by the reacted amount of parent aromatic to estimate the amount of SOA attributable to each aromatic parent species. Summing these values for all aromatics in a given fuel for a specific experiment gave a quantitative estimate of the amount of SOA that was produced by the aromatic fraction of the fuel.

Use of this concept to determine secondary organic aerosol formation in the atmosphere requires knowledge of the following:

1) The concentrations of individual organic compounds, which contain more than 6 carbon atoms,

2) The amount of each ROG that has reacted as a function of time, and

3) Yield formula for each organic compound; the yield relationships should be determined in experiments that mimic the atmospheric chemistry of interest. This is crucial because the yield formula is strongly influenced by the ambient chemistry.

Seinfeld and colleagues were able to explain their observations of SOA formation with an absorption model for the situations considered, which involved fairly high organic 
loading. Pankow describes models for both absorptive and adsorbtive partitioning with the latter being more relevant for small organic loading.

\section{Biogenic SOA Precursors}

Anthropogenic emissions of hydrocarbons include alkanes, alkenes, aromatics, and carbonyls. Biogenic emissions from trees and plants include terpenes and sesquiterpenes. Biogenic emissions are dependent on the plant demography of the ambient terrestrial biosphere and are very seasonally dependent. Currently most information concerning biogenics is associated with isoprene, which is a major product of deciduous tree emissions. Emissions of isoprene (2-methyl-1,3-butadiene) by terrestrial vegetation provide the dominant input of reactive non-methane hydrocarbons to the atmosphere. Isoprene influences tropospheric chemistry on the regional scale, but it does not form SOA. In contrast, pinenes form SOA resulting from their reactions with $\mathrm{OH}, \mathrm{O}_{3}$, and $\mathrm{NO}_{3}$ and have the potential to contribute greatly to $\mathrm{SOA}$ in areas with high vegetation coverage. The identity and the characteristics of biogenic emissions in environments characteristic of the rural west have received little study.

Biogenic organic emissions appear to have large aerosol formation potentials and react with $\mathrm{OH}, \mathrm{O}_{3}$, and $\mathrm{NO}_{3}$. Because concentrations of these three species in the ambient rural environment are different from those in urban environments, the fitting parameter values $\left(\alpha_{i}, K_{i}\right)$ appropriate to Wyoming will be quite different from those obtained from the smog chamber experiments. Calculating new and accurate values of the fitting parameters will require knowledge of the reaction pathways in the rural environment and accurate values of the concentrations of $\mathrm{OH}, \mathrm{O}_{3}$, and $\mathrm{NO}_{3}$. Moreover, in analogy with the gasoline experiments, the total amount of biogenic ROG that reacts as a function of time must be known.

\section{Treatment of SOA Formation by EarthTech}

In treating SOA formation, EarthTech built a model that is based on the following assumptions:

\section{Only select VOCs with carbon numbers greater than 6 significantly contribute to secondary aerosol mass.}

Comment: This has been established in a number of studies.

Concern: Their current model includes only toluene, xylene, and $\alpha$ - and $\beta$-pinene.

\section{VOC emissions of only-aerosol producing organic gases (APOGs) need be modeled.}

Concern: Only a few (relative to the potentially large number) of APOGs have been identified.

Comment: In the chemical analysis of organic aerosols, no more than $20 \%$ of the constituent species have been identified with chemical analysis. The list of organics that produce SOA is woefully incomplete. Semi-volatile compounds have a high propensity for aerosol formation and are also difficult to measure. There are most likely (based on studies elsewhere) large concentrations of biogenics and oil field hydrocarbon emissions that are semi-volatile. To infer that they are only modeling the chemistry of APOGs is incorrect. They are treating a limited number of APOGs. Furthermore, we do not know what the APOGs for Wyoming are. Although there have been extremely modest efforts, 
characterization studies of more complex (than monoterpenes) biogenics and semivolatile compounds with respect to their potential for aerosol formation have not been conducted. It is important to note that yield formula are not developed for higher molecular weight (semi-volatiles and non-volatiles) that might be found in oil field emissions and that may contribute to SOA formation.

\section{A two-parameter absorption aerosol yield model is suitable to model APOG yields as functions of environmental conditions such as temperature, ozone, and solar radiation.}

Concern: There have been limited applications of the two-parameter model and these have been in highly controlled laboratory (smog-chamber) environments.

Comment: The smog chamber experiments have treated pure compounds, binary mixtures, and mixtures of gasoline vapors. This two-product model has not been extended to, or demonstrated to be reliable for, the atmosphere. Seinfeld and colleagues indicate that such a model concept would require a description of the gas phase chemistry as well. Also, large classes of compounds have not been evaluated with respect to their conformity to the model. Furthermore, it would appear that EarthTech misinterprets the two-product model. The two sets of parameters that are used to describe aerosol yield from a given hydrocarbon parent are determined by numerically fitting smog chamber results. Seinfeld and colleagues indicate that the $\mathrm{K}$ parameters have magnitudes comparable to those observed for partitioning coefficients; however, the authors clearly state that the $\mathrm{K}$ values are developed from curve fits, and should not be interpreted as physical constants. The EarthTech model considers the K's as partition coefficients rather than numerical fitting coefficients. It is critical to note that adsorption pathways to SOA formation may also be important in Wyoming.

\section{A limited number of yields may be specified for a limited number of environmental conditions to produce a first order SOA production term.}

Concern: This has not been demonstrated.

Comment: See previous discussion of SOA chemistry. A two-product yield formula is needed to estimate SOA formation from each organic compound in the inventory with Cnumber greater than 6 carbon atoms. The yield formula must be combined with a robust chemical mechanism describing chemistry in the gas phase, and the rate equations must be solved to determine the amount of parent organic compound that has reacted. Proper initial conditions and emissions must also be provided. The chemistry is complex and non-linear; hence, first order treatments are invalid.

\section{Background Free Particle Mass (FPM) is specified by air mass category and CALPUFF inputs (e.g., ozone, temperature, solar radiation).}

Concern: The organic aerosol mass, $\mathbf{M}_{0}$, is used to represent the amount of aerosol produced from the specific organic compound in eqn. 1 (Odum et al., 1996. ES\&T, 25802585), but represents the total organic aerosol mass concentration in Eqns. 3, 6, and 7. In their discussion following Eq.(7), they state "...for low organic mass concentrations and for products that have relatively small partitioning coefficients, the SOA yield will be directly proportional to the total aerosol organic mass concentration, $\mathbf{M}_{0}$ ".

Comment: The relationships required to obtain the appropriate FPM as a function of CALPUFF inputs have not been developed and reported in the scientific literature. 


\section{APOGs may be lumped into a half dozen or so categories based on APOG conversion rate and dependency of yield on FPM.}

Concern: This has neither been hypothesized nor confirmed in any of the studies of the aerosol yield model.

Comment: EarthTech partitions the aromatic species as toluene-type and xylene-type species. Toluene and xylene are important organic species in urban environments due to their significant emissions from mobile sources. There has been no attempt to partition the inventory to reflect the volatile and semi-volatile compounds that might be more representative of a rural environment and of oil and gas exploration and production activities. If the biogenic source terms (emissions) are large in the area, it is reasonable to assume that they will contribute to SOA. The tree population, tree type, other vegetation populations, types and emissions must be known. Furthermore, recent research in the Western United States has revealed that biogenic emissions are dependent on both the temperature and water content of the atmosphere.

\section{The concentrations of $\mathrm{OH}, \mathrm{O}_{3}$, and $\mathrm{NO}_{3}$ are modeled with steady state approximations and by assuming linear chemistry.}

Concern: These extremely simplified assumptions may not be acceptable.

Comment: We have discussed how concentrations for these species are estimated in the Wyoming study. OH concentration is computed from a steady state expression, $\mathrm{O}_{3}$ from averages of measured data, and $\mathrm{NO}_{3}$ from a linear expression involving a conversion rate that depends on $\mathrm{O}_{3}$ concentration. No justification for these approximations is provided. These quantities are generally determined from the solution of detailed rate equations of a grid-based photochemical model. Knowing how much parent organic compound reacts with each of the three pathways is important because $\triangle R O G$ must be known for each of the pathways to determine the yields

\section{Sets of parameters determined in the Seinfeld et al. experiments may be used after scaling them with factors depending on the solar radiation, water vapor concentration, temperature, and gas concentrations.}

Concern: There is no scientific justification for attributing fitting parameter characteristics that depend on physics and chemistry.

Comment: It is extremely difficult to justify such approximations. Two product model parameters are fitting parameters that are determined in smog chamber experiments representative of urban atmospheric environments. New experiments should be performed in representative rural environments. The various factors representing variables that might influence the fitting parameters (concentrations, light intensity, etc.) have not been identified and their relationship to the fitting parameters is not currently understood.

\section{Issues Related to Modeling of SOA Formation}

\section{Lumping:}

Frequently, emission inventories are partitioned to "match", in some sense, the lumping scheme of the chemical mechanism. For example, if one were to use the CB-IV mechanism, the lumping would be of one sort because the lumped chemistry would be of a particular form. However, if one were to use LCC, the partitioning and lumping would 
be different as would also be for the case for SAPRAC chemistry. Since CB-IV is not being used to describe atmospheric VOC reactivity, why is it appropriate to use the CBIV partitioning approach for the VOCs? What are the implications of adopting this approach?

What are the consequences of the assumption made regarding partitioning the organics into toluene- and xylene-type species and partitioning the biogenics into pinenes? How uncertain are their concentrations? How much of the total SOA can be accounted for by these compounds? How does one know that they are in some sense representative? How reliable are their yield formulae?

\section{Two-Product Model:}

Will the two-product model, which has been demonstrated for smog chamber experiments, be relevant for estimating SOA in a rural atmosphere?

If we assume that we can use the two-product model, we must be able to partition the inventory. How do we apply the model in Wyoming where speciation data are not available?

We must also have the relevant sets of parameters for the hydrocarbon (mostly) aromatic species in the atmosphere. What experiments must be performed to acquire these data?

What are the two-product model yield parameters for the semi-volatile hydrocarbon compounds that are typical of oil field emissions? There are no data for these. Is the model relevant for them? How might their contribution to SOA be evaluated for Wyoming?

How will chamber studies that simulate biogenic loading and oxidant $\left(\mathrm{OH}, \mathrm{O}_{3}, \mathrm{NO}_{3}\right)$ concentration typical of urban environments be used to model yields from biogenics in rural environments? The biogenic concentrations are different and the ambient oxidant levels are different. Even though the reactions are the same, the differences in concentrations give rise to different rates and different yields. How does this affect SOA prediction in Wyoming?

\section{Chemical Transformations:}

Aromatics tend to react only with $\mathrm{OH}$ in the atmosphere. What about other hydrocarbons like terpenes (i.e., biogenic emissions) and the semi-volatiles that react with $\mathrm{OH}, \mathrm{O}_{3}$, and $\mathrm{NO}_{3}$ ? What are the sources of kinetic and thermodynamic data for these compounds?

In the CALPUFF treatment of SOA, the transformations of organic species due to gas phase chemical reactions are only treated with the reactants $\mathrm{O}_{3}, \mathrm{OH}$, and $\mathrm{NO}_{3}$ assuming linear chemistry. What is the justification for not describing the VOC oxidation chemistry in a detailed manner as suggested by Seinfeld and colleagues when they suggest that their model might be extensible to the atmosphere? This is required so that the $\triangle R O G$ may be determined. What are the implications of this approximation on SOA yields? 


\section{E. Bibliography}

Atmospheric Chemistry and Physics From Air Pollution to Climate Change, Seinfeld, J.

H., and Pandis S. N., John Wiley and Sons, New York, 1997

Wyoming's Long Term Strategy For Visibility Protection 1997 Draft Review Report,

Wyoming Department of Environmental Quality, Air Quality Division, April 1997

Southwest Wyoming Air Quality Study Proposal, Wyoming Department of

Environmental Quality, Air Quality Division, May 1997

Emerging Resources of Wyoming Air Quality Issues, Impacts, \& Technology

Opportunities, Barlow \& Haun, Inc., Klym, D., and Doelger, M. J., October, 1998.

Chemistry of Aromatic Hydrocarbons: Secondary Organic Aerosol Formation, Seinfeld, J. H., Odum, J. R., Forstner, H. J. L., Andino, J. M., Jungkamp, T. P. W., Griffin, R., and Flagan, R. C., Report to Coordinating Research Council, November 1997

1995 Air Emissions Within The Southwest Wyoming Regional Modeling Domain (Draft

Report 2/98), Air Sciences Inc., EarthTech, Concord, MA

Record of Proceedings, SWYTAF Meeting, Casper, Wyoming, April 1998

A User's Guide for the CALMET Meteorological Model (vs. 5.0) Draft, Scire, J. S., Robe, F. R., Fernau, M. E., and Yamartino, R. J., EarthTech, Inc., June 1998

A User's Guide for the CALPUFF Dispersion Model (vs. 5.0), Draft, Scire, J. S., Strimaitis, D. G., and Yamartino, R. J., EarthTech, Inc., June 1998

Atmospheric Chemistry of VOCs and NOx, 1998 NARSTO Assessment - Critical Review, Atkinson, R., Air Pollution Research Center, Department of Environmental Sciences and Department of Chemistry, UC Riverside, August 1998

SAPRAC-97: State Air Pollution Research Center for Atmospheric Chemistry. Webpage, University of California Riverside, Ce-Cert.

A Critical Review of Regulatory Air Quality Modeling For Tropospheric Ozone, Roth, P. M., Tesche, T. W., and Reynolds, S. D., American Petroleum Institute, September 1998

Peer Review of The CALMET/CALPUFF Modeling System, Allwine, K. J., Dabberdt, W. F., and Simmons, L. L., September 1998

Record of Proceedings, SWYTAF Meeting, Cheyenne, Wyoming, October 1998

Record of Proceedings, SWYTAF Meeting, Casper, Wyoming, December 1998

Seasonal Course of Isoprene Emissions From A Midlatitude Deciduous Forest, Goldstein, A. H., Goulden, M. L., Munger, J. W., Wofsy, S. C., and Geron, C. D., J. Geophysical Research 103, (D23) 31,045, December 1998

Current Source Groupings, Final Model Output, Department of Environmental Quality, (Memo), December 1998

A Photochemical Kinetics Mechanism for Urban and Regional Scale Kinetics Modeling. Gery, M. W.; Whitten, G. Z.; Killus, J. P.; Dodge, M. C. J. Geophys. Res., 1992, 94, 12925-12956. 
A Surrogate Species Chemical Reaction Mechanism for Urban-Scale Air Quality Simulation Models. Lurmann, F. W.; Carter, W. P. L.; Coyner, L. A. ERT Inc., Newbury Park, CA and Statewide Air Pollution Research Center, University of California, Riverside, CA, 1987. Report to the US Environmental Protection Agency under contract 68-02-4104.

Odum, J.R., T. Hoffman, F. Bowman, D. Collins, R.C. Flagan, and J.H. Seinfeld. (1996) Gas/particle partitioning and secondary organic aerosol yields. Environmental Science \& Technology 30: N8:2580-2585.

Odum, J.R., T.P.W. Jungkamp, R.J. Griffin, H.J.L. Forstner, R.C. Flagan, and J.H. Seinfeld. (1997) Aromatics, reformulated gasoline, and atmospheric organic aerosol formation. Environmental Science \& Technology 31: N7:1890-1897.

Pankow, J.F. (1987) Review and comparative analysis of the theories of partitioning between the gas and aerosol particulate phases in the atmosphere. Atmos. Environ., 21, 2275-2283. 


\title{
APPENDIX VII: A COMPARISON OF CALPUFF WITH GRID-BASED MODELS
}

\author{
By Philip Roth \\ Envair, 836 Fawn Dr., San Anselmo, CA 94960
}

CALPUFF, developed by EarthTech, has been selected as the model of choice for simulating visibility impairment as a function of location and time throughout the area in which oil and gas exploration is occurring. As the model is not commonly used for situations of this type, we thought it appropriate to inquire about the rationale behind its selection. The information that we were able to obtain was undocumented, ambiguous, and not definitive. Consequently, we sought to pursue another approach for evaluating the selection: comparing the attributes of a commonly used gridbased, photochemical model with CALPUFF and appraising their differences. We have done so in tabular form (see Table I).

The primary differences of concern that were identified are the following:

- CALPUFF is designed to model large point sources. While it is also applied to aggregates of point sources (i.e., area sources), it is less well suited for such applications than the traditional grid-based model. In southwestern Wyoming, "build-out" scenarios include up to 10,000 individual sources. Grid models are designed to address this type of source situation; CALPUFF really is not.

- Grid models were designed and are applied to situations in which the treatment of gas phase chemistry is a primary feature of the dynamic system in which pollutants are formed in the atmosphere. They address chemistry through simulation of dynamics using a detailed chemical mechanism. In contrast, CALPUFF is primarily a multi-source plume model that treats transport downwind and dispersion along the transport path. The representation of gas phase chemistry is highly simplified - linearization and parameterization of the chemical relationships. These simplifications are often deficient when applied to situations in which complex chemistry dominates the processes responsible for formation of secondary air pollutants.

- Grid models provide a framework for accommodating more fundamental treatment of aerosol dynamics and gas phase chemistry. CALPUFF cannot incorporate such treatments; instead, derived correlations may be used. Generally, these are less able to describe the dynamic behavior of aerosol formation.

- Application of CALPUFF in southwestern Wyoming entails the modeling of a large number of plumes, which inevitably will display many cases of overlap. The chemistry of overlapping plumes is not treated directly in CALPUFF - or for that matter in any model. However, the plume orientation of CALPUFF does not confer any advantage in this regard.

Table I presents a number of other comparisons of model attributes. However, those briefly discussed here raise serious questions about the appropriateness of adopting CALPUFF for use. We suggest that this issue be referred to the contractor and the technical committee for consideration and comment. 


\section{COMPARISON OF CALPUFF AND GRID MODEL FORMULATIONS}

\begin{tabular}{|c|c|c|c|}
\hline $\begin{array}{l}\text { ATTRI- } \\
\text { BUTE }\end{array}$ & CALPUFF & GRID MODEL & DIFFERENCES AND IMPLICATIONS \\
\hline $\begin{array}{l}\text { Model } \\
\text { formulation }\end{array}$ & $\begin{array}{l}\text { Time-varying Gaussian } \\
\text { puff formulation is } \\
\text { intended to simulate the } \\
\text { transport of emissions from } \\
\text { point sources. Approach is } \\
\text { feasible only if gas and } \\
\text { aerosol chemistry are } \\
\text { linearized, a restrictive } \\
\text { assumption. Acceptability } \\
\text { of assumption should be } \\
\text { demonstrated prior to any } \\
\text { application. Grid structure } \\
\text { is imposed on model to } \\
\text { facilitate use of grid- } \\
\text { averaged meteorological } \\
\text { and emissions fields. }\end{array}$ & $\begin{array}{l}\text { Modeling involves solution } \\
\text { of the time-averaged } \\
\text { primitive equations that } \\
\text { govern atmospheric } \\
\text { dynamics. Emissions are } \\
\text { summed within a grid cell } \\
\text { and thus treated as area } \\
\text { sources. Large point sources } \\
\text { may be treated separately } \\
\text { using a sub-grid scale plume } \\
\text { model. }\end{array}$ & $\begin{array}{l}\text { CALPUFF is a point-source-oriented formulation that is applied to a large array of point } \\
\text { sources of limited emissions rate and spatial scale. However, many of the point sources } \\
\text { are clustered into area sources. Area sources are assumed to emit at ground level, even } \\
\text { though, for oil and gas fields, they comprise point sources emitting at various elevations } \\
\text { above the ground. } \\
\text { In a grid model, point sources may emit into the layer consistent with their estimated } \\
\text { plume rises. Historically, large point sources are treated individually using a plume-in- } \\
\text { grid model. Other point sources are aggregated as area sources, emitting at the surface. } \\
\text { While the latter assumption is not necessary, it is usually made for expediency. } \\
\text { In CALPUFF, the treatment of gas and aerosol phase chemistry must be simplified } \\
\text { (linearized) to facilitate its use. This is in strong contrast to the grid model, which } \\
\text { accommodates the "best available" representation of the chemistry. } \\
\text { When applied to a chemically reactive atmosphere, a grid model generally relies on fewer } \\
\text { and less severe assumptions than does CALPUFF. }\end{array}$ \\
\hline $\begin{array}{l}\text { Gas phase } \\
\text { chemistry }\end{array}$ & $\begin{array}{l}\text { A simplified chemical } \\
\text { mechanism has been } \\
\text { adopted for use. Linear- } \\
\text { ized relationships are } \\
\text { developed between rates of } \\
\text { pollutant reaction and } \\
\text { ambient concentrations and } \\
\text { are included in the model. } \\
\text { Substantial simplifications } \\
\text { are required. }\end{array}$ & $\begin{array}{l}\text { A lumped or detailed } \\
\text { chemical mechanism is } \\
\text { included in the model, } \\
\text { permitting best available } \\
\text { (nonlinear) representation of } \\
\text { chemistry. }\end{array}$ & $\begin{array}{l}\text { Where two categories of primary pollutants are precursors to the formation of a secondary } \\
\text { pollutant, reduction in ambient concentrations of the secondary pollutant is best achieved } \\
\text { by reducing emissions of the limiting pollutant. One then expects the relationship } \\
\text { between the secondary and excess pollutants to be nonlinear. The grid model readily } \\
\text { accommodates this; CALPUFF cannot, except through linearization. This simplification } \\
\text { may be suitable for certain limited conditions, but probably not for many conditions of } \\
\text { interest. }\end{array}$ \\
\hline $\begin{array}{l}\text { Aerosol } \\
\text { chemistry }\end{array}$ & $\begin{array}{l}\text { The linearization } \\
\text { requirement imposed by } \\
\text { the model formulation } \\
\text { limits severely the nature } \\
\text { of representation of aerosol } \\
\text { chemistry that is feasible. }\end{array}$ & $\begin{array}{l}\text { In principle and in practice, } \\
\text { the grid model can } \\
\text { accommodate more } \\
\text { fundamental and detailed } \\
\text { representations of chemical } \\
\text { dynamics. In reality, } \\
\text { however, knowledge of many } \\
\text { reactions is still limited. }\end{array}$ & $\begin{array}{l}\text { The grid model provides a framework for accommodating more fundamental treatment of } \\
\text { aerosol dynamics and gas phase chemistry. CALPUFF cannot incorporate such } \\
\text { treatments; instead, derived correlations may be used. Generally, well developed } \\
\text { correlations apply for the range of conditions under which the relationships were } \\
\text { developed, but not for conditions outside the range. The "real" significance of actual } \\
\text { differences in approach is unclear at this time. } \\
\\
\text { Effort is being made to include in CALPUFF chemical correlations developed by Seinfeld } \\
\text { and co-workers that are intended as surrogates for more fundamental representations. }\end{array}$ \\
\hline
\end{tabular}


COMPARISON OF CALPUFF AND GRID MODEL FORMULATIONS

\begin{tabular}{|c|c|c|c|}
\hline $\begin{array}{l}\text { ATTRI- } \\
\text { BUTE }\end{array}$ & CALPUFF & GRID MODEL & DIFFERENCES AND IMPLICATIONS \\
\hline $\begin{array}{l}\text { Treatment of } \\
\text { emissions }\end{array}$ & $\begin{array}{l}\text { In SW Wyoming, about } \\
5000 \text { oil and gas wells are } \\
\text { presently emitting. Large } \\
\text { point sources are simulated } \\
\text { individually; all other } \\
\text { sources are treated as } \\
\text { gridded area emissions. } \\
\text { Emissions heights for large } \\
\text { point sources are } \\
\text { calculated using available } \\
\text { stack data. Area source } \\
\text { emissions are released at } \\
\text { ground level. }\end{array}$ & $\begin{array}{l}\text { For most sources, emissions } \\
\text { within each grid cell are } \\
\text { summed. "Average" plume } \\
\text { height can be calculated by } \\
\text { weighting individual plume } \\
\text { heights by emissions rates } \\
\text { prior to averaging. } \\
\text { Typically, however, } \\
\text { emissions from small point } \\
\text { sources are assumed to be at } \\
\text { ground level. Larger sources } \\
\text { are assigned plume rises and } \\
\text { injected at the appropriate } \\
\text { vertical level. } \\
\text { The largest point sources can } \\
\text { be treated individually, with } \\
\text { their emissions placed in the } \\
\text { appropriate elevated layer. }\end{array}$ & $\begin{array}{l}\text { A grid model can allocate emissions to appropriate cells and layers. However, the } \\
\text { averaging process results in "lost information". In principle, CALPUFF can track each } \\
\text { plume thereby providing a superior representation of emissions location. In practice, } \\
\text { however, most oil and gas sources are aggregated at the scale of the grid cell and emitted } \\
\text { at the surface. } \\
\text { In general, to the extent that a meteorological representation is inaccurate, the accuracy of } \\
\text { placement of emissions is diminished. Thus, the emissions representation of each } \\
\text { formulation is only as good as the weaker of the meteorological and emissions } \\
\text { representations. } \\
\text { In estimating future emissions, each individual source must be "projected". Agency and } \\
\text { industry staff suggest that projections may be required for as many as } 5000 \text { additional } \\
\text { sources. Developing emissions estimates and addressing uncertainty for a large number } \\
\text { of sources, if done well, is likely to be a challenging task. Plans for developing } \\
\text { projections for future gas and oil sources are unclear. }\end{array}$ \\
\hline $\begin{array}{l}\text { Overlapping } \\
\text { plumes }\end{array}$ & $\begin{array}{l}\text { Proper treatment of } \\
\text { overlapping plumes and } \\
\text { their chemistry is not } \\
\text { readily accomplished using } \\
\text { a puff model. Because } \\
\text { there are many plumes in } \\
\text { the modeling region, this } \\
\text { limitation may be quite } \\
\text { significant. }\end{array}$ & $\begin{array}{l}\text { Plume treatments in grid } \\
\text { models do not account for } \\
\text { overlapping plumes. Mixing } \\
\text { all sources in a cell does not } \\
\text { address the need either. }\end{array}$ & $\begin{array}{l}\text { Both types of models treat this situation inadequately. Further work is needed to } \\
\text { determine the severity of the problem associated with each type of model and to develop } \\
\text { more satisfying representations. We are told that EarthTech is attempting to address this } \\
\text { need through the introduction of additional algorithms. }\end{array}$ \\
\hline
\end{tabular}




\section{COMPARISON OF CALPUFF AND GRID MODEL FORMULATIONS}

\begin{tabular}{|c|c|c|c|}
\hline $\begin{array}{l}\text { ATTRI- } \\
\text { BUTE }\end{array}$ & CALPUFF & GRID MODEL & DIFFERENCES AND IMPLICATIONS \\
\hline Wind shear & $\begin{array}{l}\text { CALPUFF follows a puff } \\
\text { or cloud and treats effects } \\
\text { of wind shear through the } \\
\text { use of the local wind } \\
\text { velocity at the puff } \\
\text { centroid. CALPUFF } \\
\text { includes an option that } \\
\text { allows a vertically well- } \\
\text { mixed puff to split into two } \\
\text { or more pieces when wind } \\
\text { shear is important. Each } \\
\text { portion of the puff is then } \\
\text { independently transported } \\
\text { and dispersed. }\end{array}$ & $\begin{array}{l}\text { Grid models, coupled with } \\
\text { suitable meteorological } \\
\text { models, can take into account } \\
\text { the impacts on air quality of } \\
\text { wind shear. To do so, both } \\
\text { the meteorological and air } \\
\text { quality models must have } \\
\text { sufficient vertical resolution } \\
\text { to adequately represent } \\
\text { changes in wind speed and } \\
\text { direction with height. In } \\
\text { practice, data may not be } \\
\text { available to support the } \\
\text { modeling efforts. }\end{array}$ & $\begin{array}{l}\text { Grid models provide a more natural framework for accounting for the effects of wind } \\
\text { shear. Where data are sparse, the importance of this attribute may be moot; accuracy may } \\
\text { be more limited by data than by formulation. However, in this circumstance the reliability } \\
\text { of any effort would come into question. The significance of this limitation of CALPUFF } \\
\text { will vary with application and is unknown for the case at hand. }\end{array}$ \\
\hline Dispersion & $\begin{array}{l}\text { CALPUFF provides five } \\
\text { options for estimating puff } \\
\text { dispersion. Three levels of } \\
\text { input data are provided, } \\
\text { depending on which of the } \\
\text { five dispersion options is } \\
\text { selected. }\end{array}$ & $\begin{array}{l}\text { Various algorithms are } \\
\text { employed in grid-based } \\
\text { models for representing } \\
\text { horizontal and vertical } \\
\text { diffusivities. }\end{array}$ & $\begin{array}{l}\text { The dispersion coefficients employed in CALPUFF are derived from field measurements } \\
\text { and other studies of plume dispersion. In flat terrain under conditions with limited wind } \\
\text { shear, CALPUFF probably provides a better means for representing plume dispersion than } \\
\text { a grid-based model without special point source treatment. The representation would be } \\
\text { more comparable for grid-based models with a plume-in-grid option. The ability of } \\
\text { CALPUFF or grid-based models to provide an accurate representation of plume } \\
\text { dispersion in complex terrain situations (like that in Southwest Wyoming) is questionable. } \\
\text { In the Southwest Wyoming application, emissions from oil and gas wells are represented } \\
\text { as area sources. It is unclear that the treatment of dispersion for area sources in } \\
\text { CALPUFF offers any advantage over that employed in a grid-based model. }\end{array}$ \\
\hline Deposition & $\begin{array}{l}\text { The treatment of } \\
\text { deposition in CALPUFF is } \\
\text { based on an approach that } \\
\text { expresses the deposition } \\
\text { velocity as the inverse of a } \\
\text { sum of "resistances" plus, } \\
\text { for particles, gravitational } \\
\text { settling. }\end{array}$ & $\begin{array}{l}\text { Various resistance-based } \\
\text { algorithms are adopted in } \\
\text { grid models. }\end{array}$ & $\begin{array}{l}\text { Both CALPUFF and grid-based models employ similar means for representing the effects } \\
\text { of deposition. Differences are largely associated with the choice of values for the various } \\
\text { "resistances." The primary issue is the large uncertainties that attend such calculations in } \\
\text { any model. }\end{array}$ \\
\hline
\end{tabular}




\section{COMPARISON OF CALPUFF AND GRID MODEL FORMULATIONS}

\begin{tabular}{|l|l|l|l|}
\hline ATTRI- & CALPUFF & GRID MODEL & DIFFERENCES AND IMPLICATIONS \\
\hline Visibility & $\begin{array}{l}\text { Visibility impacts are } \\
\text { calculated in a post } \\
\text { processor program } \\
\text { (CALPOST) in accordance } \\
\text { with IWAQM } \\
\text { recommendations. Little } \\
\text { documentation is provided } \\
\text { concerning this aspect of } \\
\text { CALPUFF usage. }\end{array}$ & $\begin{array}{l}\text { In general, most grid-based } \\
\text { models do not include means } \\
\text { for calculating effects on } \\
\text { visibility, though it is } \\
\text { theoretically possible to } \\
\text { incorporate such capabilities. }\end{array}$ & $\begin{array}{l}\text { There is limited demonstrated ability of modeling to accurately calculate visibility } \\
\text { impacts. Given a suitable treatment of atmospheric optics, either framework could be } \\
\text { used for such studies. The key issue is the ability of the modeling system to provide } \\
\text { accurate estimates for all the variables needed in the visibility calculations. }\end{array}$ \\
\hline $\begin{array}{l}\text { Extent of use } \\
\text { and testing }\end{array}$ & $\begin{array}{l}\text { Gaussian models are } \\
\text { commonly applied to } \\
\text { assess point source air } \\
\text { quality issues. However, } \\
\text { these applications typically } \\
\text { involve a large source or } \\
\text { industrial facility. Most of } \\
\text { the testing has occurred in } \\
\text { flat terrain situations, with } \\
\text { limited applications in } \\
\text { complex terrain. There is } \\
\text { little experience in the } \\
\text { combined use of } \\
\text { CALPUFF and MM5 in a } \\
\text { complex terrain situation. }\end{array}$ & $\begin{array}{l}\text { There is a considerable body } \\
\text { of experience in the } \\
\text { evaluation and use of grid- } \\
\text { ozone formation. However, } \\
\text { there is much less experience } \\
\text { in the of these models to } \\
\text { visibility, especially in the } \\
\text { near proximity of complex } \\
\text { terrain. }\end{array}$ & $\begin{array}{l}\text { Both Gaussian and grid-based models have been used extensively. However, there is little } \\
\text { experience in the use of either type of model to simulate secondary aerosol formation or to } \\
\text { on pollutant transport. A thorough assessment and finding of adequate performance will } \\
\text { be a necessary prerequisite to the adoption of either type of model for regulatory usage } \\
\text { Southwest Wyoming. }\end{array}$ \\
\hline
\end{tabular}


Absorption

Advection

Aerosol

Anthropogenic

Emissions

Area Source

Aromatics

ATT

BACT

BART

Biogenic Emissions

BLM

Boundary Layer

Buoyant Plume and Plume Rise

CAA

CALPOST

CALPUFF
The transformation of light incident on a particle to radiant energy within the particle.

The transport of pollutants by the action of the mean wind

An aerosol is a suspension of small solid or liquid particles in a gas, such as air. The term small usually refers to particles of order tens of microns and smaller.

Emissions resulting from human activities

An emissions source not attributable to a single, clearly identifiable point of release. An area source spreads emissions spatially, such as dust emissions from many dry fields.

Compounds such as benzene where each carbon is bonded to another with a single or double bond. Every other $\mathrm{C}$ bond is either single or double.

Air Technical Team, a working group of the Federal Leadership Forum

Best Available Control Technology

Best Available Retrofit Technology

Emissions from natural sources, such as vegetation.

United States Department of the Interior, Bureau of Land Management

The lowest layer of the atmosphere through which pollutants from surface and other low-level sources mix.

A pollutant emission plume or stream that is hotter than the surrounding air; the buoyant plume will rise upon release.

Federal Clean Air Act

A model that calculates visibility impacts based on the output of CALPUFF

A Guassian puff model used by SWYTAF to predict ambient 
Chemical

Functionality

Chemical Lumping

Scheme

Coagulation

Coarse Mass

Convection

Deciview

Deposition Velocity

Diurnal

EIS

Elemental Carbon

EPA

Extinction Budget

Extinction

Coefficient

Extinction

Efficiency

Fine Mass

\section{pollutant concentrations}

The relationship between a particular molecular property (i.e., reactivity) and its molecular structure.

The representation of several elementary reactions as one when the grouping is based on similarity in structure.

The process where a larger particle is formed as a result of a collision between two smaller particles.

The combined mass of aerosol particles larger than 2.5 microns in size.

Vertical wind motions that arise from thermal buoyancy forces

An index of visibility that is presumably linear with perceived changes in the visual scene.

The rate at which ambient pollutants subject to gravitational force drop out of the atmosphere

Daily, over the course of a day. Diurnal variation is a periodic fluctuation occurring between day and night.

Environmental Impact Statement

Carbonaceous particles directly emitted as soot from combustion processes.

United States Environmental Protection Agency

The apportionment of a fraction of the total extinction of a population of aerosol particles to a particular constituent of the population. This apportionment is often assigned by the size or chemical constitution of the particles.

A measure of the degree to which pollutants extinguish light per unit distance in the atmosphere. This extinction is caused by the light being either absorbed by the particle or scattered out of the line of sight of the observer.

The amount of light scattered and absorbed by the particle versus the amount of light incident on the particle.

The combined mass of aerosol particles smaller than 2.5 microns in size. 
Fitting parameters

FLAG

FLF

FLM

Gaussian Puff

Model

Grid-based model

Hygroscopic

Inversion

Isotach

IWAQM

LBL

LTV

Mesoscale

Mixing height

MM5

NAAQS

NEPA
The numerical values that are derived when data are modeled as a particular representation. An example is a fitting parameter derived from a least square's analysis.

Federal Land Managers' Air Quality Related Values Workgroup

Federal Leadership Forum

Federal Land Managers, including BLM, FWS, NPS, and USFS

A three-dimensional model that predicts the change in concentration of a pollutant as a function of time and location downwind of a release point based on the assumption that pollutants disperse according to Guassian diffusion

A three-dimensional model that parses an airshed into grids, and then predicts pollutant concentrations in each grid

A property of a substance that indicates its water-loving character.

A layer of the lower atmosphere in which the temperature increases with altitude

a line on a wind map indicating a particular wind speed

Interagency Workgroup on Air Quality Modeling

Atmospheric Program of the Environmental Energy Technologies Division at Ernest Orlando Lawrence Berkeley National Laboratories

Long Term Visibility Plan

Meteorological phenomena with a scale of a few 100 kilometers.

The distance from the ground to the base of an elevated inversion layer

A prognostic, mesoscale meteorological model used in the SWYTAF study to predict meteological conditions in a nested domain with 60 and $20 \mathrm{~km}$ grid resolutions. The results of MM5 are to be used in the CALMET model to predict meteology at a 4 $\mathrm{km}$ horizontal resolution.

National Ambient Air Quality Standards

National Environmental Policy Act 
Nitrates

NMC

$\mathrm{NO}_{\mathrm{x}}$

NPS

NSR

Nucleation

Organics

Oxidize

PAW

Point Source

PSD

Radical

RASS

Rate Equations

Reaction

Mechanism/

Chemical

mechanisms

Reduced

Compounds
Particulate nitrogen assumed to be in the form of ammonium nitrate.

National Meteorological Center

Nitrogen Oxides

United States Department of the Interior National Park Service

New Source Review

The first step in the transformation of phase one to phase two. For example, in gas-to-particle conversion, the small grouping of a cluster of phase one entities to form phase two.

Aerosol particles that are formed from organic species originally emitted as gasses.

When a molecule loses one or more electrons in a chemical reaction.

Petroleum Association of Wyoming

An emission source that is associated with a single, clearly identifiable location or piece of equipment, e.g. a power plant smoke stack.

Prevention of Significant Deterioration

A chemical species having an unpaired electron; radicals are usually very reactive.

Radio Acoustic Sounding System

The first-order differential equations that are derived from the chemical mechanisms that describe the production and destruction of species in the chemical mechanism.

The suite of chemical reactions that describe the transformation of reactants into products, giving consideration to the intermediate species and their reactions, that are important in describing a complex chemical transformation that occurs as a result of several reactions. An example is the suite of reactions that occur in the atmosphere in the formation of ozone from its precursor compounds.

Compounds in which the atom of interest is not in its highest oxidation state. For example, $\mathrm{S}$ in $\mathrm{H}_{2} \mathrm{~S}$ is not in its highest 
oxidation state so $\mathrm{H}_{2} \mathrm{~S}$ is a reduced compound.

Scattering

Secondary Organic Aerosol

Semi-volatile

Compounds

Semi-volatiles

Sigma Coordinate

Sigma Level

SIP

Smog Chamber

$\mathrm{SO}_{2}$

Steady State

Stoichiometric

Sulfates

SWYTAF

Synoptic
The reflection of light from a particle, deflecting it from its original direction.

Aerosol that forms in the atmosphere, typically from the condensation and adsorption (sticking) of low volatility products of compounds that are emitted in the gas-phase.

see Volatility.

Hydrocarbon species that have low vapor pressures under ambient conditions.

A vertical coordinate system, wherein the numerical value of the vertical coordinate ranges between 0 and 1 from the surface to the top of the modeling domain.

A particular vertical grid level in a sigma coordinate system

State Implementation Plan

An experimental device that simulates a closed perfectly stirred reactor. In practice, ozone formation has been studied in these devices by exposing a bag containing reactants to solar radiation. The chemistry occurring in these experiments is modeled as a function of time using a model referred to as a box model.

The chemical formula for sulfur dioxide.

The condition where the net rate of production of a species is assumed to be zero.

A property that describes the molar relationships between reactants in a chemical reaction.

This term often refers to any particle that originates as a result of gaseous sulfur emitted into the atmosphere. Particulate sulfur is most often in the form of ammonium sulfate, although acidic species such as ammonium bisulfate and sulfuric acid are not uncommon.

Southwestern Wyoming Technical Air Forum

Meteorological systems of a scale large enough to affect several states at a given time 
USFS

USFWS

Visibility

Volatility

WA

WAAQS

WAQS\&R

WDEQ

Wind shear

Yield (Chemical

Yield, Yield

Formula)
United States Department of Agriculture Forest Service

United States Department of the Interior Fish and Wildlife Service

The distance that an observer can see through the atmosphere. Visibility is a measure of how transparent the atmosphere is to visible light.

The tendency of a chemical compound to exist in the gas-phase, as opposed to the liquid or solid phase, at atmospheric conditions (i.e. pressures and temperatures encountered at Earth's surface). Semi-volatile compounds will exist as both a gas and liquid/solid; whereas non-volatile compounds will exist almost entirely as a solid or liquid at atmospheric conditions.

Wilderness Act

Wyoming Ambient Air Quality Standards

Wyoming Air Quality Standards and Regulations

Wyoming Department of Environmental Quality

Wind shear relates to the spatial variation of wind velocity. In a one-dimensional world, wind shear may be the variation in the wind velocity's vertical dimension, but it can also relate to the horizontal dimension.

The fraction of a particular reactant that is converted to another entity, for example the fraction of a VOC that is converted to an aerosol. 